\title{
Mechanisms Governing the Direct Removal of Wastes from the Waste Isolation Pilot Plant Repository Caused by Exploratory Drilling*
}

\author{
J.W. Berglund \\ New Mexico Engineering Research Institute \\ 851 University Blvd., SE, Suite 101 \\ Albuquerque, NM 87106
}

\begin{abstract}
Two processes are identified that can influence the quantity of wastes brought to the ground surface when a waste disposal room of the Waste Isolation Pilot Plant is inadvertently penetrated by an exploratory borehole. The first mechanism is due to the erosion of the borehole wall adjacent to the waste caused by the flowing drilling fluid (mud); a quantitative computational model based upon the flow characteristics of the drilling fluid (laminar or turbulent) and other drilling parameters is developed and example results shown. The second mechanism concerns the motion of the waste and borehole spall caused by the flow of waste-generated gas to the borehole. Some of the available literature concerning this process is discussed, and a number of elastic and elastic-plastic finitedifference and finite-elernent calculations are described that confirm the potential importance of this process in directly removing wastes from the repository to the ground surface. Based upon the amount of arialysis performed to date, it is concluded that it is not unreasonable to expect that volumes of waste several times greater than that resulting from direct cutting of a gauge borehole could eventually reach the ground surface. No definitive quantitative model for waste removal as a result of the second mechanism is presented; it is concluded that decomposed waste constitutive data must be developed and additional experiments performed to assess further the full significance of this latter mechanism.
\end{abstract}

\footnotetext{
* Prepared for Sandia National Laboratories under Contract No. 12-9827.
} 


\section{ACKNOWLEDGMENT}

The author wishes to recognize the technical reviews of this report by David Holcomb (6117) of Sandia National Laboratories and Dennis Morrison of the New Mexico Engineering Research Institute. 


\section{CONTENTS}

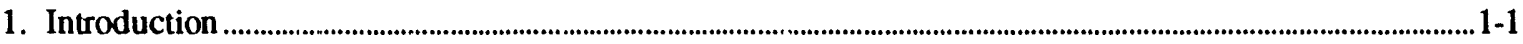

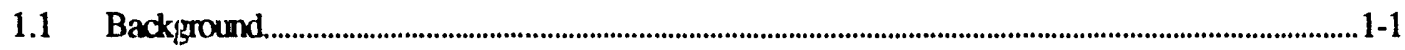

1.2 Current Drilling Practices ...................................................................................................................

1.3 Mechanisms for Waste Removal.................................................................................................................. 1-2

2. Mechanism I: Erosion within the Borehole Annulus ….........................................................................................2-1

2.1 Introduction .......................................................................................................................................2-1

2.2 Analysis ..............................................................................................................................................2-2

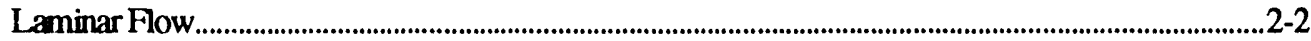

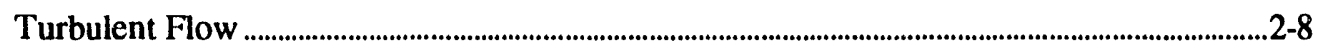

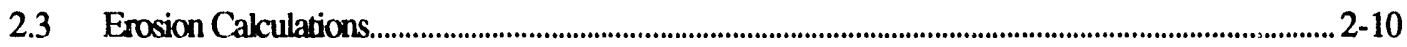

3. Mechanism II: Waste-Gas-Induced Borehole Spall.............................................................................................. 3-1

3.1 Introduction .......................................................................................................................................

3.2 Existing Literature ………...................................................................................................................... 3-1

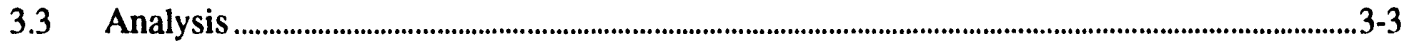

Overview.............................................................................................................................................3-3

One-Dimensional Cylindrical Elastic Approximation...........................................................................3-4

Uncoupled Gas Flow .................................................................................................................................3-6

Coupled Response ............................................................................................................................................ 3-8

Two-Dimensional Effects ............................................................................................................................... 3-13

Borehole Pressure Decay Model........................................................................................................... 3-24

Elastic Stress State Adjacent to Borehole as a Function of Pressure Decay Time ............... 3-30

Inelastic Dynamic Response of the Waste ................................................................................................ 3-40

3.4 Discussion............................................................................................................................................ 3-48

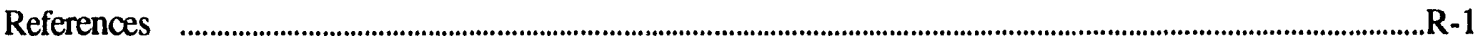

Appendix A: The AFWL Engineering Model and Its Use in a One-Dimensional Code/CERF1D.........A-1

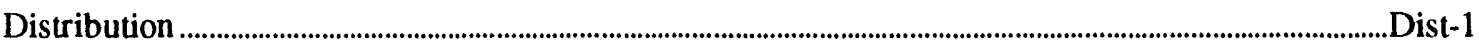




\section{Figures}

1-1 Rotary drilling.

Viscous shear stress for Oldroyd and real drilling fluids. $. .2-3$

Detail of rotary drill string adjacent to drill bit.....

Iteration procedure for finding the final hole radius.

Sensitivity of eroded diameter to initial mud flow velocity in annulus............................ 2-12

Sensitivity of eroded diameter to absolute borehole roughness........................................... 2-13

3-1 Borehole penetrating gas-filled repository (time $=0$ ).

Radial effective stress at 3 seconds after penetration for three

different values of initial pore pressure.

3-9 Static effective stress contours $\sigma_{x}$ for gas pressure distribution at 6 seconds.

3-10 Static effective stress contours $\sigma_{y}$ for gas pressure distribution at 6 seconds..

Static stress contours $\tau_{x y}$ for gas pressure distribution at 6 seconds..

Radial effective stress and principal effective stress for element radials

3-14 Magnified nodal displacements elastic material model............................................................... 3-25

3-15 Moving Salado boundary ........................................................................................................ 3-27

3-16 Nondimensional plot of Equation (3-9) ................................................................................... 3-28

3-17 Peak radial tensile envelopes for different decay times (three different Salado permeabilities) .................................................................................................................... 3-31

3-18 Peak radial tensile envelopes for different decay times (three different Salado permeabilities).................................................................................................................... 3-34

3-19 Peak radial tensile envelopes for different decay times (three different Salado permeabilities)..................................................................................................................... 3-37

3-20 Constitutive model chosen for repository wastes............................................................... 3-41

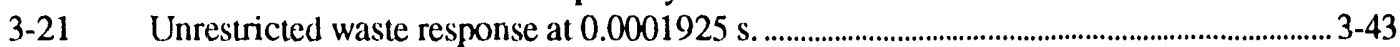

3-22 Waste response at $0.0325 \mathrm{~s}$ (radial displacement of borehole wall limited

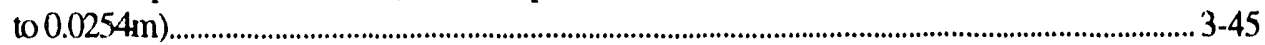

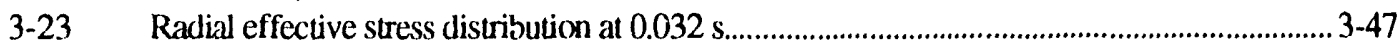

3-24 Unmagnified deformed mesh using soil material model........................................................... 3-49 


\section{Tables}

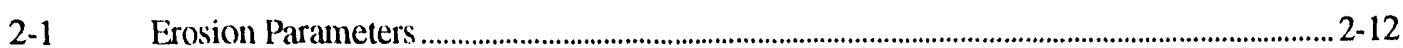

3-1 Properties Used for Uncoupled Gas Flow Assuming an Instantaneous

Pressure Drop .........................................................................................................................................3-7

3-2 Properties Used for Coupled Calculations Assuming an Instantaneous Borehole

Pressure Drop ........................................................................................................................................3-9

3-3 Thickness of Boundary Layer and Drilling Times for Different

Perneabilities and Drill Velocities.................................................................................................. 3-29

3-4 Properties for Coupled Calculations with Varying Borehole Pressure ............................... 3-30

3-5 Properties used for Coupled Flow and Inelastic S AMSON2 Calculations ...................... 3-42 


\section{INTRODUCTION}

The Waste Isolation Pilot Plant (WIPP), located in southern New Mexico, is the first planned, mined geologic repository for transuranic wastes generated by U.S. defense programs. WIPP is currently being evaluated to assess compliance with the requirements of EPA 40 CFR 191 Subpart B (WIPP PA Division, 1991a). Briefly, this requirement, promulgated by the Environmental Protection Agency, limits the amount of radioactive material that can be released to the accessible environment over a 10,000-year regulatory period.

Of the possible pathways for release during this period, one of the most important is that caused by the inadvertent penetration of a waste disposal room by an exploratory drill bit. The current performance assessment model relies on the assumption that future drilling techniques will be similar to those in use today. The validity of this assumption is unknown, but is necessary to provide a basis on which predictions of release can be estimated. Thus, assuming that current, standard drilling practices for gas and oil are used, mechanisms governing the direct removal of radioactive waste will be discussed and, where possible, quantified. The following report summarizes the current understanding of the processes related to the direct removal of wastes. It is anticipated that with the development of additional data and analytical procedures, quantitative predictions of waste removal can be improved considerably.

\subsection{Background}

The WIPP repository will consist of a number of excavated waste disposal rooms located in bedded halite (salt) approximately $650 \mathrm{~m}$ below the ground surface in southeast New Mexico (WIPP PA Division, 1991a). Most excavated rooms will be approximately $91-\mathrm{m}$ long, $10-\mathrm{m}$ wide, and 4-m high. Transuranic waste packaged in 55 -gallon drums or standard waste boxes will be placed in each room and backfilled primarily with crushed salt.

After the WIPP repository is filled with waste and sealed, the waste is expected to be slowly compacted by salt creep from an original waste room height of $4 \mathrm{~m}$ to a compacted height of 1.5 to $2 \mathrm{~m}$ within 100 to 200 years. The overburden (vertical) stress acting on the waste will also increase to the lithostatic stress ( 14.8 MPa) during this period. The waste in its unmodified form will consist of a mixture of contaminated organic (e.g., cloth, wood, rubber, plastics) and inorganic (e.g. metals, glass) materials. After placement in the mined (salt) repository, the waste will be compacted by creep closure of the surrounding salt and, in addition, may become exposed to brine. The exposure of the metallic waste to brine is expected to cause corrosion of the metals and as a by-product will generate gas $\left(\mathrm{H}_{2}\right)$. Additional gas will be generated by the biodegradation of the organic materials in the waste inventory. The gas volumes generated by corrosion and biodegradation are expected to increase continuously for hundreds of years, and the pore pressure may reach and possibly exceed the lithostatic overburden stress. During this time, the repository is also expected to expand under the influence of the elevated gas pressure.

At some time within the 10,000-year regulatory period, it is probable that one or more exploration boreholes will be drilled into and through the vertically compacted waste and some of the waste will be carried to the surface as a direct result of the drilling process. The volume of waste removed to the ground surface will depend upon the physical properties of the compacted, decomposed wastes, the drilling procedures used, and the pore pressures 
encountered. Because of radioactive decay, the radioactivity of nuclides in the removed waste (in curies) will also depend upon the time of intrusion.

\subsection{Current Drilling Practices}

In traditional rotary drilling, a cutting bit attached to a series of hollow drill collars and drillpipes is rotated at a fixed angular velocity and is directed to cut downward through the underlying strata. To remove the drill cuttings, a fluid is pumped down the drillpipe, through and around the drill bit, and up to the surface within the annulus formed by the drillpipe and the borehole wall (Figure 1-1). In addition to the removal of cuttings, the drilling fluid (mud) serves to cool and clean the bit, reduce drilling friction, maintain borehole stability, prevent the inflow of unwanted fluids from permeable formations, and form a thin, low-permeability filter cake on penetrated formations. When drilling through salt, to prevent excessive erosion of the borehole wall through dissolution, a saturated brine is often used as the drilling fluid (Berglund, 1990; Pace, 1990). For a gauge borehole, the volume of cuttings removed and transported to the surface is equal to the product of the drill bit area and the drill depth. Thus, to estimate the total volume of waste removed due to the cutting action of the drill bit, it is only necessary to know the compacted repository height and the drill bit area. The cuttings volume calculated in this manner is a lower bound to the total quantity of waste removed by drilling.

After passing through the drill bit, the drilling fluid flows up the annulus formed by the borehole wall and the drill collar (or drill pipe). In the annulus, the motion of the drilling fluid has both a vertical and rotational component, the latter caused by the rotating drill string. Depending on fluid properties, annulus geometry, and flowrates, the fluid flow within the annulus may be smooth and laminar or turbulent.

\subsection{Mechanisms for Waste Removal}

There are at least two mechanisms that can be identified as contributing to the removal of waste to the accessible environment over and above that transported by the direct cutting of a gauge borehole. The first is the erosion of the borehole wall caused by the action of the upward-flowing drilling fluid within the annulus. The second arises from the effect on the waste of waste-generated gas escaping to the lower-pressure borehole. Both of these phenomena are discussed in detail in this report, and models for them are also described. In the case of erosion, a quantitative model is developed that is based on an effective shear strength for erosion of the compacted, decomposed waste. In the absence of specific experimental data, waste removal from the borehole wall into the drilling fluid due to gas flow is much more difficult to address. For this latter mechanism, the general phenomenology is discussed, but no definitive quantitative model for this phenomenon is presented in this report. 

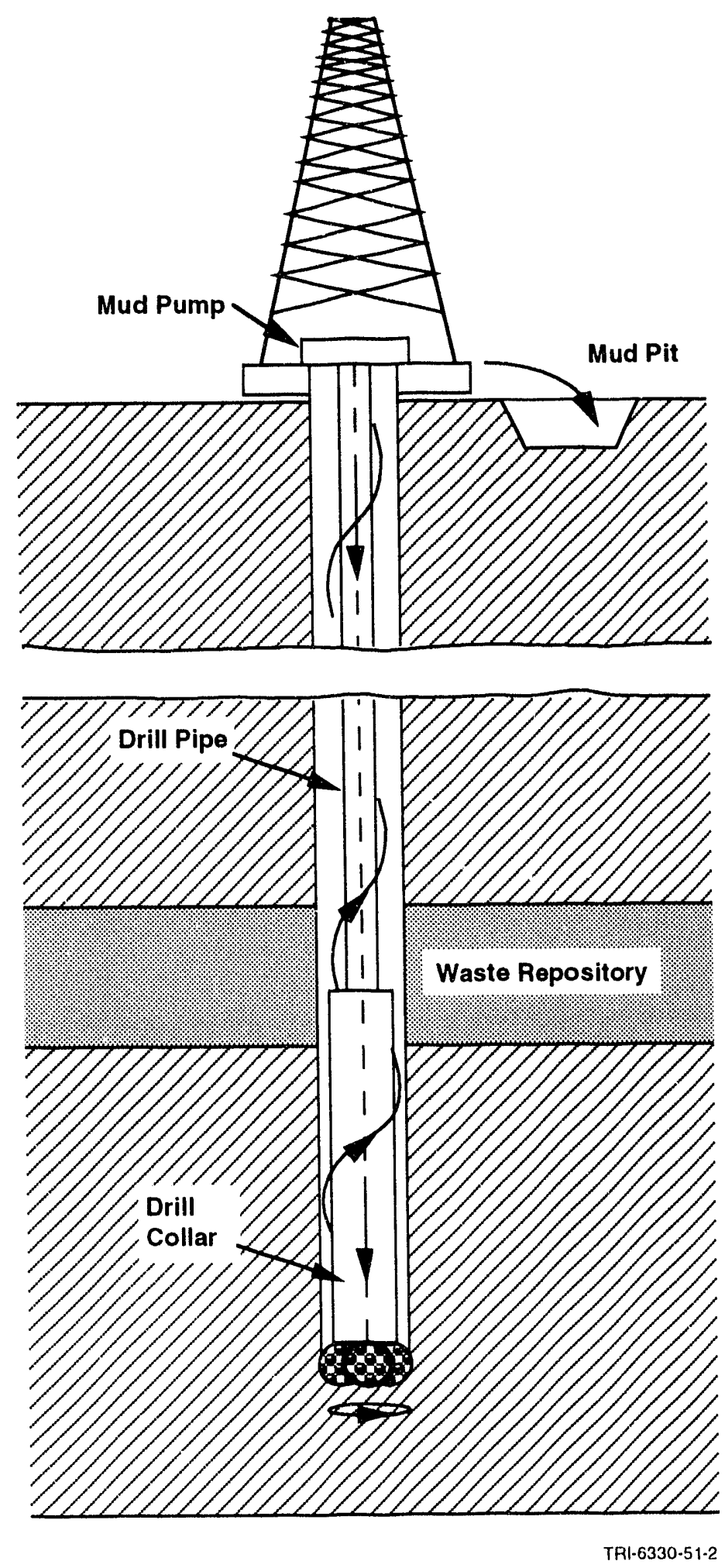

Figure 1-1. Rotary drilling. 


\section{MECHANISM I: EROSION WITHIN THE BOREHOLE ANNULUS}

\subsection{Introduction}

In the oil and gas drilling industry, it has been suggested (Broc, 1982) that drillhole wall erosion may be influenced by a number of factors:

- The shear of the drilling fluid against the hole wall during circulation.

- Suction effect during pipe movement.

- Eccentricity of pipe with respect to the hole.

- Impact of the solid particles in the mud on the walls.

- Physical and chemical interaction between the mud and the exposed formation.

- Time of contact between the mud and the formation.

A number of investigators maintain the view that the flow pattern has a major effect on the stability of the walls. Walker and Holman (1971) defined an index of erosion that is a function of the shear stress acting on the walls and the type of flow (laminar or turbulent) opposite the drill collars. They postulate that erosion occurs primarily opposite the drill collars where the mud flow rates are greatest and is considerably more prevalent when the flow is turbulent rather than laminar. Darley (1969), in a number of laboratory experiments, also shows that for aqueous drill fluids, erosion is sensitive to flow rates. For certain types of shales, Darley shows that the material in the exposed borehole wall can undergo a swelling because of the decrease in the lateral effective stress and by undergoing surface hydration and osmotic action. In such cases, the circulation of clear liquids causes severe erosion of the walls. Erosion is much slower when colloidal suspensions are circulated, partly because the formation of a filter cake on the borehole wall inhibits the formation of a soft swollen zone. Brittle shales also exhibit a weakening when penetrated by a drillhole, due in part to the infiltration of drilling fluid into old fracture or cleavage planes.

The mechanical and chemical properties of the compacted wastes in a WIPP waste storage room at some time in the distant future will undoubtedly be quite different than any material encountered in the experience of today's oil and gas drilling industry. However, the characteristics that influence erosion are likely to be similar.

Although a number of factors exist that may influence borehole erosion, industry opinion appears to single out the effects of fluid shear acting on the borehole wall and the character of the fluid flow (laminar or turbulent). To consider these effects, it is necessary to know the threshold fluid shear stress acting on the borehole wall that will initiate erosion. This "effective" borehole shear strength for erusion must be determined by experiment and may be different for laminar and turbulent flow. In the following analysis, it is assumed that borehole erosion is 
caused primarily by the magnitude of the fluid shear stress acting on the borehole wall. Other effects are generally ignored, except insofar as they may influence the experimentally determined effective shear strength for erosion of the repository material.

\subsection{Analysis}

In the annulus formed by the collars or drill pipe and the borehole wall, the flow of the drilling fluid has both a vertical and rotational component. Within this helical flow pattern, shear stresses are generated by the relative motion of adjacent fluid regions and by the action of the fluid on the borehole wall. In this analysis, it is assumed that if the fluid shear stress at the wall exceeds the effective shear strength for erosion of the wall material (filter cake or compacted repository wastes), erosion of the wall material will occur, increasing the diameter of the bored hole. The eroded material will then be passed to the surface in the flowing drilling fluid.

Flow in the annulus between the drillpipe and borehole wall is usually laminar (Darley and Gray, 1988). Adjacent to the collars (Figure 1-1), however, the flow may be either laminar or turbulent as a consequence of the larger collar diameter and resulting higher mud velocities (Berglund, 1990; Pace, 1990). For laminar flow, the analysis lends itself to classical solution methods. Turbulent flow, where the flow is assumed to be axial with no rotational component, requires a more approximate approach. A discussion of these two cases follows.

\section{Laminar Flow}

Below Reynolds numbers of about 2100 for Newtonian fluids and 2400 for some non-Newtonian fluids (Walker, 1976), experiments have shown that the flow of a fluid in a circular pipe or annulus is well behaved and can be described using a well-defined relationship between the velocity field and the fluid shear stress. This type of flow is called laminar.

Some of the early work on laminar helical flow of a non-Newtonian fluid in an annulus was erformed by Coleman and Noll (1959), and Fredrickson (1960). The laminar helical flow solution procedure outlined below is, for the most part, an adaptation of methods described in a paper by Savins and Wallick (1966).

One of the principal difficulties in solving for the shear stresses within a helically flowing drilling fluid is the shear rate dependence of the fluid viscosity. This non-Newtonian fluid behavior necessitates choosing a functional form for the variation of viscosity with shear rate for the fluid. There are several functional forms for the viscosity of drilling fluids that can be assumed. For example, in the oil and gas industry, the Bingham and power law models are often used to approximate the shear rate dependence of the fluid viscosity. A less common function is a form chosen by Oldroyd (1958) and used in the analysis by Savins and Wallick (1966). Oldroyd assumed that the viscosity varied according to the functional relation

$$
\eta=\eta_{\mathrm{o}}\left(\frac{1+\sigma_{2} \Gamma^{2}}{1+\sigma_{1} \Gamma^{2}}\right)
$$


where $\sigma_{1}$ and $\sigma_{2}$ are constants, $\eta_{o}$ is the limiting viscosity at zero rate of shear, $\eta_{\infty}$ (defined as $\eta_{o}\left(\sigma_{2} / \sigma_{1}\right)$ ) is the limiting viscosity at infinite rate of shear, and $\Gamma$ is the shear rate. The viscous shear stress is described by $\tau=\eta \Gamma$.

Using the Oldroyd viscosity, Equation (2-1), the viscous shear stress can be illustrated graphically as in Figure 2-1. This is a rate softening (pseudoplastic) model that has an initial slope of $\eta_{o}$ and a limiting slope of $\eta_{\infty}$ for large shear rates.

The Oldroyd model cannot account for drilling fluids that exhibit a yield stress. However, above a shear rate of zero, parameters can be chosen so that the model can be made to approximate the pseudoplastic rate response of many drilling fluids (see Figure 2-1).

Savins and Wallick (1966), expanding on the work of Coleman and Noll (1959) and Fredrickson (1960), showed that the solution for laminar helical flow of a non-Newtonian fluid in an annulus could be written in terms of three nonlinear integral equations.

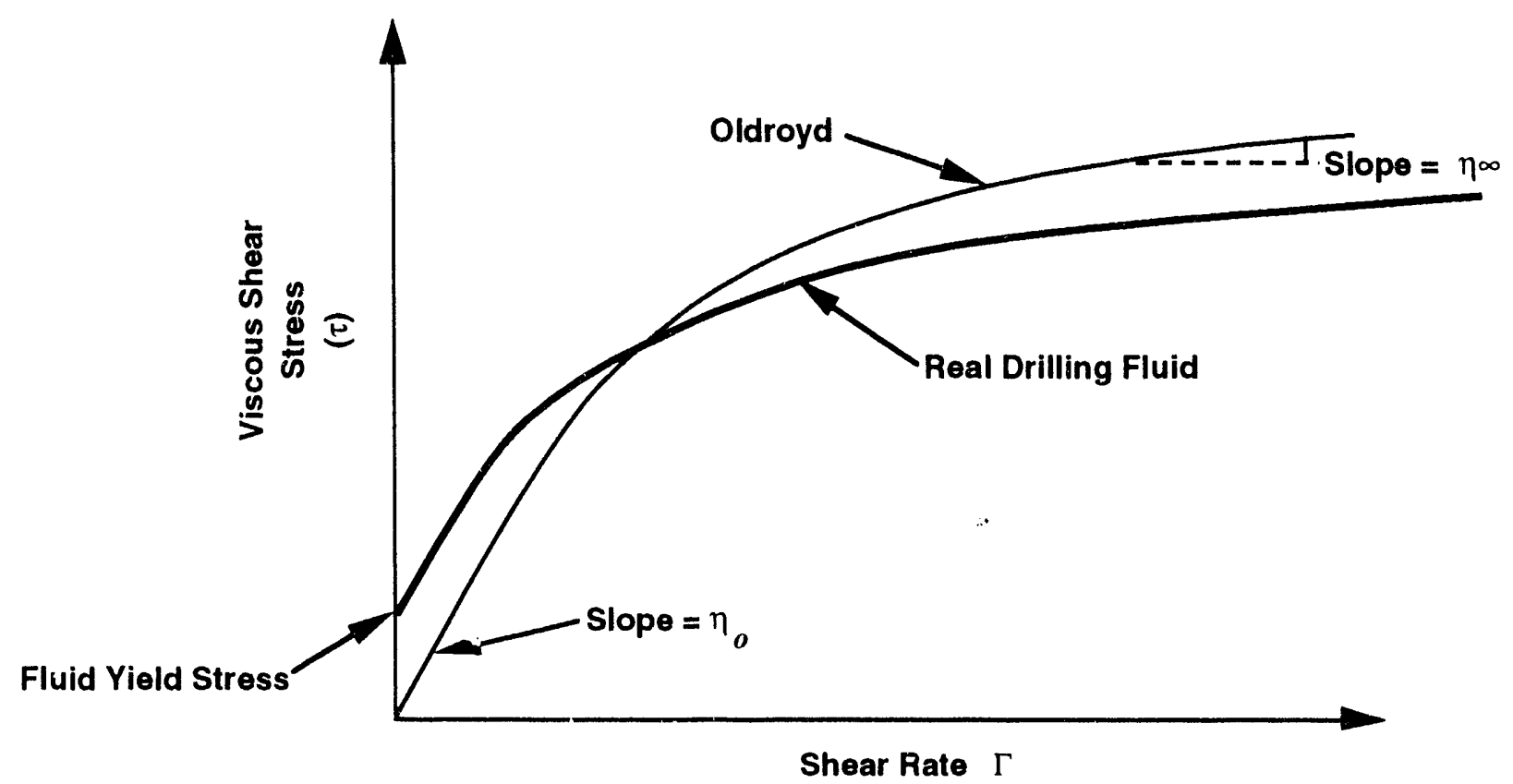

TRI-6342-1872-0

Figure 2-1. Viscous shear stress for Oldroyd and real drilling fluids. 


$$
\begin{gathered}
F_{1}=\int_{\alpha}^{1}\left(\frac{\rho^{2}-\lambda^{2}}{\rho}\right) \frac{d \rho}{\eta}=0 \\
F_{2}=C \int_{\alpha}^{1} \frac{d \rho}{\rho^{3} \eta}-\Delta \Omega=0 \\
F_{3}=\frac{4 Q}{\pi R^{3}}+4\left(\frac{R J}{2}\right) \int_{\alpha}^{1}\left(\frac{\alpha^{2}-\rho^{2}}{\eta}\right)\left(\frac{\rho^{2}-\lambda^{2}}{\rho}\right) d \rho=0,
\end{gathered}
$$

where $\alpha$ is the ratio of the collar radius over the cutting radius $\left(R_{i} / R\right)$ (Figure 2-2), $\Delta \Omega$ is the drill string angular velocity, $Q$ is the drilling fluid (mud) flow rate, $r$ is the radial coordinate, anci $r$ is the non-dimensional radial coordinate representing the ratio $r / R$.

The unknown parameters $\lambda^{2}, R . J / 2$, and $C$ are related to the fluid shear stresses through the relations

$$
\begin{gathered}
\tau_{r \theta}=\frac{C}{\rho^{2}} \\
\tau_{r z}=\frac{R . I}{2}\left(\frac{\rho^{2}-\lambda^{2}}{\rho}\right) \\
\tau^{2}=\tau_{r \theta}^{2}+\tau_{r z}^{2},
\end{gathered}
$$

where $r, \theta$, and $\mathrm{z}$ represent radial, tangential, and vertical coordinates associated with the cylindrical geometry of Figure 2-2.

The three nonlinear integral equations represented by Equation $(2-2)$ generally must be solved numerically. By expanding each of the integral equations into a Taylor series and retaining only the linear terms, a recursive solution procedure can be used (Newton-Raphson) to find the solution for the unknowns $\delta \lambda^{2}, \delta(R . J / 2)$, and $\delta C$. The three linear equations are

$$
\begin{aligned}
& \frac{\partial F_{1}}{\partial \lambda^{2}} \delta \lambda^{2}+\frac{\partial F_{1}}{\partial C} \delta C+\frac{\partial F_{1}}{\partial\left(\frac{R . I}{2}\right)} \delta\left(\frac{R I}{2}\right)=-F_{1} \\
& \frac{\partial F_{2}}{\partial \lambda^{2}} \delta \lambda^{2}+\frac{\partial F_{2}}{\partial C} \delta C+\frac{\partial F_{2}}{\partial\left(\frac{R . J}{2}\right)} \delta\left(\frac{R I}{2}\right)=-F_{2} \\
& \frac{\partial F_{3}}{\partial \lambda^{2}} \delta \lambda^{2}+\frac{\partial F_{3}}{\partial C} \delta C+\frac{\partial F_{3}}{\partial\left(\frac{R . I}{2}\right)} \delta\left(\frac{R . J}{2}\right)=-F_{3} .
\end{aligned}
$$


Analysis

Laminar Flow

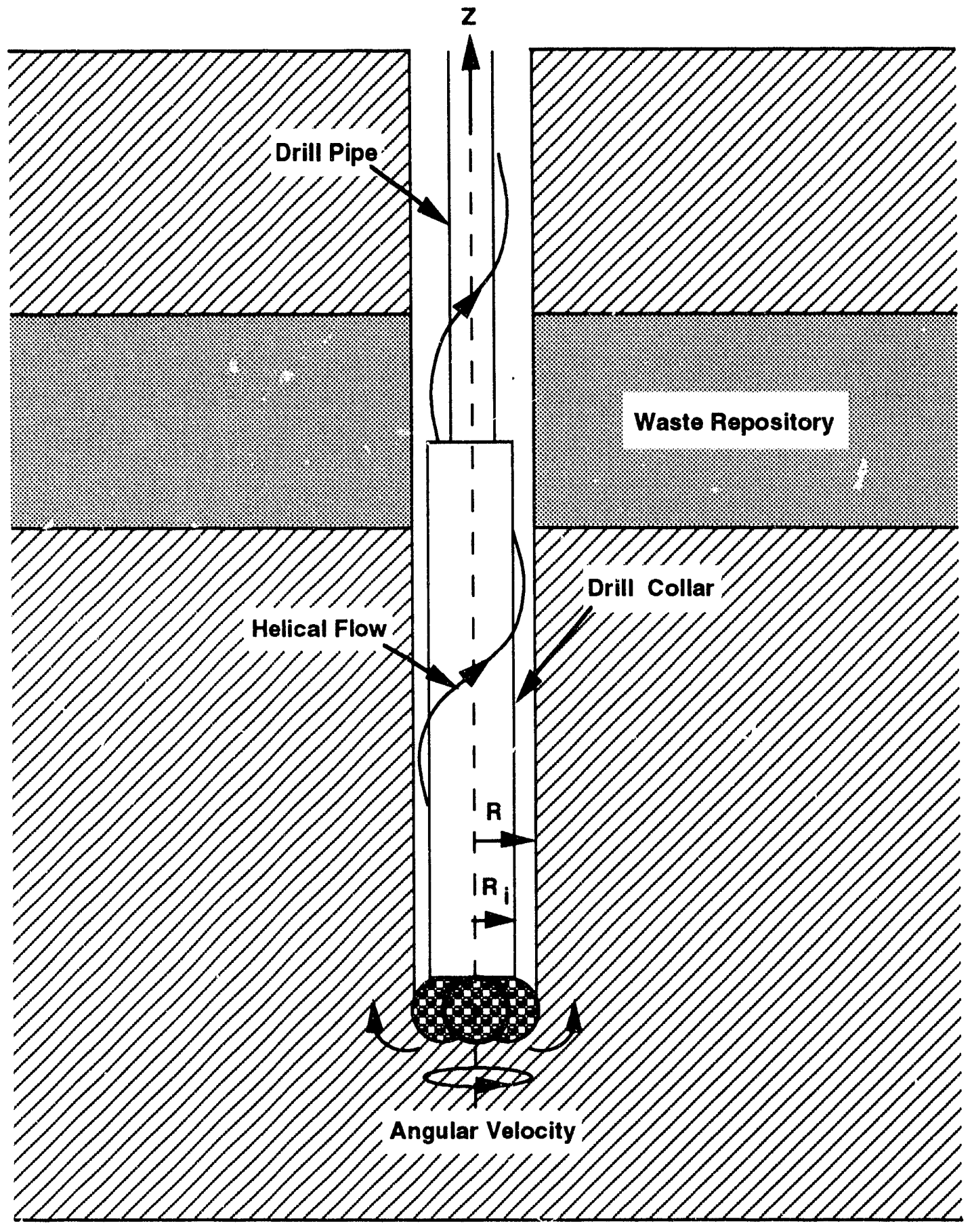

TR1-6342-1190-1

Figure 2-2. Detail of rotary drill string adjacent to drill bit. 
The solution procedure consists of assuming initial values for $\lambda^{2}, R J / 2$, and $C$ and solving the three linear equations in Equation (2-4) for the corrections $\delta \lambda^{2}, \delta(R J / 2)$, and $\delta C$. The unknowns $\lambda^{2}, R J / 2$, and $C$ are then replaced by $\lambda^{2}+\delta \lambda^{2},(R J / 2)+\delta(R J / 2)$, and $C+\delta C$. This recursive solution procedure is repeated until $\left|\delta \lambda^{2}\right|$, $|\delta(R J / 2)|$, and $|\delta C|$ are all less than some specified limit.

The coefficients of the unknowns $\delta \lambda^{2}, \delta\left(R J_{1}-\right)$, and $\delta C$ in Equation (2-4) are determined by differentiating the equations in Equation (2-2). These derivatives are:

$$
\begin{aligned}
& \frac{\partial F_{1}}{\partial \lambda^{2}}=-\int_{\alpha}^{1} \frac{1}{\eta \rho}\left[1+\frac{\left(\rho^{2}-\lambda^{2}\right)}{\eta} \frac{\partial \eta}{\partial \lambda^{2}}\right] d \rho \\
& \frac{\partial F_{1}}{\partial C}=-\int_{\alpha}^{1} \frac{1}{\eta \rho} \frac{\left(\rho^{2}-\lambda^{2}\right)}{\eta} \frac{\partial \eta}{\partial C} d \rho \\
& \frac{\partial F_{1}}{\partial\left(\frac{R J}{2}\right)}=-\int_{\alpha}^{1} \frac{1}{\eta \rho} \frac{\left(\rho^{2}-\lambda^{2}\right)}{\eta} \frac{\partial \eta}{\partial\left(\frac{R J}{2}\right)} d \rho \\
& \frac{\partial F_{2}}{\partial \lambda^{2}}=-C \int_{\alpha}^{1} \frac{1}{\eta^{2} \rho^{3}} \frac{\partial \eta}{\partial \lambda^{2}} d \rho \\
& \frac{\partial \mathrm{F}_{2}}{\partial \mathrm{C}}=\int_{\alpha}^{1} \frac{1}{\eta \rho^{3}}\left(1-\frac{\mathrm{C}}{\eta} \frac{\partial \eta}{\partial \mathrm{C}}\right) \mathrm{d} \rho \\
& \frac{\partial F_{2}}{\partial\left(\frac{R J}{2}\right)}=-C \int_{\alpha}^{1} \frac{1}{\eta^{2} \rho^{3}} \frac{\partial \eta}{\partial\left(\frac{R J}{2}\right)^{d \rho}} \\
& \frac{\partial F_{3}}{\partial \lambda^{2}}=-4\left(\frac{R I I}{2}\right) \int_{\alpha}^{1} \frac{\alpha^{2}-\rho^{2}}{\eta \rho}\left[1+\frac{\left(\rho^{2}-\lambda^{2}\right)}{\eta} \frac{\partial \eta}{\partial \lambda^{2}}\right] d \rho \\
& \frac{\partial F_{3}}{\partial C}=-4\left(\frac{R J}{2}\right) \int_{\alpha}^{1} \frac{\left(\alpha^{2}-\rho^{2}\right)}{\eta \rho} \frac{\left(\rho^{2}-\lambda^{2}\right)}{\eta} \frac{\partial \eta}{\partial C} d \rho \\
& \frac{\partial F_{3}}{\partial\left(\frac{R J}{2}\right)}=4 \int_{\alpha}^{1} \frac{\left(\alpha^{2}-\rho^{2}\right)}{\eta \rho}\left(\rho^{2}-\lambda^{2}\right) d \rho-4\left(\frac{R J}{2}\right) \int_{\alpha}^{1} \frac{\left(\alpha^{2}-\rho^{2}\right)}{\eta \rho} \frac{\left(\rho^{2}-\lambda^{2}\right)}{\eta} \frac{\partial \eta}{\partial\left(\frac{R J}{2}\right)^{2}} d \rho .
\end{aligned}
$$


The viscosity is related to the the shear rate function $Y(\Gamma)$ by the equation

$$
\eta^{2} Y=2\left[\left(\frac{R J}{2}\right)^{2}\left(\frac{\rho^{2}-\lambda^{2}}{\rho}\right)^{2}+\frac{C^{2}}{\rho^{4}}\right]
$$

where

$$
Y=2 \Gamma^{2}
$$

For the Oldroyd viscosity function, Equation (2-1), the unknown derivatives of the viscosity in Equation (2-5) can be determined by using the chain rule of differentiation and Equation (2-6):

$$
\begin{gathered}
\frac{\partial \eta}{\partial \lambda^{2}}=\frac{\partial\left(\eta^{2} Y\right)}{\partial \lambda^{2}} \frac{\partial \eta}{\partial\left(\eta^{2} Y\right)}=-4\left(\frac{R J}{2}\right)^{2}\left(\frac{\rho^{2}-\lambda^{2}}{\rho^{2}}\right) \frac{\partial \eta}{\partial\left(\eta^{2} Y\right)} \\
\frac{\partial \eta}{\partial C}=\frac{\partial\left(\eta^{2} Y\right)}{\partial C} \frac{\partial \eta}{\partial\left(\eta^{2} Y\right)}=\frac{4 C}{\rho^{4}} \frac{\partial \eta}{\partial\left(\eta^{2} Y\right)} \\
\frac{\partial \eta}{\partial\left(\frac{R J}{2}\right)}=\frac{\partial\left(\eta^{2} Y\right)}{\partial\left(\frac{R J}{2}\right)} \frac{\partial \eta}{\partial\left(\eta^{2} Y\right)}=4\left(\frac{R J}{2}\right)\left(\frac{\rho^{2}-\lambda^{2}}{\rho}\right)^{2} \frac{\partial \eta}{\partial\left(\eta^{2} Y\right)}
\end{gathered}
$$

The derivative $\partial \eta / \partial\left(\eta^{2} Y\right)$ can be determined by combining Equation (2-1) and Equation (2-7) and differentiating to obtain

$$
\frac{\partial \eta}{\partial\left(\eta^{2} Y\right)}=\frac{\left(\frac{\sigma_{2}}{2} \eta_{o}-\frac{\sigma_{1}}{2} \eta\right)^{2}}{\left(\frac{\sigma_{2}}{2} \eta_{o}-\frac{\sigma_{1}}{2} \eta\right)\left[\eta^{2}+2\left(\eta-\eta_{o}\right) \eta\right]+\left(\eta-\eta_{o}\right) \eta^{2} \frac{\sigma_{1}}{2}}
$$

Based upon the preceding equations, a Fortran computer code was written to perform the necessary computations for a solution to the problem of laminar helical flow in an annulus. This code was partially verified by comparing its results against those published by Savins and Wallick (1966).

For the specific case of borehole erosion, once a solution to the three integral equations in Equation (2-2; is found, the shear stress in the fluid at the wall can be calculated by setting $\rho=1$ in the equations in Equation (23). By changing the outer radius of the hole, the fluid shear stress can be forced to equal the repository effective shear strength for erosion. The required outer hole radius is determined by iteration as shown in Figure 2-3. The derivatives required for the iteration $d \tau / d R$ are found numerically.

The effective shear strength for erosion ( $\tau_{\text {fail }}$ ) equals the threshold value of fluid shear stress required to sustain general erosion at the borehole wall. Parthenaides and Paaswell (1970), in discussing investigations on 
the erosion of seabed sediments and in channels, have noted that this effective soil shear strength is not related to the soil shear strength as normally determined from conventional soil tests. The effective shear strength for erosion based on seabed data, as determined by Parthenaides and Paaswell (1970), is on the order of 1 to $5 \mathrm{~Pa}$ and is thus smaller by several orders of magnitude than the macroscopic soil shear strength.

\section{Turbulent Flow}

For Newtonian fluids with Reynolds numbers greater than about 2100 , flow in a circular pipe or annulus starts to become more or less random in character, which makes orderly mathematical analysis of the flow difficult, if not impossible. With increasing Reynolds numbers, this random behavior increases until, at a Reynolds number of about 3000 , the flow becomes fully turbulent. In fully turbulent flow, momentum effects dominate and the fluid viscosity is no longer important in characterizing pressure losses.

The Reynolds number $\left(R_{e}\right)$ is defined as

$$
R_{e}=\frac{\bar{\rho} \bar{V} D_{e}}{\bar{\eta}}
$$

where $D_{e}$ is the equivalent hydraulic diameter, $\bar{\rho}$ is the drill fluid density, $\bar{V}$ is the average fluid velocity, and $\bar{\eta}$ is the average iluid viscosity.

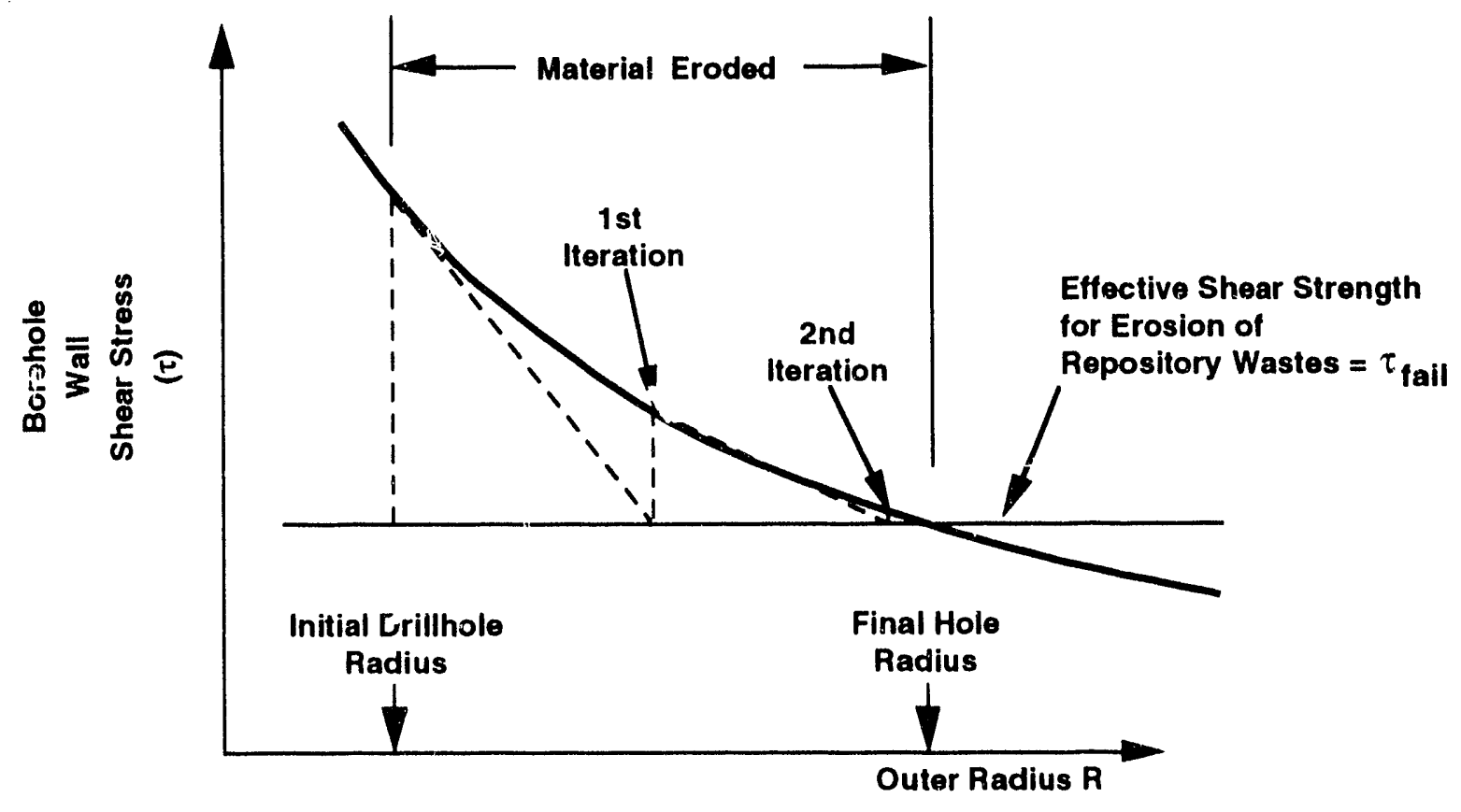

Figure 2-3. Iteration procedure for finding the final hole radius. 
For Newtonian fluids, the value to use for the viscosity is clear because the viscosity is constant for all rates of shear. Non-Newtonian fluids exhibit a changing viscosity with shear rate and present a special problem in calculating $R_{e}$. For fluids that exhibit a limiting viscosity at high rates of shear (such as the Bingham model and in our case the Oldroyd model), it has been suggested (Broc, 1982) that the limiting viscosity $\left(\bar{\eta}=\eta_{\infty}\right.$ ) be used in calculating the Reynolds number.

The Reynolds number for an Oldroyd fluid in an annulus can then be written as (Broc, 1982)

$$
R_{e}=\frac{0.8165 D \bar{V} \bar{\rho}}{\bar{\eta}}
$$

where the hydraulic diameter is expressed as $D=2\left(R-R_{i}\right)$ (see Figure 2-2).

The most important influence viscosity has on the calculation of pressure losses in fully turbulent flow of non-Newtonian fluids appears to be in the calculation of the Reynolds number. A far more important parameter is the surface roughness past which the fluid must flow. The Reynolds number, however, does have a role in determining the onset of turbulence. For Newtonian fluids this number is about 2100 . For non-Newtonian, ratethinning fluids, the critical value of $R_{e}$ tends to be greater than 2100 but less than 2400 (Walker, 1976). For our purposes, a value of 2100 will be used to represent $R_{e_{C}}$ (the critical Reynolds number) for the Oldroyd fluid model. Because turbulent flow is more effective in generating tluid shear stresses at the borehole wall, this assumption is conservative.

A transition region exists beyond $R_{e_{C}}$ before the development of fully turbulent flow. In this regime, the flow has the character of both laminar and turbulent flow. However, because pressure losses increase rapidly in turbulent flow and affect borehole shear stresses more severely, it will be assumed that beyond $R_{e_{c}}$ the flow is fully turbulent.

Turbulent flow is very complex and, thus, to characterize the tubulent flow regime, the great bulk of analysis has concentrated on empirical procedures. For axial flow in an annulus, the pressure loss under turbulent conditions can be approximated by (Broc, 1982)

$$
\Delta P=\frac{2 f L \bar{\rho} \bar{V}^{2}}{(0.8165) D}
$$

where $f$ is the coefficient of pressure head loss (Fanning friction factor) and $L$ is the borehole length.

If the shear stress due to the flowing fluid is assumed to be uniformly distributed on the inner and outer surfaces of the annulus, it can be easily shown using Equation (2-12) that the shear stress is related to the average fluid velocity through the relation

$$
\tau=\frac{f \bar{\rho} \widetilde{V}^{2}}{2(0.8165)},
$$


The Fanning friction factor is empirically related to the Reynolds number and relative roughness by the equation (Whittaker, 1985)

$$
\frac{1}{\sqrt{\mathrm{f}}}=-4 \log _{10}\left(\frac{\varepsilon}{3.72 \mathrm{D}}+\frac{1.255}{\mathrm{R}_{\mathrm{e}} \sqrt{\mathrm{f}}}\right),
$$

where $\varepsilon / D$ is the relative roughness. For circular pipes, $\mathrm{D}$ in this equation represents the inside diameter and $\varepsilon$ is the absolute roughness or the average depth of pipe wall irregularities. In the absence of a similar equation for flow in an annulus, it will be assumed that this equation also applies here, where $D$ is the hydraulic diameter as defined earlier and $\varepsilon$ is the absolute roughness of the waste-borehole interface.

Using a relative roughness and a calculated Reynolds number, a Fanning friction factor can be determined by iteratively solving Equation (2-14). The value of the shear stress acting on the borehole wall can then be determined from Equation (2-13). Using an iterative procedure similar to that for the laminar flow problem (Figure $2-3$ ), the fluid shear stress can be forced to equal the repository shear strength for erosion $\left(\tau_{\text {fail }}\right)$ to obtain the final eroded borehole radius.

In the actual solution sequence employed in the Fortran code, the Reynolds number is calculated first to determine which solution regime (laminar or turbulent) should first be initiated. For Reynolds numbers initially less than $R_{e_{c}}$, the code calculates the flow as laminar. Any increase in diameter of the borehole calculated during the laminar calculation will cause the Reynolds number to decrease as a result of a velocity decrease, ensuring that the calculation remains laminar. If the initial Reynolds number is greater than $R_{e_{c}}$, the turbulent formulation is used to calculate borehole erosion. When the turbulent calculation is complete, a check is again made to determine whether the Reynolds number still exceeds $R_{e_{c}}$. If it does not, the laminar calculation is performed starting with a "critical" borehole radius. The critical borehole radius corresponds to a Reynolds number of $R_{e_{c}}$ and is given by

$$
R_{\mathrm{crit}}=\frac{\bar{\rho} Q}{1286 \pi \eta_{\infty}}-R_{i}
$$

\subsection{Erosion Calculations}

The equations governing erosion based on laminar and turbulent flow were combined into a single Fortran computer code called CUTTINGS. Using appropriately selected input based on the physical properties of the waste and other drilling parameters, this code calculates the final eroded diameter of the borehole that passes through the waste. The drilling parameters chosen must reflect data typical of that valid near the WIPP repository.

For drilling operations through salt in the Delaware basin (where the WIPP site is located), the drilling mud most likely to be used is a brine (Berglund, 1990; Pace, 1990), with the density cut somewhat with an emulsified oil. The mud density and viscosity parameters required in the erosion calculations can be estimated based on the assumption of the use of such a brine-based drilling mud. 
For drilling through salt, the drilling speeds can vary from 40 to 220 rpm (Austin, 1983; Berglund, 1990; Pace, 1990). The most probable speed is about $70 \mathrm{rpm}$ (Berglund, 1990; Pace, 1990).

Mud flow rates are usually selected to be from 30 to 50 gallons/minute per inch of drill diameter (Austin, 1983) and usually result in flow velocities in the annulus between the drill collars and the borehole wall at or near the critical flow state (laminar-turbulent transition) (Berglund, 1990; Pace, 1990).

The drill diameter is related to the total planned depth of the hole to be drilled. For gas wells in the 4000- to 10,000 -foot range, it is likely that the drill used that passes through a waste room would have a diameter of 10.5 to 17.5 inches. The collar diameter is assumed to be less than the drill diameter by 2 inches.

The amount of material eroded from the borehole wall is dependent upon the magnitude of the fluid-generated shear stress acting on the wall and the effective shear strength for erosion of the compacted, decomposed waste. In the absence of experimental data, the effective shear strength for erosion of the repository material is assumed to be similar to that of a montmorillonite clay, with an effective shear strength for erosion of 1 to $5 \mathrm{~Pa}$ (Sargunam et al., 1973).

For turbulent flow, the shear stress acting at the borehole at the repository is dependent on the absolute surface roughness. The value chosen for the calculations exceeds that oî very rough concrete or riveted steel piping (Streeter, 1958).

Based on the sample set of input parameters shown in Table 2-1, the CUTTINGS code predicts that an original (gauge) borehole diameter of $0.41 \mathrm{~m}$ would erode to a final diameter of $0.597 \mathrm{~m}$. During the erosion process, the Reynolds number would decrease from an initial value of 7259 to 5803 . Thus, for the parameters chosen in this case, the flow in the annulus remains turbulent and only those equations governing turbulent flow in the CUTTINGS code are implemented.

The greatest borehole wall stresses and thus the most severe erosion occurs in the turbulent flow regime. It is interesting to note the sensitivity of borehole wall erosion to variations of selected input parameters. This sensitivity is illustrated in Figures 2-4, 2-5, and 2-6 for variations in initial mud velocity, absolute borehole roughness, and effective shear strength for erosion, respectively. For these three studies, the "base-case" parameters in Table 2-1 are used and only the selected variable was allowed to vary. For mud flow rate and absolute roughness, the chosen values cover their expected ranges. (Expected ranges are shown on the ordinates of Figures 2-4 and 2-5.) Because greater uncertainty is inherent in the assumed values for effective shear strength for erosion, this parameter is varied over a larger range.

For borehole roughness and initial mud velocity (whose expected ranges are more precisely established than the expected range of effective shear strength), final eroded diameter is less sensitive to borehole roughness and more sensitive to initial mud velocity. The sensitivity of final eroded diameter to effective shear strength for erosion reveals that no erosion occurs if the chosen shear strength is increased by a factor of 100 . 
Table 2-1. Erosion Parameters

\begin{tabular}{|c|c|c|}
\hline Paramelers & Value & Definition \\
\hline DOMEGA & $7.8 \mathrm{radians} / \mathrm{s}$ & drillstring angular velocity \\
\hline ROUTER & $0.204 \mathrm{~m}$ & drill radius \\
\hline UPHOLEV & $1.326 \mathrm{~m} / \mathrm{s}$ & initial mud flow velocity in annulus \\
\hline ETA0 & $0.01834 \mathrm{~Pa} \bullet \mathrm{s}$ & $\begin{array}{l}\text { Oldroyd viscosity parameter (limiting } \\
\text { viscosity at zero shear rate) }\end{array}$ \\
\hline SIGMAl & $0.1082 \times 10^{-5}$ & Oldroyd viscosity parameter \\
\hline SIGMA2 & $0.5410 \times 10^{-6}$ & Oldroyd viscosity parameter \\
\hline DENSITY & $1210 \mathrm{~kg} / \mathrm{m}^{3}$ & drilling fluid (mud) density \\
\hline TAUFAIL & $1 \mathrm{~Pa}$ & $\begin{array}{l}\text { effective shear strength for erosion of waste } \\
\text { material }\end{array}$ \\
\hline ROUGH & $0.025 \mathrm{~m}$ & absolute borehole roughness \\
\hline
\end{tabular}

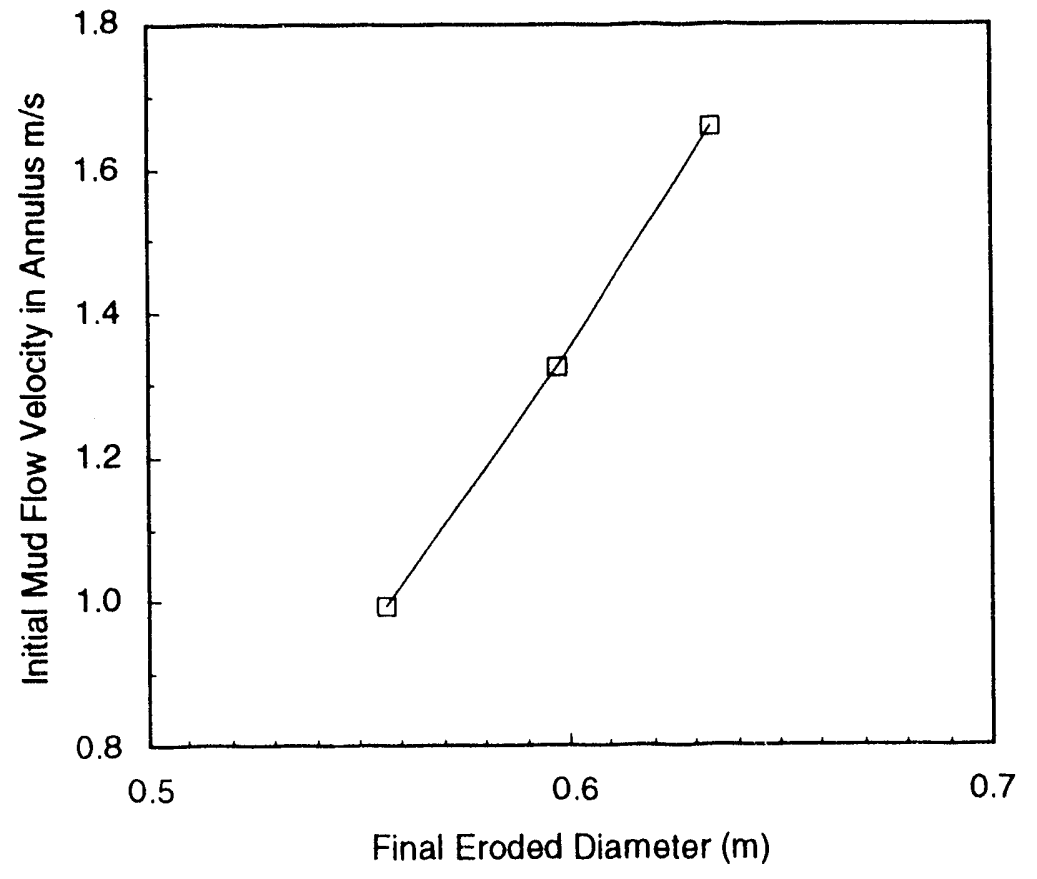

Figure 2-4. Sensitivity of eroded diameter to initial mud flow velocity in annulus. 


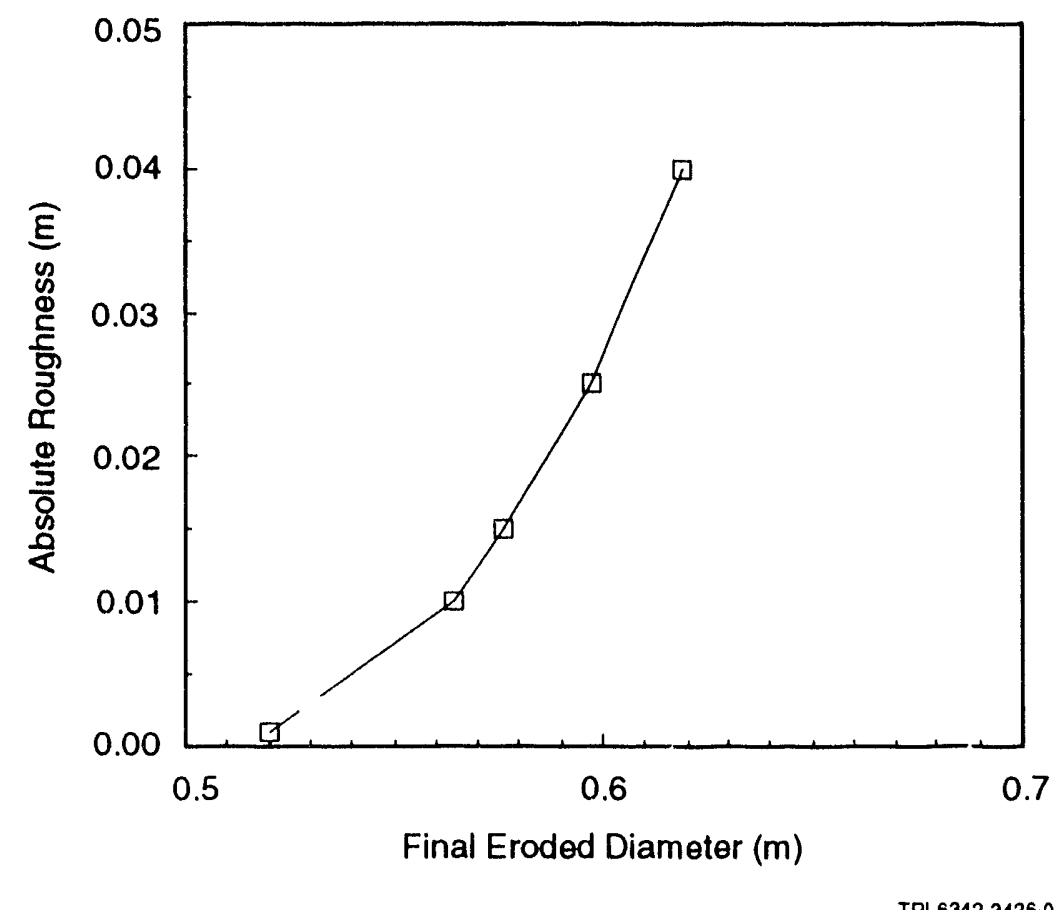

Figure 2-5. Sensitivity of eroded diameter to absolute borehole roughness.

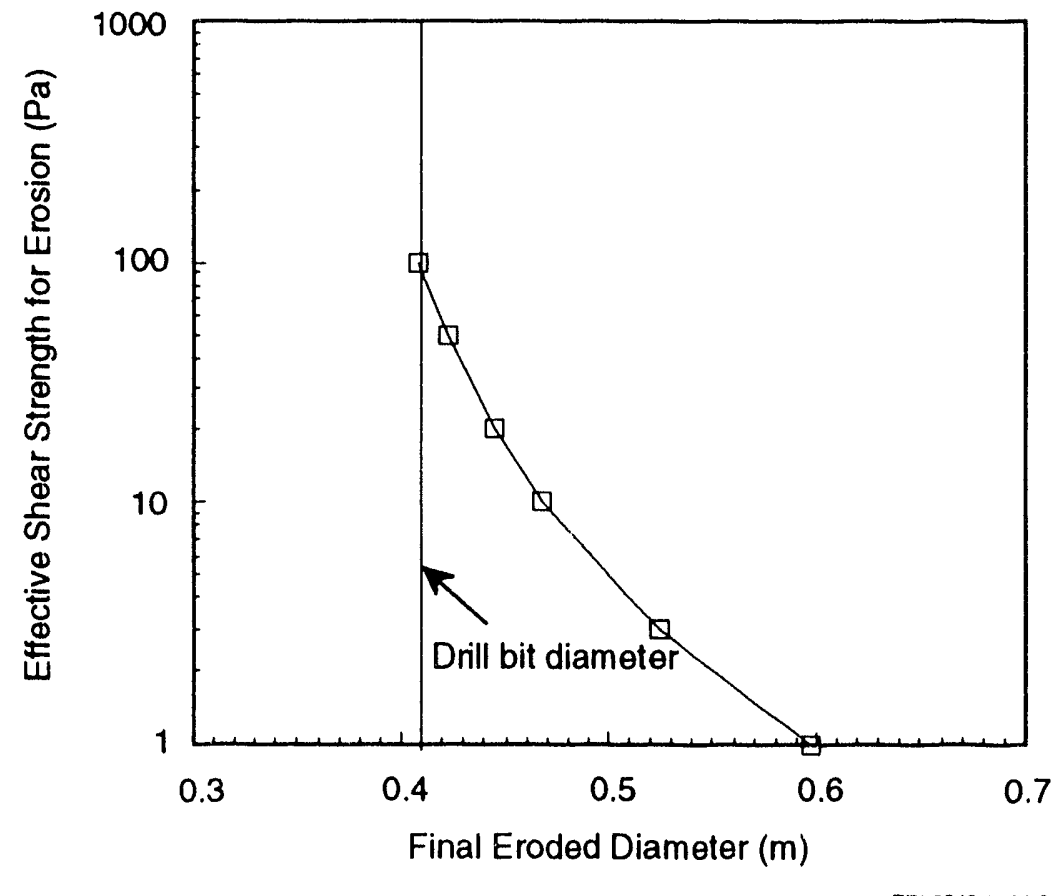

Figure 2-6. Sensitivity of eroded diameter to effective shear strength for erosion. 


\section{MECHANISM II: WASTE-GAS-INDUCED BOREHOLE SPALL}

\subsection{Introduction}

As discussed earlier, after the WIPP repository is filled with waste and sealed, the waste is expected to be slowly compacted by salt creep from an original waste room height of $4 \mathrm{~m}$ to a compacted height of 1.5 to $2 \mathrm{~m}$ within 100 to 200 years. The overburden (vertical) stress on the waste will also increase to the lithostatic stress $(\sim 14.8 \mathrm{MPa})$ during this period. Corrosion and biodegradation of the waste prompted by brine intrusion will generate gas, raising the gas pore pressure in the waste to values approaching and perhaps exceeding the lithostatic level within the next 700 to 2,000 years. The gas will force any residual brine to the bottom of the waste repository and below, and for the most part, much of the waste will be gas-saturated, as will a very small purtion of the halite (Salado Formation) above the waste.

The permeability of the Salado formation above the waste is dependent on whether it is considered disturbed, or disturbed and healed. It is expected that the Salado permeability will range from $1 \times 10^{-18}$ to $1 \times 10^{-20} \mathrm{~m}^{2}$. The compacted waste permeability will vary between $1 \times 10^{-13}$ and $2.4 \times 10^{-17} \mathrm{~m}^{2}$, depending on waste form. Thus, the difference in permeability of the compacted waste and the upper Salado formation is between approximately 1 and 7 orders of magnitude; hence, for much of this range and for "brief" events the Salado can be considered impermeable compared to the waste. As a first approximation, the intrusion of a drill bit into the waste will "suddenly" expose the waste with its high pore pressure (for example, 14.8 MPa) to the borehole hydrostatic pressure of $7.7 \mathrm{MPa}$ (assuming a saturated salt solution is used while drilling), and the gas will escape to the borehole after flowing through the compacted waste. The question that must be answered is this: What effect does the flow of gas through the waste have on the stability of the borehole wall, and does this process contribute 10) the quantity of waste material that reaches the surface environment?

\subsection{Existing Literature}

The disposal, compaction, and brine-induced corrosive degradation of entombed contaminated waste is a unique scenario and is not directly analogous to any phenomenon that has occurred in nature. However, considerable information exists in the literature on the exploration for and production of fossil fuels and the problems encountered during these activities. It is interesting to note that, in these areas, related phenomena have been observed.

The failure, sloughing, or spalling of borehole walls is a common occurrence in oil and gas drilling and can be caused by a number of different mechanisms, including an encounter with a geopressurized formation. Short (1982) describes in general terms the spalling or "popping off" of shale fragments into the borehole caused by formation pore pressures greater than the borehole pressure. He states that the condition occurs primarily in shales, but adso indicaltes that field evidence exists that this hehavior may also occur in very-fine-grained, well-cemented sands or in other formations with very low permeability. (heatham (1984) reviewed the causes of wellbore 
instability, and indicated that one mechanism for collapse was the result of low borehole pressure adjacent to a geopressurized formation.

The stress state around a borehole in the absence of pore pressure can in itself cause structural failure and has become an important consideration associated with drill tool sticking and lost circulation (Nakken et al., 1989). A review of some of the many works in this area was presented by Roegiers (1989). Analyses often consider the porous nature of the material (Detournay and Cheng, 1988) or treat borehole failure as a bifurcation phenomenon (Vardoulakis et al., 1988).

Fluid flow from a formation to a borehole is necessary for wells to maintain gas or oil production. High differential pressures between the formation pores and the borehole enhance fluid production but tend to cause sloughing of the borehole wall. In poorly consolidated sand formations, the sloughing of sand into the borehole (sand production) is an important problem and has been studied by numerous authors. The problem of sand production is related to the ability of sand to form a stable arch. Hall and Harrisherger (1970), through experiment, concluded that stability of a sand arch requires dilatancy and cohesiveness or some other constraint on the surface of the grains. Stein and Hilchie (1972) describes a technique to estimate the maximum rate that oil can be produced from a well adjacent to friable sand without inducing sand influx problems. Their method is based on formation strength estimates from $\log$ data and on the assumption that stability arises from the development of stabl' arches. Bratli and Risnes (1981) studied the failure of spherical sand arches both experimentally and theoretically using an elastic-plastic (Mohr-Coulomb) approach. They concluded that collapse of the inner Coulomb zone of the spherical arch will occur if the pore pressure exceeds the radial stress and the difference becomes equal to the uniaxial tensile strength of the sand. Similar conclusions of stability were reached for sand in a cylindrical geometry by Risnes et al. (1982). In this work, borehole stability in an uncased hole was related to the permeability variation with radius and to the cohesive strength of the sand. In both of the latter works, it was assumed that the pore fluid was incompressible and that steady-state conditions prevailed. Vaziri (1989) extended the work of Risnes et al. (1982) by considering the time-dependent changes in the stress and fluid fields by using finite-element procedures.

The effects of gas escaping from a geopressurized formation to a borehole are also related to the phenomenon of coal outbursts. An outburst is the violent and potentially dangerous failure of a freshly exposed coal surface that occasionally occurs in underground mining. An extensive review of outbursts and some of the theories hypothesized to explain them was given by Shepherd et al. (1981). In this work, the role of geologic structures, coal stresses, and matrix gases is discussed. A definitive model for coal outbursts was presented by Paterson (1986). The model is based on the pressure gradients generated by the flow of gas from the micropores within the coal to the lower-pressure mine surface. These gradients generate body forces within the coal and a tensile stress state that can exceed the tensile capacity of the coal. The outburst occurs when the coal near the mined surface fails at a naturally weakened plane.

Numerous methane-gas-induced outhursts have also heen observed in sandstone formations located near coal seams. Sato and Itakura (1989) describe in detail one such event that occurred in the Horonai coal mine in 1978. While mining advanced progressively along a $17.45-\mathrm{m}^{2}$ crosscut in a sandstone formation using explosives, the volume of fractured sandstone following a blast abruptly increased hy more that a factor of twenty and a large volume of methane $\left(1800 \mathrm{~m}^{3}\right)$ was released. Sato and Itakura (1989) postulated that the tensile strength of the 
sandstone in this case was too high for the outburst to occur spontaneously from the entrained gas alone and was initiated by unloading stress waves from the blast.

More pertinent to the possibility of spall due to a borehole penetrating a gas-saturated waste repository is the phenomenon of outbursts that occur when drilling through deep coal seams. Willis (1978) relates occurrences where "deeply buriec coal seiuns are drilled and the coal literally 'explodes' into the wellbore. . . Cases have been cited where only $1 \mathrm{ft}$ of coal has been drilled and the hole is tight for 30 to $60 \mathrm{ft}$ as the driller pulls out of it." In such a case, adthough only a small length of coal was drilled, the "explosive" response of the penetrated coal causes quantities of fractured coal to be projected up to $60 \mathrm{ft}$ into the drill annulus, thus restricting mud flow and potentially jamming the bit. Several reasons for this phenomenon are suggested, including the release to the welltore of entrapped, high-pressure gas in the coal.

Some experiments have investigated the outbursting phenomenon. Ujihira et al. (1985) demonstrated the importance of tensile strenguh and gas pressure within the porous material on failure. Their experiments illustrated the one-dimensional, progressive, calastrophic failure of a porous coal simulant when a sudden pressure drop was generated at one end. High-speed photography revealed that failure started at the specimen face exposed to the pressure drop and rapidly (within $0.025 \mathrm{~s}$ ) propagated through the specimen. Minioutbursts were also generated in circular cylindrical briquettes of coal pressurized with $\mathrm{CO}_{2}$ and $\mathrm{N}_{2}$ by Bodziony et al. (1989). In the latter, when the pressure at one end of the triquette was suddenly reduced, the ensuing outburst caused the briquette to become divided into layers much like a sliced salami.

\subsection{Analysis}

\section{Overview}

The literature addresses various aspects of borehole f tilure, including conditions conducive to borehole spall arising from fluid flow. Clearly, this evidence tends ir support the need to study the potential for gas-induced spall in waste. The problem, however, is quite conylex, involving the flow of gas in a moving waste matrix, changing stress states, changing porosity and permeability of the waste, waste failure, and, when the waste interacts with the drill bit, turbulent mixing of the three phases -... solid waste, drilling fluid, and gas. In light of this complexity, the following analyses of spall-related events associated with the WIPP repository will begin by employing relatively simple assumptions of behavior near the borehole, such as elastic waste response.

Seven types of calculations-each of which addresses a different aspect of gas flow from a penetrated, pressurized, waste-storage room-are described in the following pages:

- The first calculations (see section titled "One-Dimensional Cylindrical Elastic Approximation") consider the time period during which gas would be expected to flow from a breached room. Because spall is related 10 the flow of gas out of a room. the period of gas flow is directly related to the time during which spall may be a lactor in calculating releases 10 the surface. This time period will be shown to vary considerably depending upen the assumed waste perneability. In these calculations, one-dimensional flow is assumed. 
- The second series of calculations (see sections titled "Uncoupled Gas Flow" and "Coupled Response"), also one-dimensional, studies the coupled response of gas flow and the stress state in the waste near a borehole for a drill bit that suddenly and completely penetrates the thickness of the compacted repository. The waste is assumed to behave as an elastic porous material, and the borehole pressure drop is assumed instantaneous. Although the constitutive nature of the compacted waste composite is unlikely to behave elastically, the approach does reveal some important insights into the response of the waste-to-gas flow. The radial tensile stress state near the borehole revealed by these calculations is especially of interest.

- The third set of calculations (see section titled "Two-Dimensional Effects") again investigates the elastic stress state near a borehole caused by flowing gas; however, it considers the more realistic case where the drill bit just penetrates the top of the waste. This probiem must be solved in two dimensions. Assuming an instantaneous borehole pressure drop as before, the tensile stress field near the borehole is comparable to that found for the one-dimensional case.

- The fourth set of calculations (see section titled "Borehole Pressure Decay Model") addresses the fact that an instantaneous borehole pressure drop is incorrect hecause the drill bit moves at a finite speed. This set of calculations describes a simple one-dimensional model that can calculate an approximate borehole pressure decay time that depends upon the drilling rate, gas, and Salado properties. Using this model, approximate pressure decay times caused by the drill bit penetrating the Salado formation above the waste and into the top of a pressurized waste room are calculated.

- The fifth set of calculations (see section titled "Elastic Stress State Adjacent to Borehole as a Function of Pressure Decay 'Time") studies the effect of different borehole decay times on the elastic stress response near a borehole. Again, one-dimensional response is assumed, and the effect on stresses of a finite borehole pressure decay time is shown.

- The sixth and seventh sets of calculations (see section titled "Inelastic Dynamic Response fo the Waste") demonstrate the dynamic response of the waste adjacent to the borehole when the waste is assumed to hehave inelastically as a compacted granular material similar to a soil with a low cohesive strength. Both the one-dimensional and two-dimensional dynamic responses near the borehole are described. The purpose of these dynanic calculations is to show the waste motion near the borehole caused by the escaping gas and to assess the stress state and changing properties of the waste near the borehole.

\section{One-Dimensional Cylindrical Elastic Approximation}

As a first attempt to address the problem of borehole spall, a one-dimensional cylindrical elastic approximation will be utilized. It will be assumed that a gas-pressurized layer of material (the repository) is instantaneously penetrated by a borehole of radius $r_{h}$. At this time, the pressure in the hole is $p_{h}$ and the repository pore pressure is constant for all $r>r_{h}$ at a value of $p_{p}$ (Figure 3-1). 


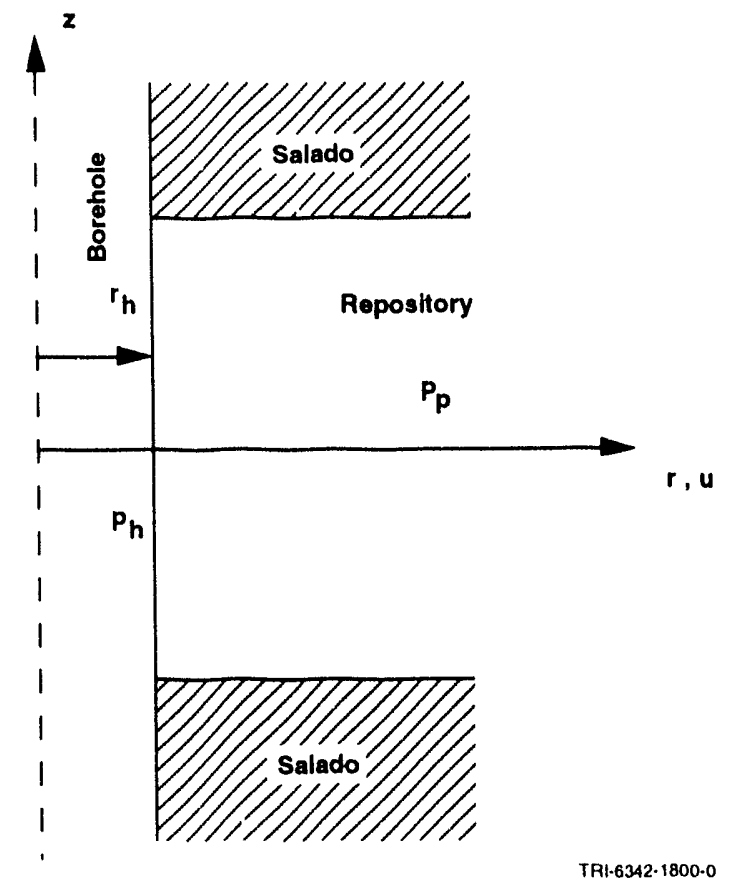

Figure 3-1. Borehole penetrating gas-filled repository (time $=0$ ).

The total stress is a function of the effective stress and the pore pressure. In cylindrical coordinates where compressive stresses and the pore pressure are assumed positive, the total normal stresses can te written:

$$
\begin{aligned}
& \sigma_{z z}=\bar{\sigma}_{z z}+p \\
& \sigma_{r r}=\bar{\sigma}_{r r}+p \\
& \sigma_{\theta \theta}=\bar{\sigma}_{\theta \theta}+p,
\end{aligned}
$$

where $\bar{\sigma}_{z z}, \bar{\sigma}_{r r}, \bar{\sigma}_{\theta \theta}$ are the effective normal stresses and $p$ is the instantaneous repository pore pressure. If plane strain behavior of the repository is assumed, the formulation is one-dimensional and the radial displacement can be represented by $u$. For small strains in a porous elastic material, the quasi-static (inertial effects are ignored) equilibrium equation in terms of displacement can be written:

$$
\frac{\partial^{2} u}{\partial r^{2}}+\frac{1}{r} \frac{\partial u}{\partial r}-\frac{u}{r^{2}}=\frac{1}{C} \frac{\partial p}{\partial r}
$$


where

$$
\begin{aligned}
& C=\frac{E(1-v)}{(1+v)(1-2 v)} \\
& E=\text { elastic modulus of the porous matrix, and } \\
& v=\text { Poisson's ratio of the porous matrix. }
\end{aligned}
$$

In the development of Equation (3-2), it is also assumed that the bulk modulus of the individual solid particles comprising the porous matrix is much greater than the bulk modulus of the porous matrix.

The pore pressure in the repository is governed by the flow and expansion of the gas $2 s$ it moves towards the lower pressure bor ehcle. This flow can be represented by a nonlinear equation in terms of pore pressure, volumetric strain, and matrix porosity (Rear, 1972). This equation assumes that a generalized Darcy's law remains valid (the effect of matrix motions on Darcy's Law is ignored) and that porosity changes are small enough that the permeability remains constant.

$$
\frac{k}{2 \mu} \nabla^{2} p^{2}=\left(\varphi_{0}+\varepsilon_{v o l}\right) \frac{\partial p}{\partial t}+p \frac{\partial \Xi_{v o l}}{\partial t}
$$

where $\mathrm{k}$ is the permeability, $\mu$ is the gas viscosity, $\varphi_{0}$ is the initial porosity, $\varepsilon_{v o l}=\partial u / \partial r+u / r$ is the volumetric strain, and $\nabla^{2}=\partial^{2} / \partial r^{2}+1 / r \times \partial ; \partial r$.

Equations (3-2) and (3-3) are coupled uhrough the volumetric strain and pore pressure. These equations can be solved numierically using central difference approximations for the derivatives on a nonuniformly spaced grid along the radius $r$ and explicit integration in time.

\section{Uncoupled Gas Flow}

Prior to describing the results of the coupled calculations, it should first be explained how the pressure in a waste disposal room decays with time after penetration. To determine this in an approximate sense, it is not necessary to solve the full coupled problem. If changes in volumetric strains are assumed to be small, an uncoupled form of Equation (3-3) governs the pressure response in the waste disposal room. Using central difference approximations for the derivatives on a nonuniform grid, a numerical solution of Equation (3-3) (with the $\varepsilon_{v o l}$ terms ignored) can be readily obtained. With a numerical grid defined by a borehole radius of $r_{h}=0.2 \mathrm{~m}$, an initial zone size of $0.05 \mathrm{~m}$, a growth factor of 1.14 , and a total of 38 nodes, the pore pressure distribution was calculated for two different compacted waste permeabilities. The additional fixed input variables necessary are shown in Table 3-1.

The $10 \mathrm{~m} \times 91 \mathrm{~m}$ waste disposal room is assumed to be penetrated at its center so that the maximum value for the radial coordinate is approximately $4.5 \mathrm{~m}$; at this outer boundary, no flow of gas is permitted $(\partial p / \partial r=0)$. The 
calculated pressure distribution at four separate timer for $k=1 \times 10^{-17} \mathrm{~m}^{2}$ is shown in Figure $3-2$. The pressure at the far boundary at 375 days decreases approximately $3 \mathrm{MPa}$ from the initial room pressure. For the case of waste with a larger permeability $\left(k=1 \times 10^{-13} \mathrm{~m}^{2}\right)$, the room is depleted much faster. The far boundary pressure for this high-permeability case drops by more than $4 \mathrm{MPa}$ within $5000 \mathrm{~s}$, or approximately 1.4 hours. The pressure distribution as a function of $r$ for the high-permeability case is not shown explicitly, but also has a character similar to that of Figure 3-2. Flow to the borehole is greatest inmediately following the formation of the borehole. The flowrate then stabilizes to a quasi steady-state rate for a period of time governed by the distance to the far-field (repository) boundary. The steady-state gas flow rate into the borehole per unit exposed area is quite different for the two permeability cases: $2 \times 10^{-5} \mathrm{~m}^{3} / \mathrm{m}^{2} \mathrm{~s}$ for the low-waste permeability case and $0.1 \mathrm{~m}^{3} / \mathrm{m}^{2} \mathrm{~s}$ for the greater permeability case. In both permeability cases, a considerable quantity of gas remains in the room and would continue to flow toward the borehole after the calculated times ( 375 days $f \circ k=1 \times 10^{-17} \mathrm{~m}^{2}$ and 1.4 hours for $k=1 \times 10^{-13} \mathrm{~m}^{2}$. The time period needed for complete pressure equilibration to occur throughout the waste storage room will be longer by several orders of magnitude for the low-permeability case than for the highpermeability case.

Table 3-1. Properties Used for Uncoupled Gas Flow Assuming an Instantaneous Pressure Drop

\begin{tabular}{lc}
\multicolumn{1}{c}{ Property } & \multicolumn{1}{c}{ Values } \\
Repository Permeabilities & $k=1 \times 10^{-17} \mathrm{~m}^{2}, 1 \times 10^{-13} \mathrm{~m}^{2}$ \\
Porosity & $\eta_{o}=0.15,0.19$ \\
Hydrogen Viscosity & $\mu=9.32 \times 10^{-6} \mathrm{~Pa} \bullet \mathrm{s}$ \\
Borehole Pressure & $p_{h}=7.7 \mathrm{MPa}$ \\
Initial Room Pressure & $p_{p}=14.8 \mathrm{MPa}$
\end{tabular}




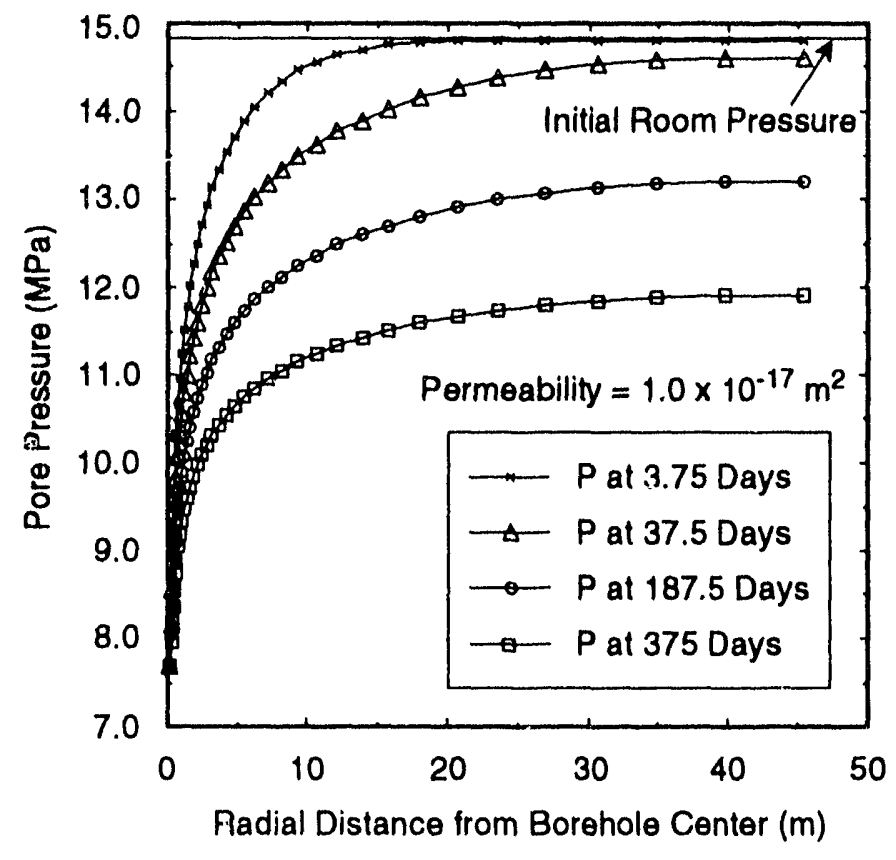

Figure 3-2. Pressure distribution in waste disposal room at four times after borehole penetration$k=1 \times 10^{-17} \mathrm{~m}^{2}$.

\section{Coupled Response}

For the coupled problem, a finer grid located near the borehole was chosen. The numerical grid was defined by a borehole radius of $r_{h}=0.2 \mathrm{~m}$, an initial zone size of $0.01 \mathrm{~m}$, a growth factor of 1.04 , and a total of 78 nodes. This grid selection places the largest value of $r$ at $5.07 \mathrm{~m}$ compared to $45 \mathrm{~m}$ for the uncoupled calculation. Solving Equations (3-2) and (3-3) simultaneously, the effective stress state and pore pressure adjacent to the borehole was calculated using the additional fixed input variables shown in Table 3-2.

Choosing an initial repository pore pressure of $p_{p}=12.9 \mathrm{MPa}$, the distribution of effective stresses and pore pressure as a function of node position at 3 seconds after penetration is shown in Figure 3-3. At 3 seconds, the hoop effective stress $\left(\bar{\sigma}_{\theta \theta}\right)$ and the vertical effective stress $\left(\bar{\sigma}_{z z}\right)$ remain compressive, while the radial effective stress $\left(\bar{\sigma}_{r r}\right)$ changes from a tensile to a compressive stress as $r$ increases. The variation of $\bar{\sigma}_{r r}$ as a function of time is plotted in Figure 3-4. 
Table 3-2. Properties Used for Coupled Calculations Assuming an Instantaneous Borehole Pressure Drop

\begin{tabular}{lrl}
\hline \multicolumn{1}{c}{ Broperty } & \multicolumn{1}{c}{ Value } \\
Repository Permeability & $k=1 \times 10^{-16} \mathrm{~m}^{2}$ \\
Initial Porosity & $\eta_{o}=0.19$ \\
Hydrogen Viscosity & $\mu=9.32 \times 10^{-6} \mathrm{~Pa} \cdot \mathrm{s}$ \\
Elastic Modulus & $\mathrm{E}=1.8 \times 10^{9} \mathrm{~Pa}$ \\
Poisson's Ratio & $v=0.2$ \\
Borehole Pressure & $p_{h}=7.0 \mathrm{MPa}$ \\
Lithostatic Stress & $\sigma_{z z}=14.8 \mathrm{MPa}$ \\
&
\end{tabular}

As the gas initially flows into the borehole, the early-time radial effective stresses adjacent to the borehole are tensile with the greatest peak tensile stress occurring very near the borehole boundary. The size of the tensile region decreases with time until, after 9 seconds, all effective stresses are compressive (Figure 3-4). For an elastic material that is weak in tension, the results suggest that some degree of tensile fracturing may occur in the vicinity of the borehole at the location of the peak tensile stress and that sections of the borehole wall could spall and fall into the flowing d.: :iling inud eventually to be brought to the surface. These results are consistent with previous results for incompressible fluids (Risnes ot al., 1982) and with oil field experience in geopressurized lowperneability shales (Short, 1982). Under these field conditions, thin sections of shale have been observed to spall or pop off the borehole wall into the drilling fluid. When spalling shales are encountered in the field, the driller often raises the drill stem slightly to avoid jamming the drill bit in the spalling material. Then the spalling process $\mathrm{i}$ - allowed to continue without further drilling until the process slows naturally (12 to 24 hours), permitting the cavings to be cleaned out by further drilling. The intermittent nature of the spalling process is the result of the exposure of new surfaces following spallation and the initiation of a new gas pressure gradient and stress cycle. The long period of time over which the spallation process occurs compared to the above calculation (hours instead of seconds) is attributable to shale permeabilities several orders of magnitude smaller and pore fluid viscosities much greater than those used in the above calculation. Calculations using a decreased permeability (not shown) show that the character of effective stress response remains much the same as for the higher permeability case illustrated above, except that the timing of events is delayed.

If the time of intrusion is such that the initial pore pressure approaches the lithostatic stress, the tensile region for the radial effective stress increases significantly in radius. This is illustrated in Figure 3-5, in which the radial effective stress is plotted for three different cases of initial pore pressure at 3 seconds after borehole penetration (all of the remaining parameters are the same as before). For an initial pore pressure equal to the lithostatic pressure, the radial effective stress in an elastic material remains tensile at all radii and indeed does so for all time. 


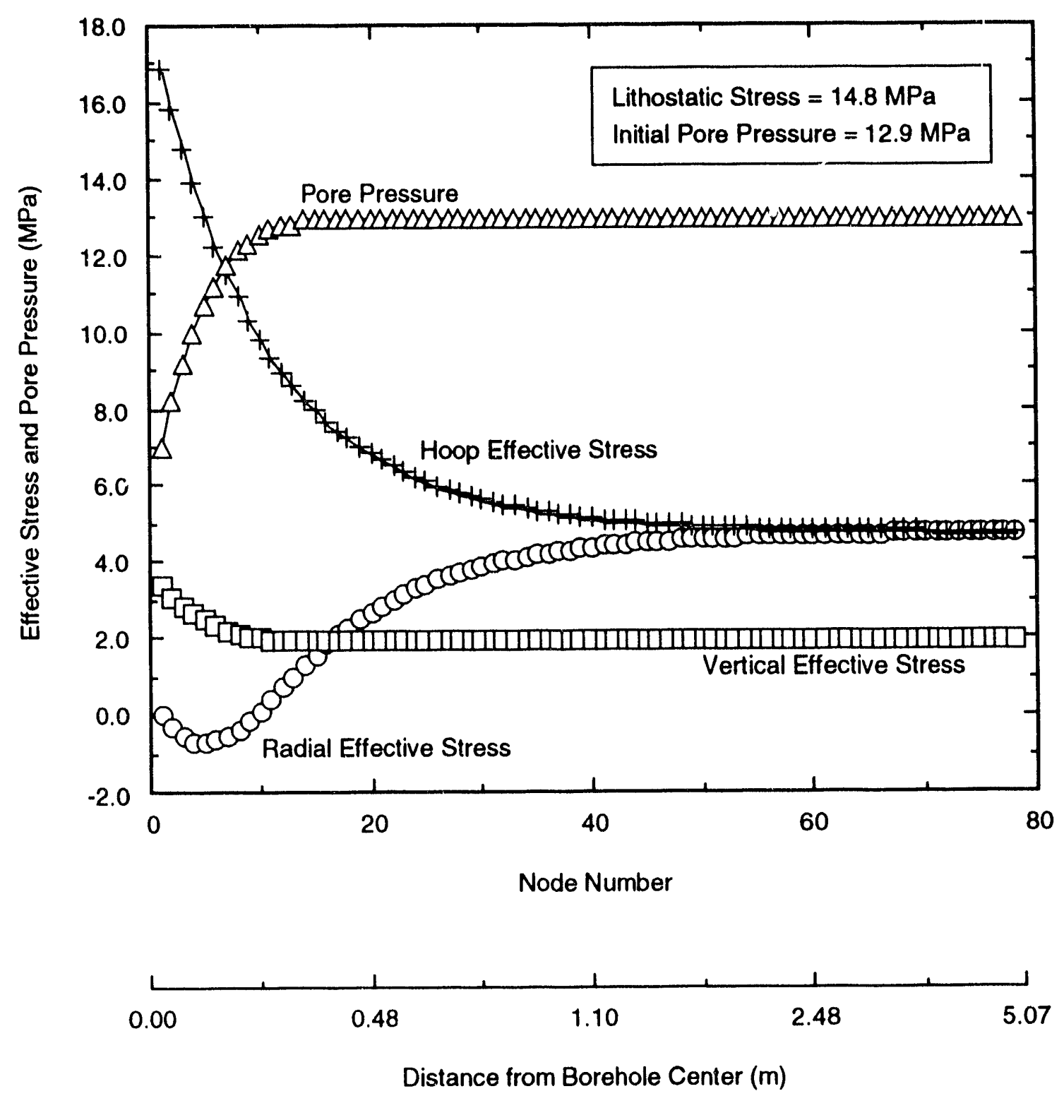

Figure 3-3. Effective stresses and pore pressure at 3 seconds after pe" dration. 


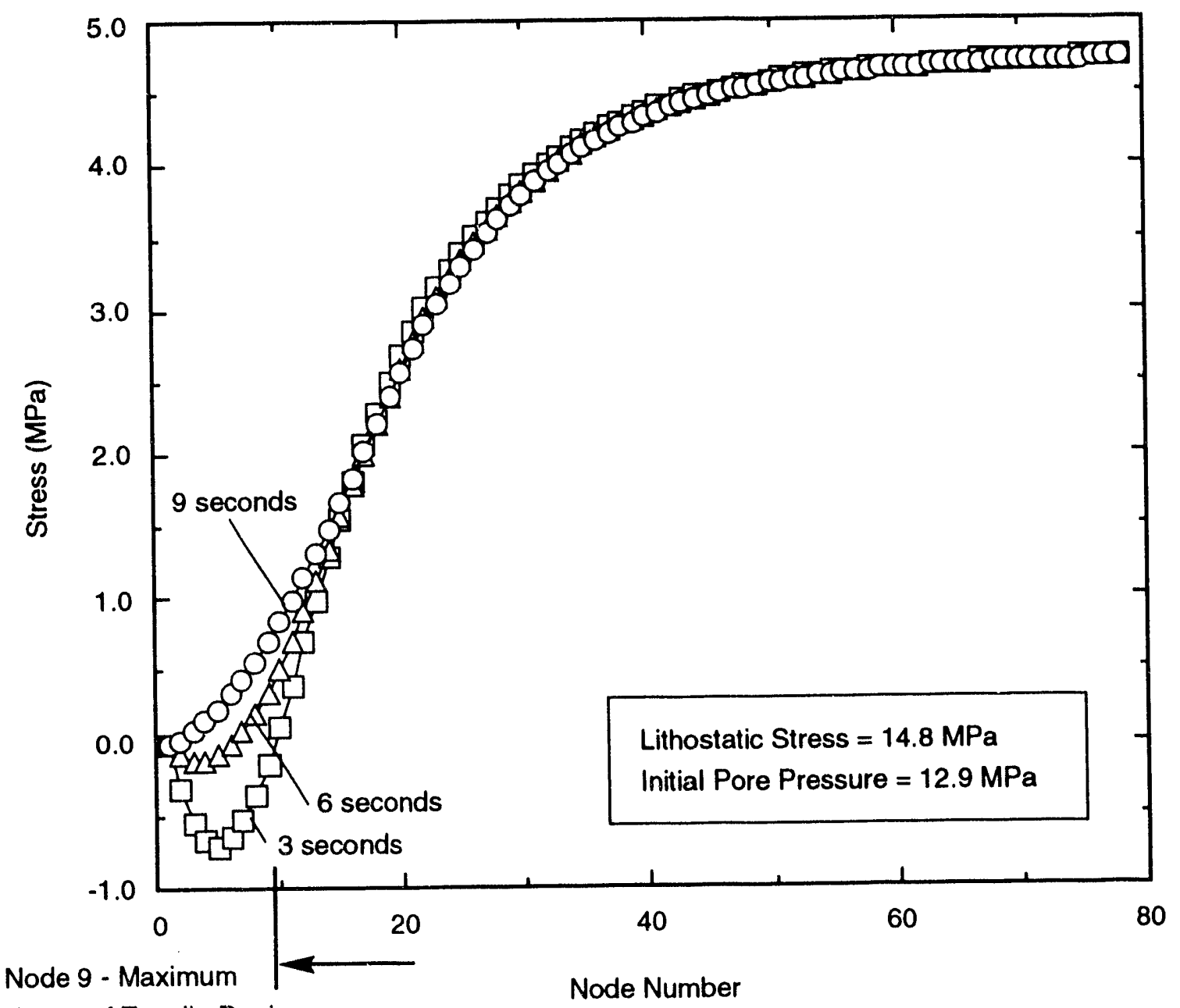

Extent of Tensile Region

(0.092 $\mathrm{m}$ into borehole wall)

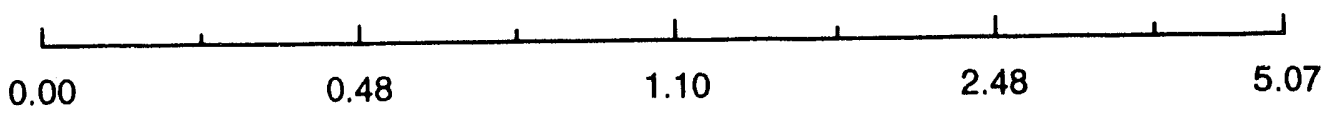

Radial Distance from Borehole Center $(\mathrm{m})$

TRI-6342-1840-0

Figure 3-4. Radial effective stress. 


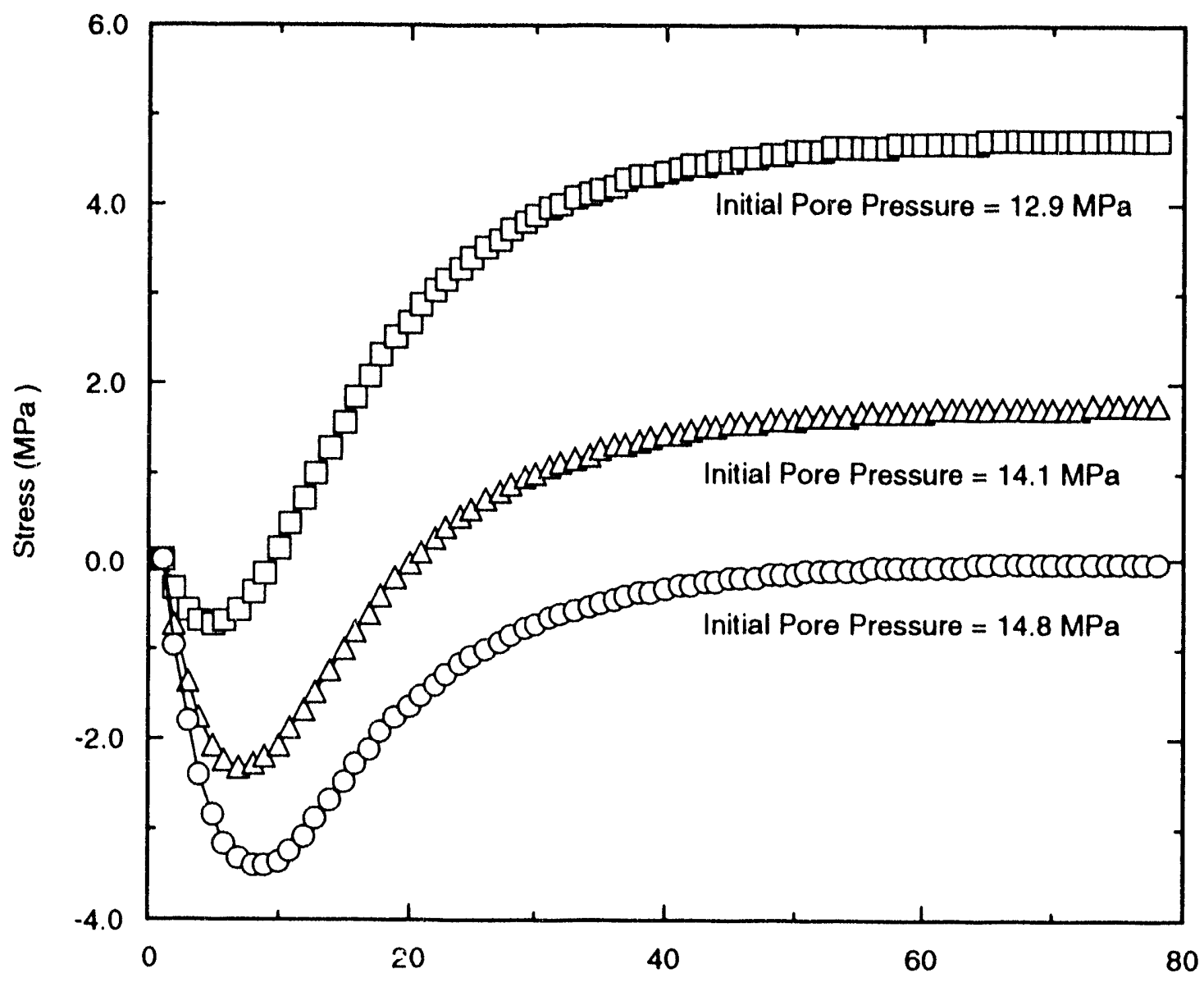

Node Numbers

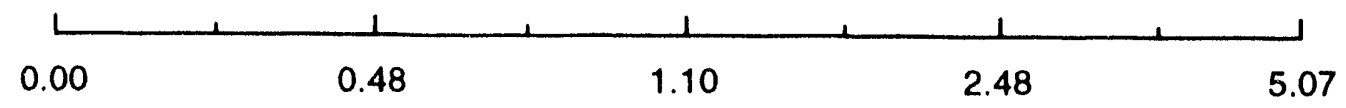

Radial Distance from Borehole Center (m)

TRI.6342-1839.0

Figure 3-5. Radial effective stress at 3 seconds after penetration for three different values of initial pore pressure. 
The volumetric strains determined from the above calculations are small compared to the value of the initial porosity. This suggests that the equilibrium equation (Equation (3-2)) and the flow equation (Equation (3-3)) are only weakly coupled through the volumetric strain and that similar results could have been obtained had this term been ignored in Equation (3-3). The uncoupling of the two equations permits the use of other existing methods to further verify the analytical procedure used above. For the uncoupled flow portion of the problem, the BOAST Il code (Fanchi et al., 1987) was used to calculate the time-varying radial pressure field. Results from BOAST II were within a few percent of the values calculated by the analytical method. Similarly, the stress field was calculated using an explicit dynamic solid-mechanics finite-element code called SAMSON2 (Rudeen and Rath, 1986). Using dynamic relaxation to obtain the quasi-static solution, the stress field calculated by SAMSON2 again compared to within a few percent to the finite-difference model.

\section{Two-Dimensional Effects}

Because the compacted waste is not instantaneously penetrated by an intrusion drill bit, the one-dimensional cylindrical approximation is not strictly correct and two-dimensional effects must be considered.

Certain aspects of the two-dimensional character of repository penetration by a borehole and the subsequent release of gas pressure can be treated in an approximate sense with the dynamic solid mechanics code SAMSON2 (Rudeen and Rath, 1986) and an analytic model for gas diffusion. If the volumetric strains of the solid matrix are small compared to the porosity of the compacted repository material and the permeability is assumed to be constant, the flow of gas within the repository is independent of strains within the solid matrix and gas flow can he determined independent of the matrix strain.

Consider the case where the drill bit instantaneously penetrates the repository to a depth equal to $1 / 2$ of the drill bit dianeter. This assumption is an inprovement over the one-dimensional cylindrical case where the entire thickness of the repository is penetrated instantaneously. Under these conditions, it is possible to model a portion of the repository and borehole boundaries with a rather simple two-dimensional geometry (Figure 3-6).

In this geometry, the equation governing the flow of gas out of the repository can be written

$$
\frac{k}{2 \mu} \nabla^{2} p^{2}=\varphi_{0} \frac{\partial p}{\partial t}
$$

Comparing this equation wilh Equation (3-3) reveals that the term involving volumetric strain has been ignored. By ignoring the lower boundary between the compacted repository waste and the Salado (intinite waste thickness) and assuming that the Salado/waste boundary is inpermeable, the pressure field can be assumed to be point symmetric, and $\nabla^{2}$ is the one dimensional spherical differential operator defined by:

$$
\nabla^{2}=\frac{\partial^{2}}{\partial r^{2}}+\frac{2}{r} \frac{\partial}{\partial r}
$$


It is observed that the choice of a uniform spherical geometry (Figure 3-6) and small strains allows the gas flow to be approximated using an uncoupled one-dimensional equation. In a manner similar to the one-dimensional cylindrical case, Equation (3-4) can be solved numerically using central difference approximations for the derivatives on a nonuniformly spaced grid along the radius $r$.

The material response, however, must be calculated in two dimensions. After dividing the region shown in Figure 3-7 into 390 elements, the SAMSON2 code can be used to calculate the material response near the borehole. The regions shown in Figure 3-7 and the subsequent regional figures are inverted. The positive $y$ coordinate physically points downward. For simplicity, the radial spacing of the nonuniform SAMSON2 grid was chosen to correspond to the finite-difference spacing of the gas-diffusion equation. This eliminates the need to map the gas-pressure results onto the solid mechanics grid. An examination of the governing equations in SAMSON2 reveals that the gas-pressure gradient acts as a body force on the elements. The gas-pressure field determined from the solution of Equation (3.4) is therefore used to generate a radial-body force field on the elements used in the SAMSON2 simulation. The gas-pressure field is a function of both the radial coordinate $r$ and time $t$. For a fixed time, the gas-pressure field is used to generate a static solution of the effective stress field near the borehole. Dynamic relaxation is used within SAMSON2 to achieve the static solution.

In addition to the radial gas gradient field applied to elements within SAMSON2, the boundary conditions include fixed remote boundary nodes (Figure 3-7) and an applied vertical effective stress on the top surface (bottom surface as shown in the figure) of the repository. The sum of the gas pressure and the vertical effectivestress at the boundary is equal to the lithostatic stress at the repository depth.

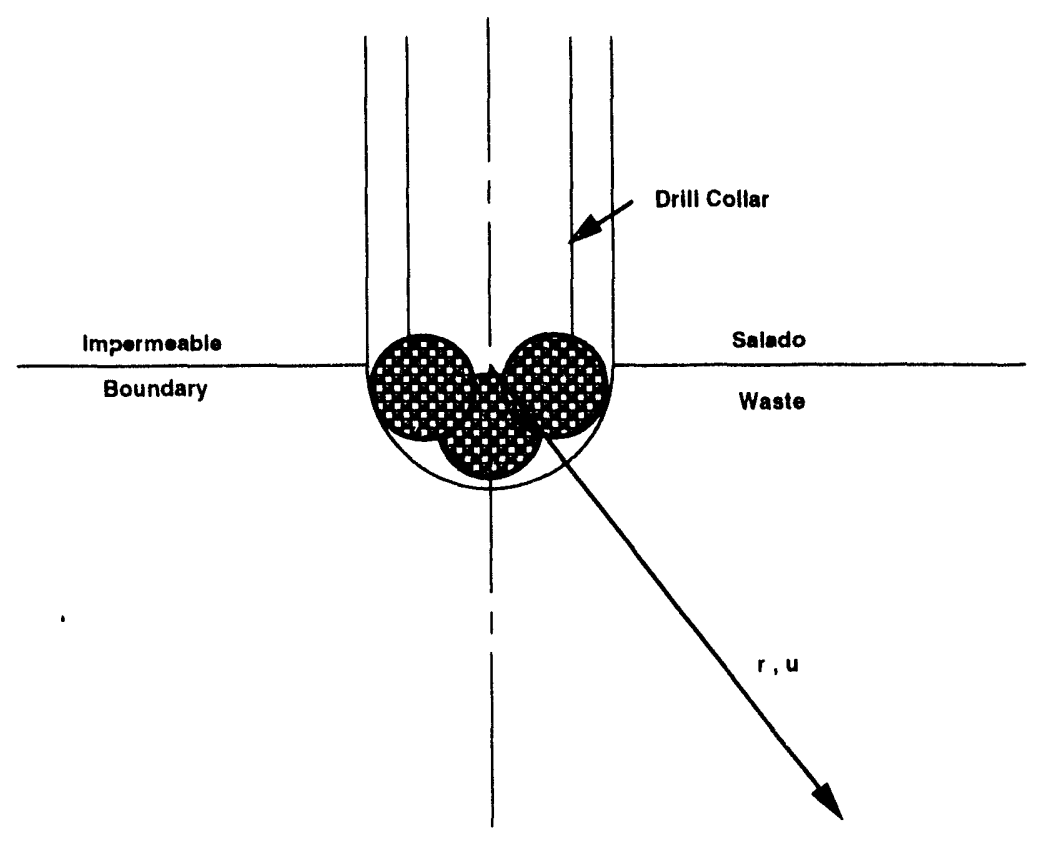

Figure 3-6. Two-dimensional borehole model. 


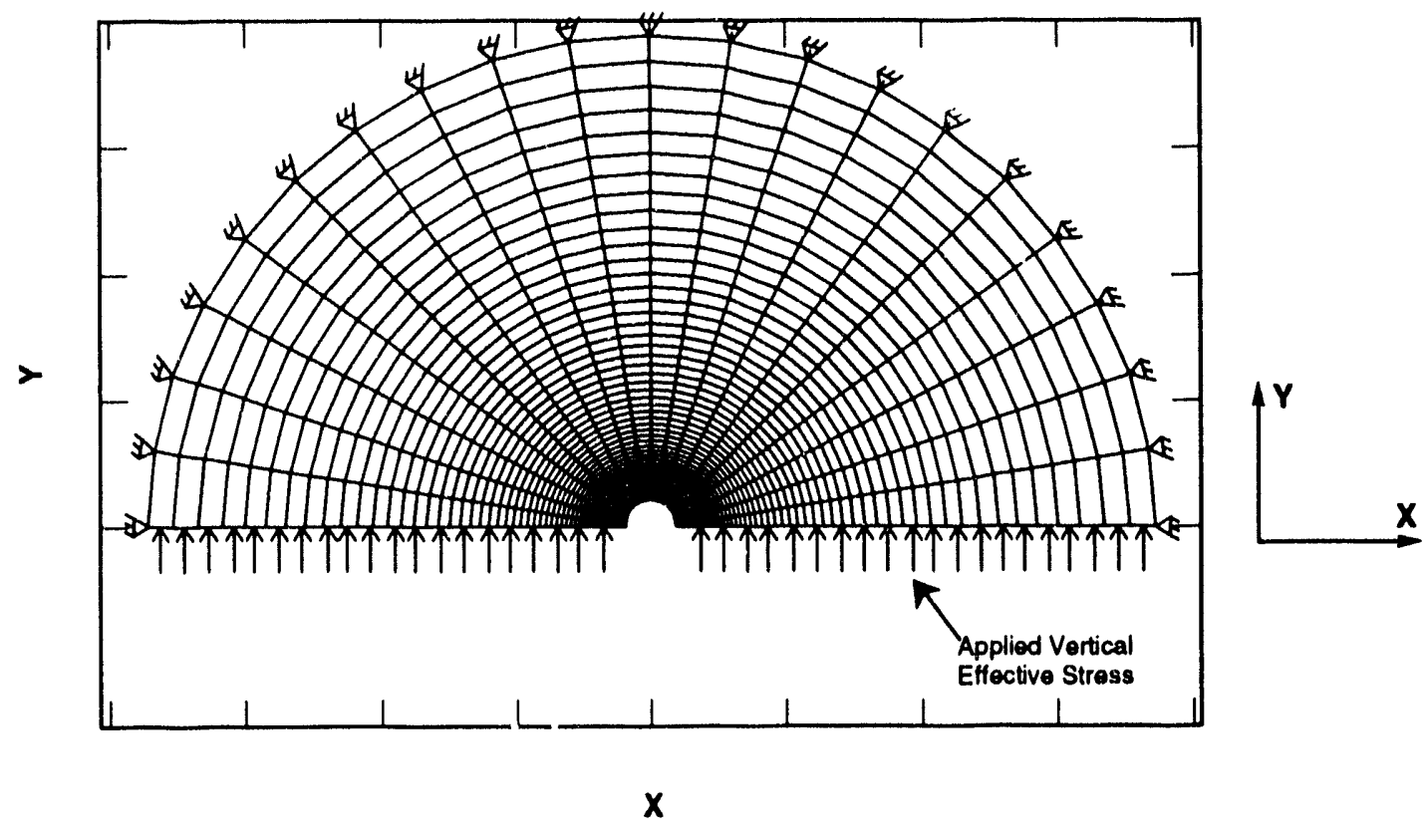

TRI.6342.3429.0

Figure 3-7. SAMSON2 tinite element grid and boundary conditions.

The numerical solution of Equation (3-4) for gas flow was performed with the same input variables as those listed in Table 3-2, except for the initial repository pore pressure, which was made identical to the lithostatic stress of 14.8 MPa. A plot of the gas pressure as a function of the spherical radial node number at 6 seconds is shown in Figure 3-8. For comparison, results for one-dimensional gas flow in a cylindrical geometry are also plotted in this figure.

To obtain SAMSON2 results for the static stress field, the pressure profile for 6 seconds (spherical geometry) (Figure 3-8) was applied in the form of a pressure gradient to nodes in the SAMSON2 finite-element grid. Using the material properties in Table 3-2 and dynamic relaxation in SAMSON2, the static stress and displacement field were calculated. Effective stress contour results are presented in Figures 3-9 through 3-11 (without magnitudes). The stresses in these figures are based on an $x-y$ rectangular coordinate system and consequently do not readily reveal the radially oriented stress ficld. To overcome this difficulty, the effective stresses can be transformed into spherical coordinates and the radial effective stresses can be plotted for each element radial. The element radials are shown in Figure 3-12. The radial effective stresses are plotted in Figure 3-13 for the 40 elements in each radial and where tensile stresses are negative. For comparison, one of the principal effective stresses is also plotted in Figure 3-13. The radial effective stress and principal effective stress almost overlay completely in all of the plots, indicating that the radial effective stress approximates the peak effective tensile stress and that the radial direction is almost identical to one of the principal directions. 


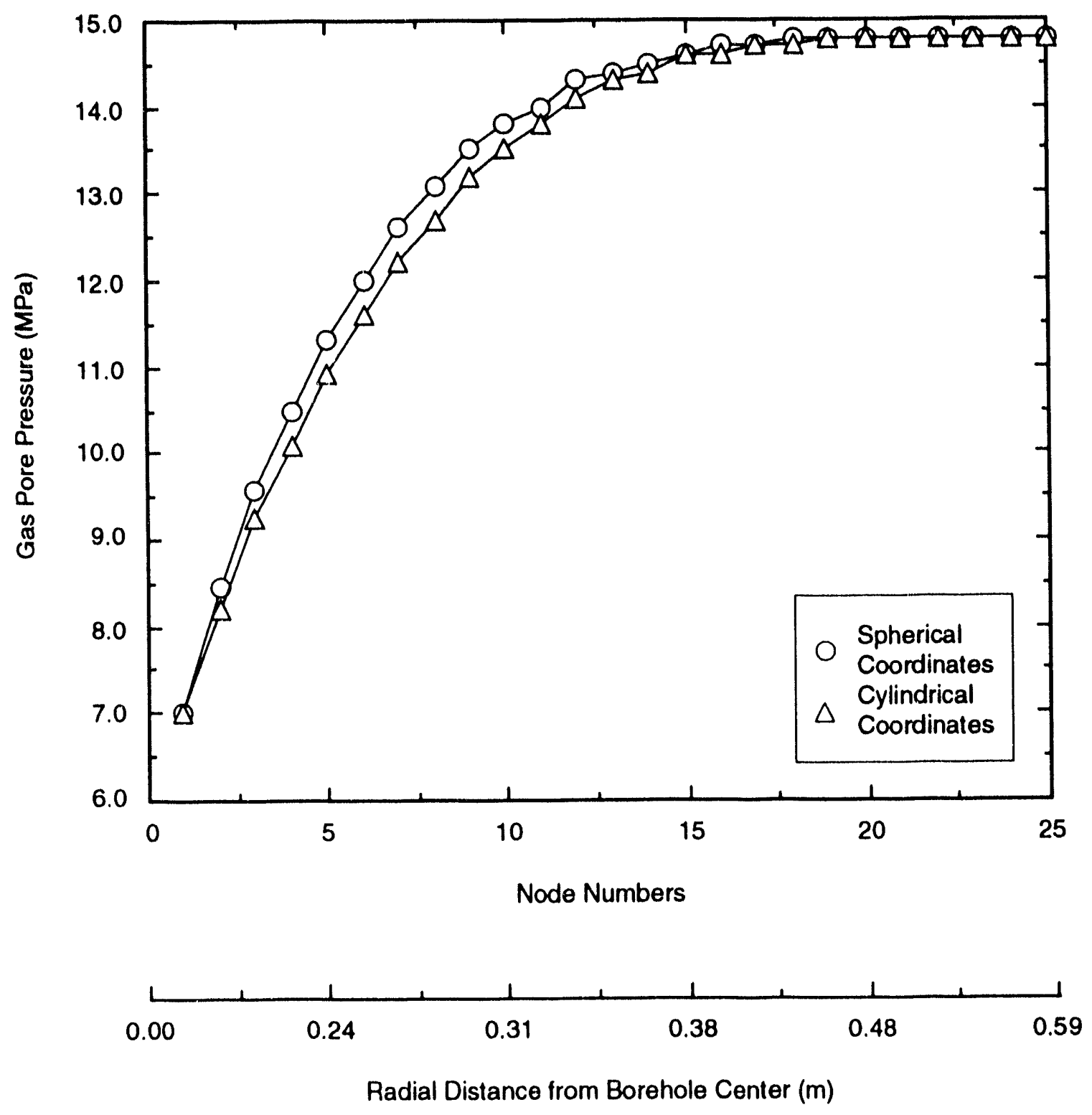

TA1.6342.1871.0

lïgure 3-8. Pore pressure distribution at 6 seconds for spherical and cylindrical geonetry. 


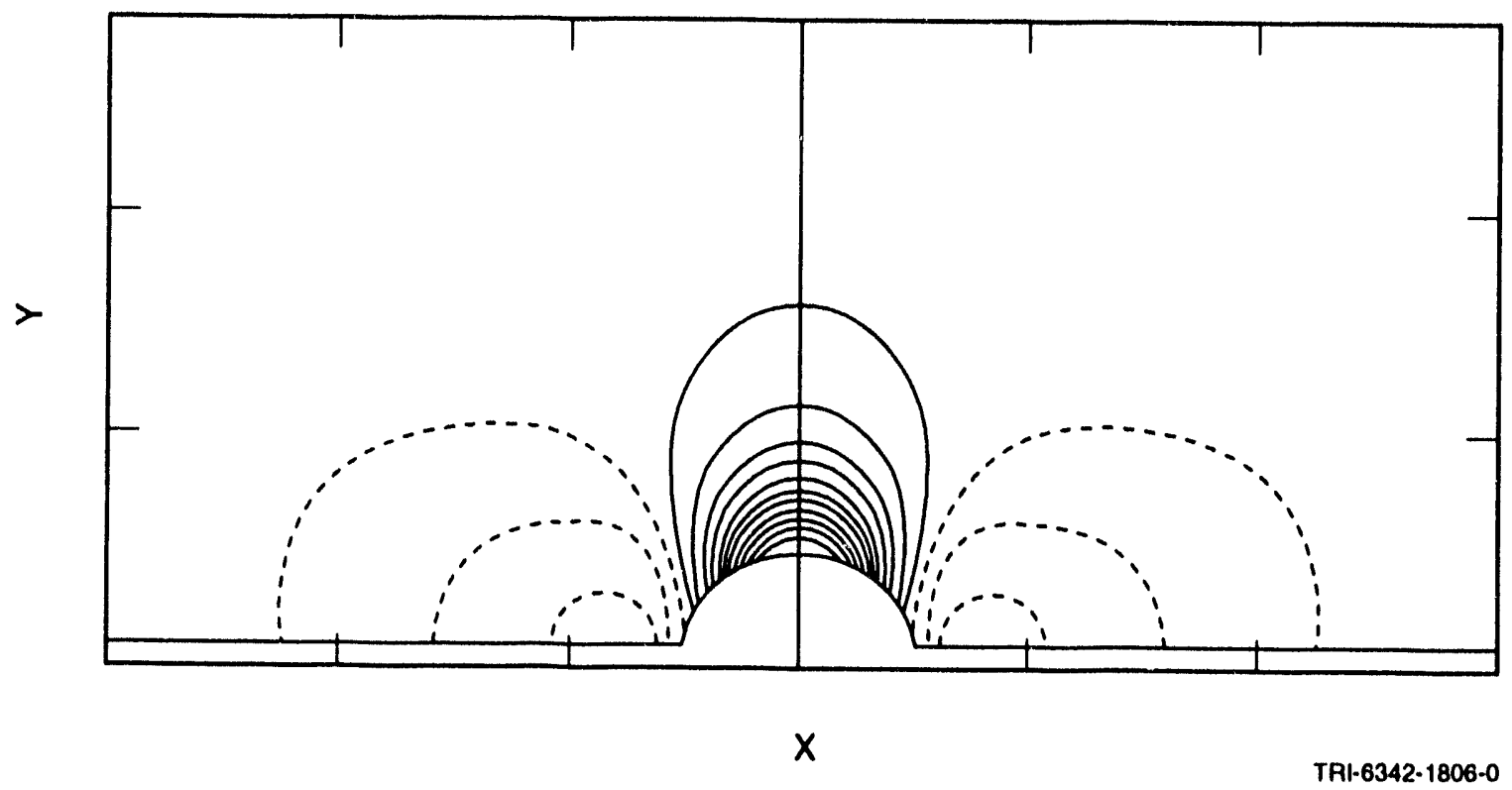

Figure 3-9. Static effective stress contours $\sigma_{x}$ for gas pressure distribution at 6 seconds. (Dashed line represents tension.)

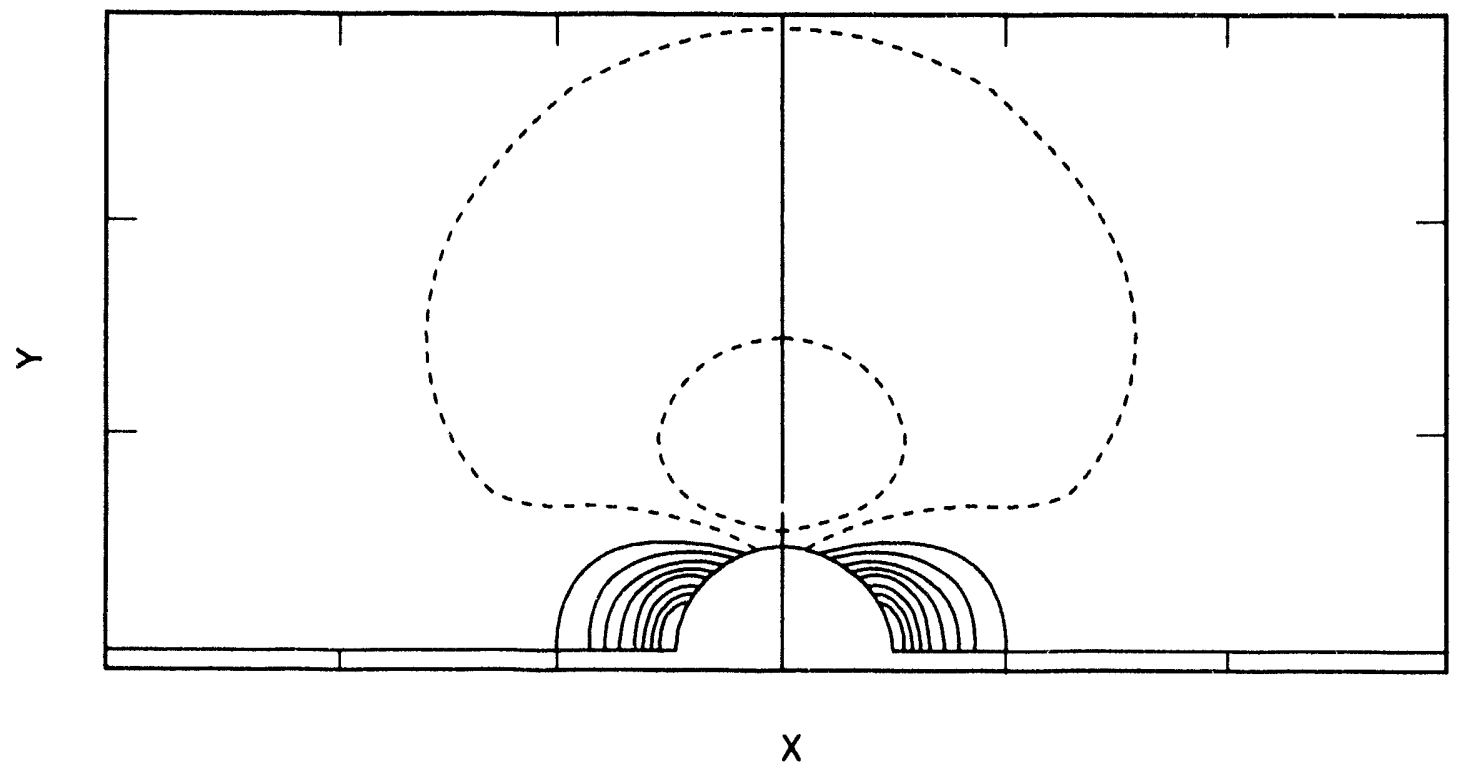

TR1-6342-1807-0

Figure 3-10. Static effective stress contours $\sigma_{y}$ for gas pressure distribution at 6 seconds. (Dashed line represents tension.) 
3. Mechanism II: Waste-Gas-Induced Borehole Spall

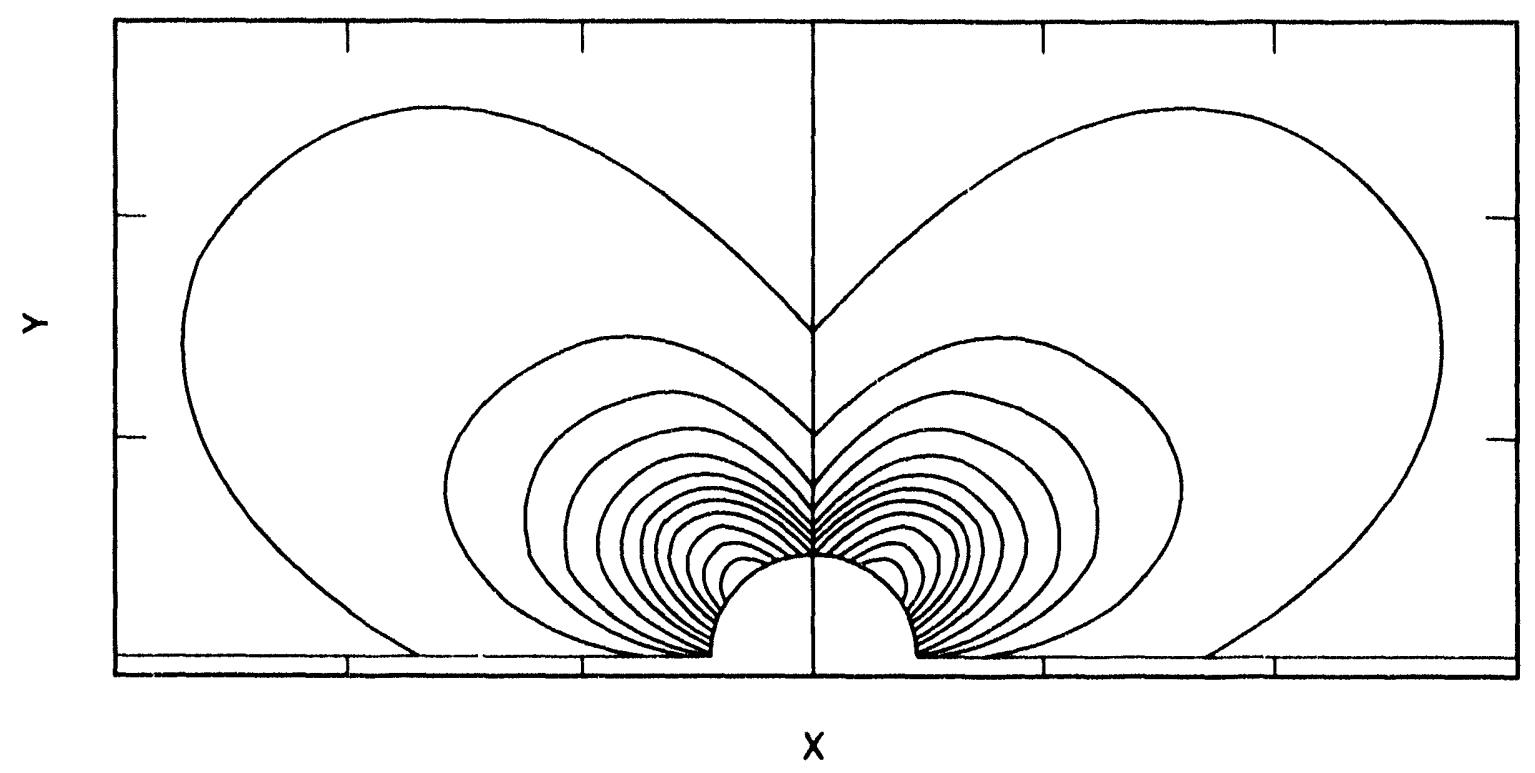

TR1-6342-1808-0

Figure 3-11. Static stress contours $\tau_{. y}$ for gas pressure distribution at 6 seconds.

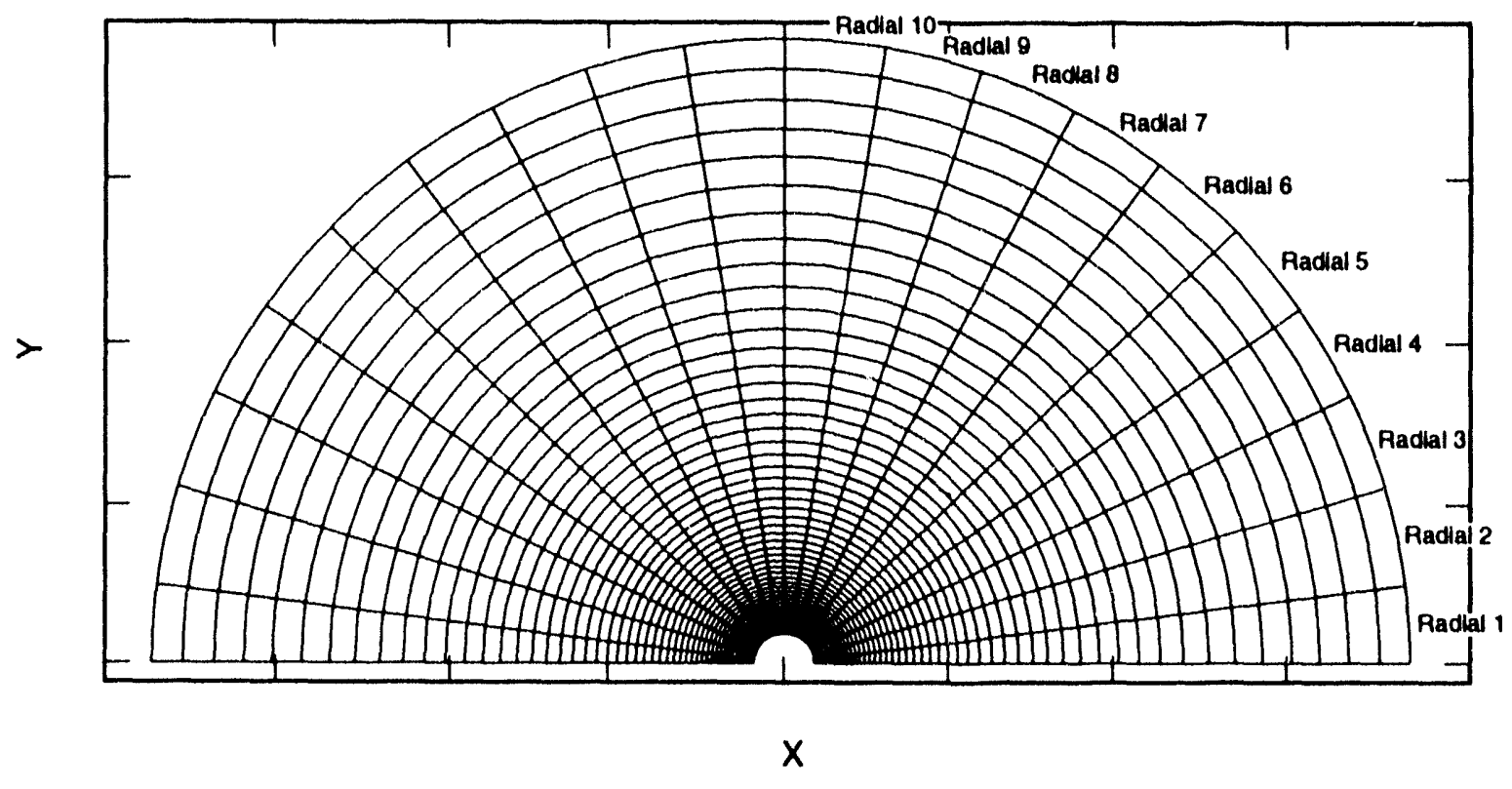

Figure 3-12. Element radials. 


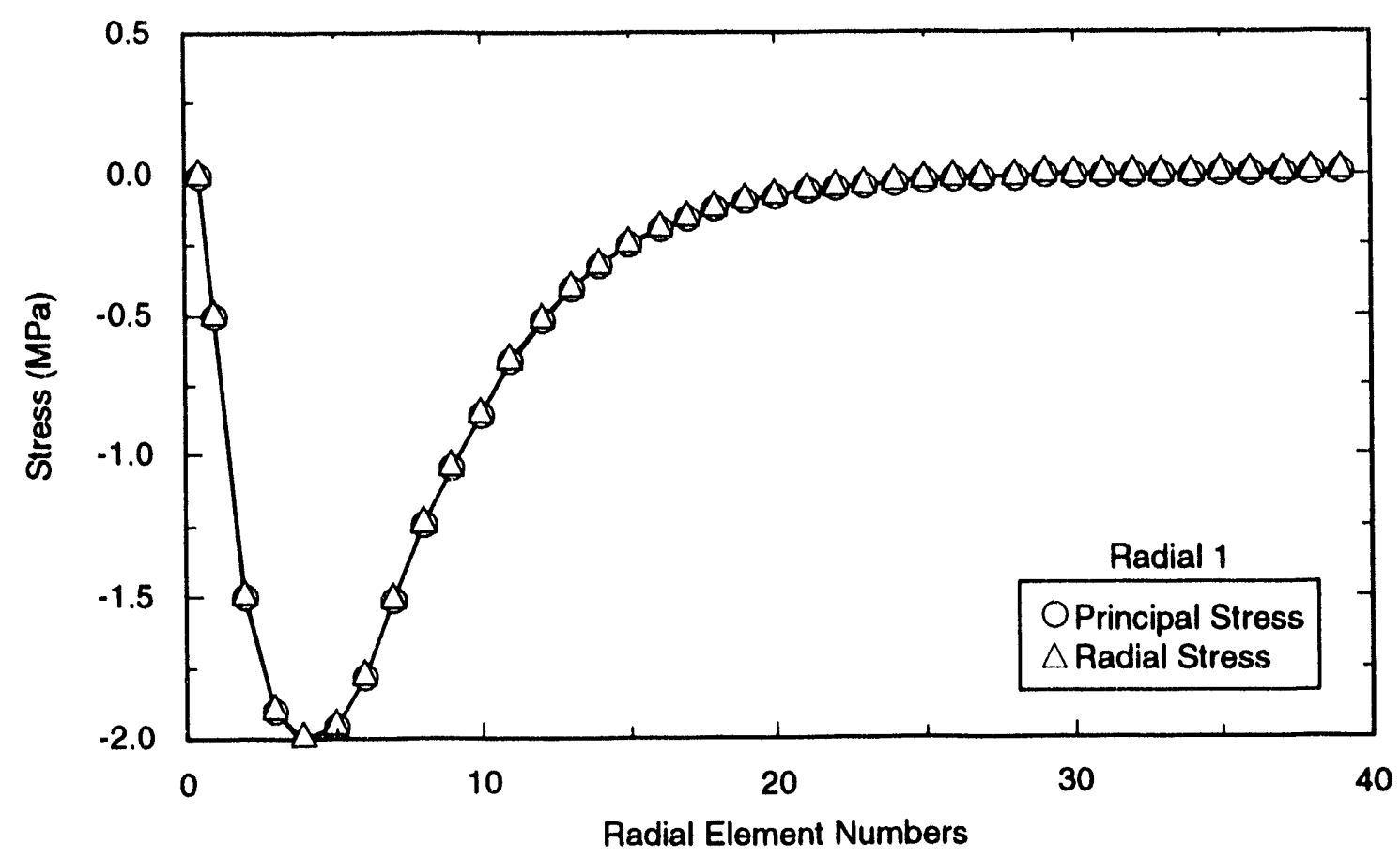

TRI.6342.1869-0

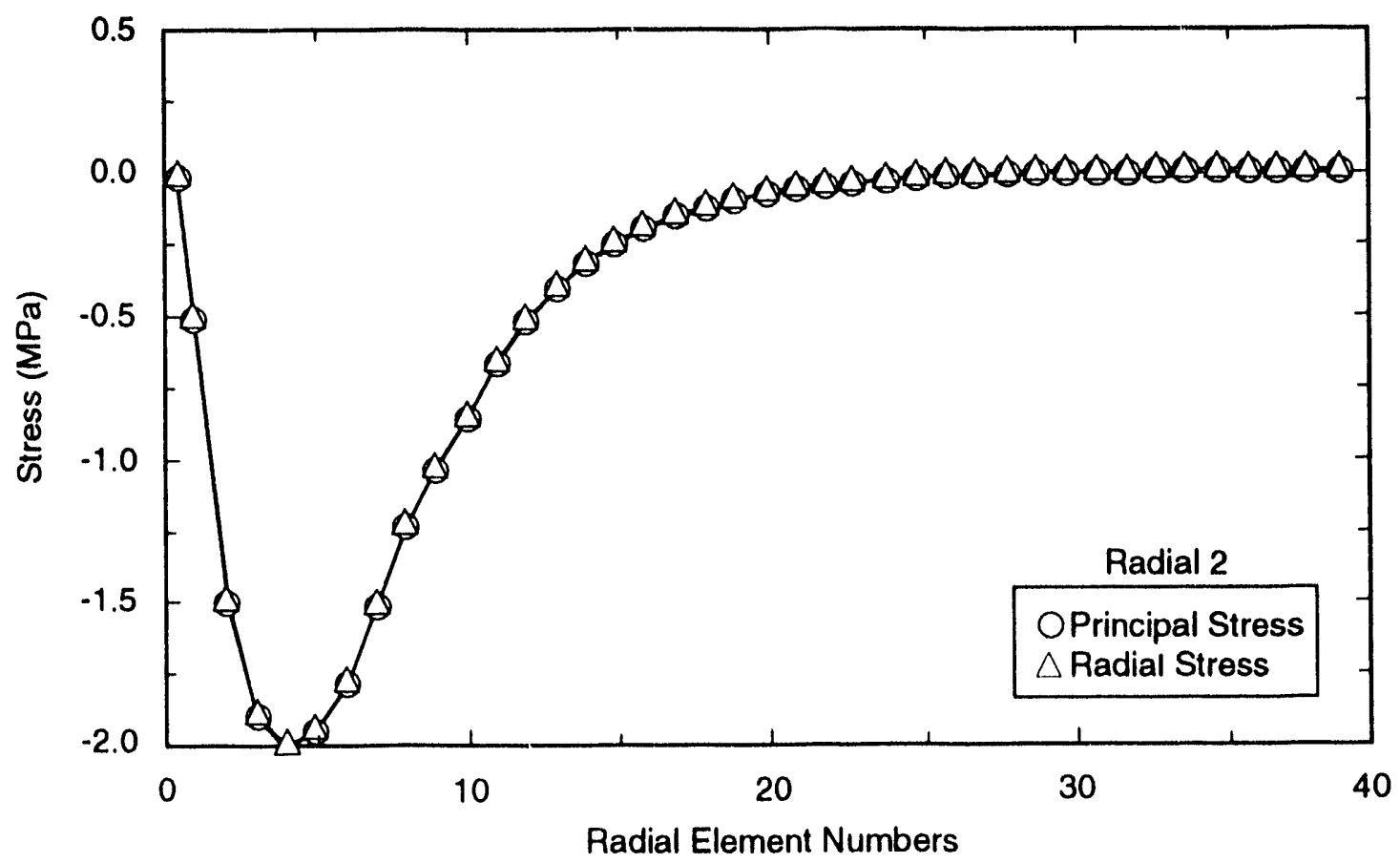

TAI.6342.1870.0

Figure 3-13a. Radial effective stress and principal effective stress for element radials at 6 seconds. 
3. Mechanism II: Waste-Gas-Induced Ecrehole Spall

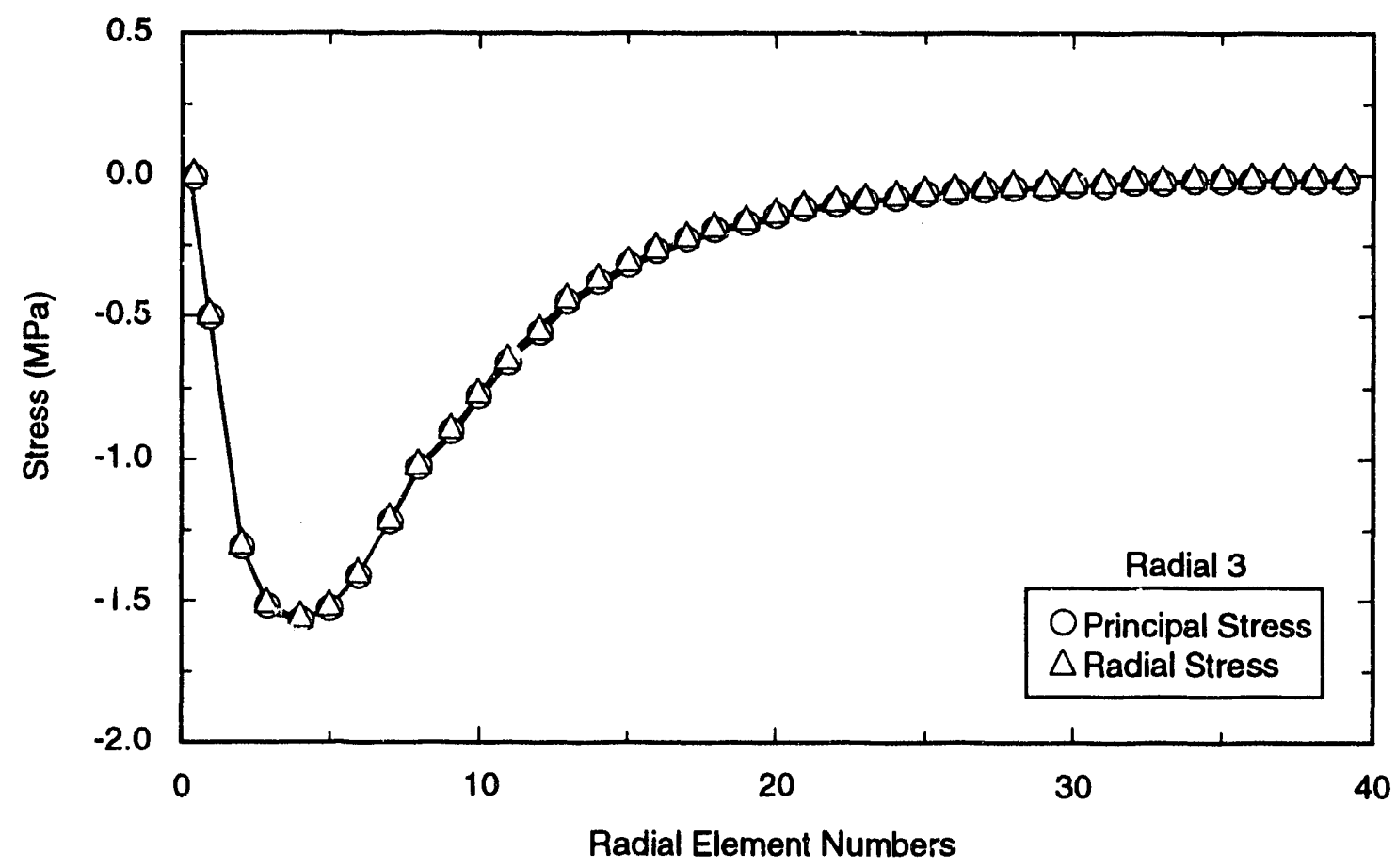

TRI-6342-1868-0

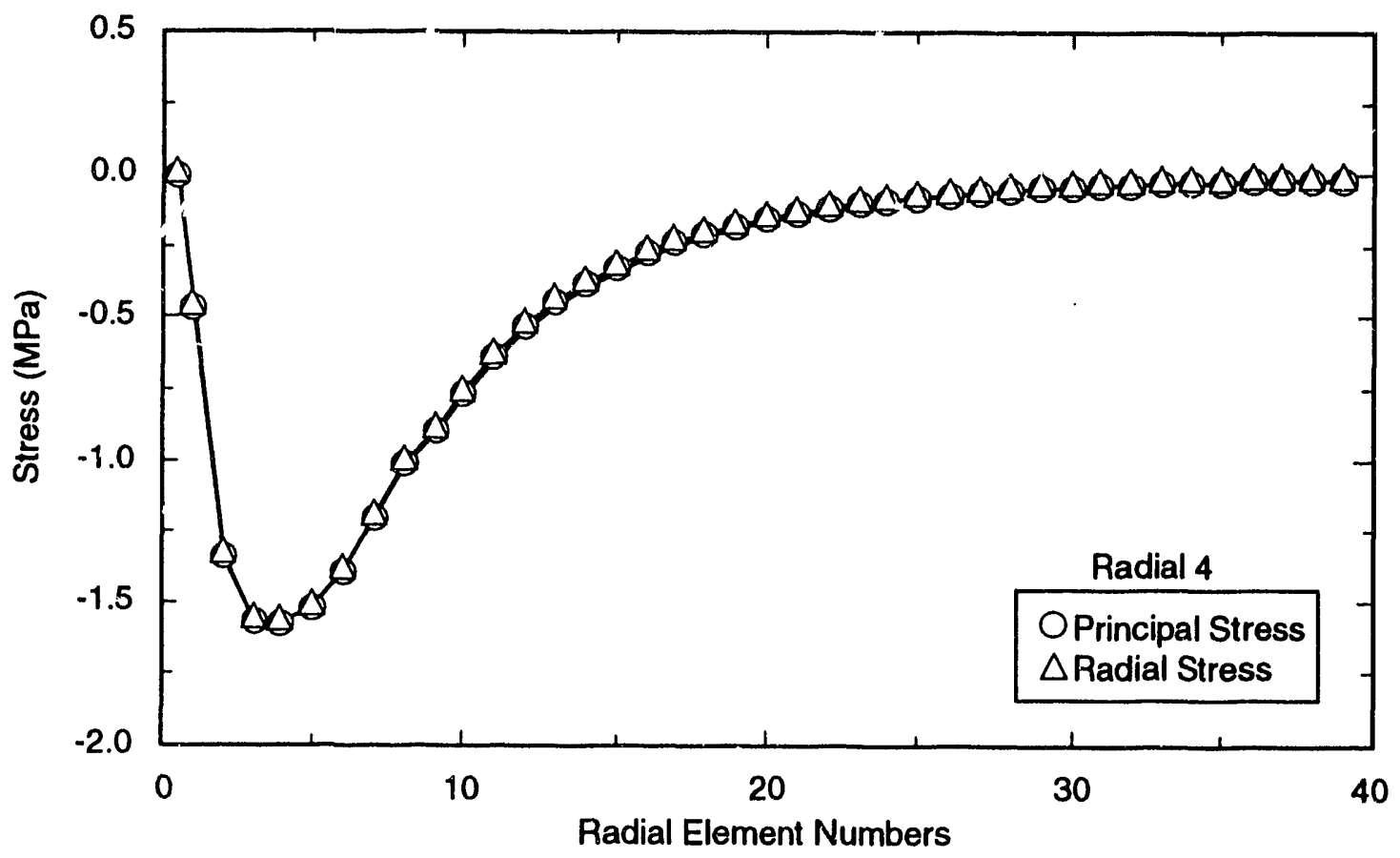

TRI-6342-1867-0

Figure 3-13b. Rarlial effecti:e stress and principal effective stress for element radials at 6 seconds (continued). 


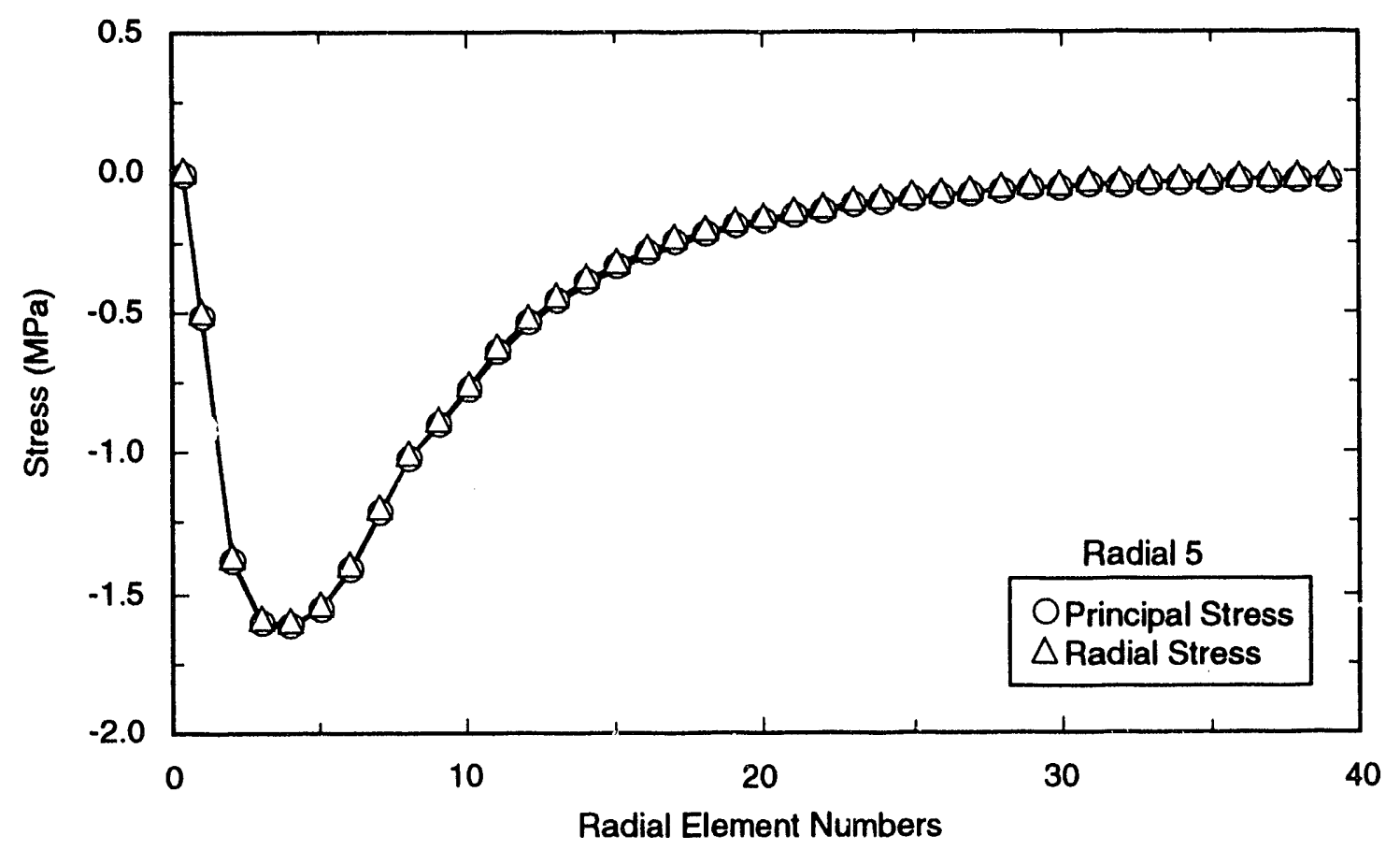

TAI-6342-1866-0

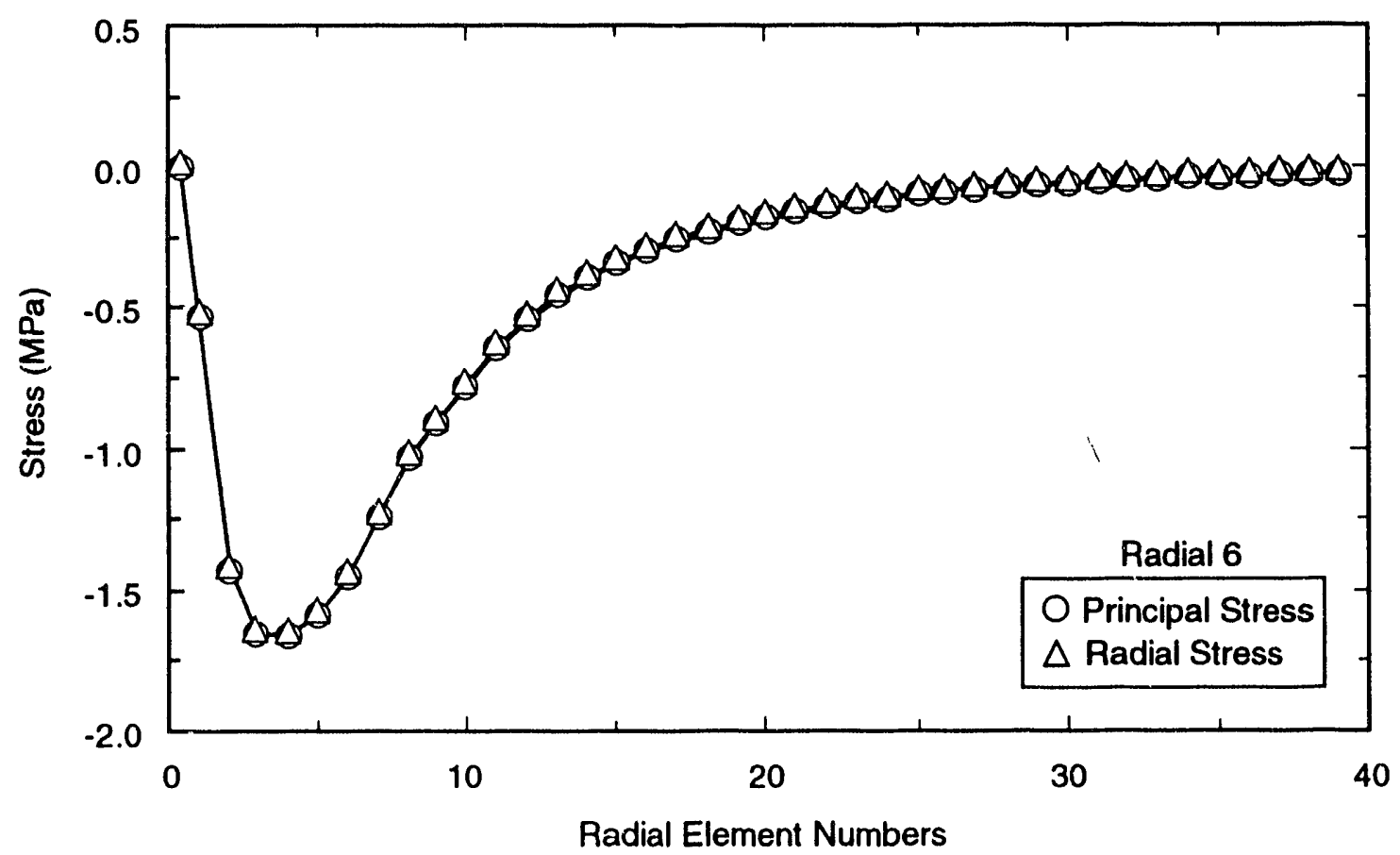

TRI-6342-1865-0

Figure 3-13c. Radial effective stress and principal effective stress for element radials at 6 seconds (continued). 


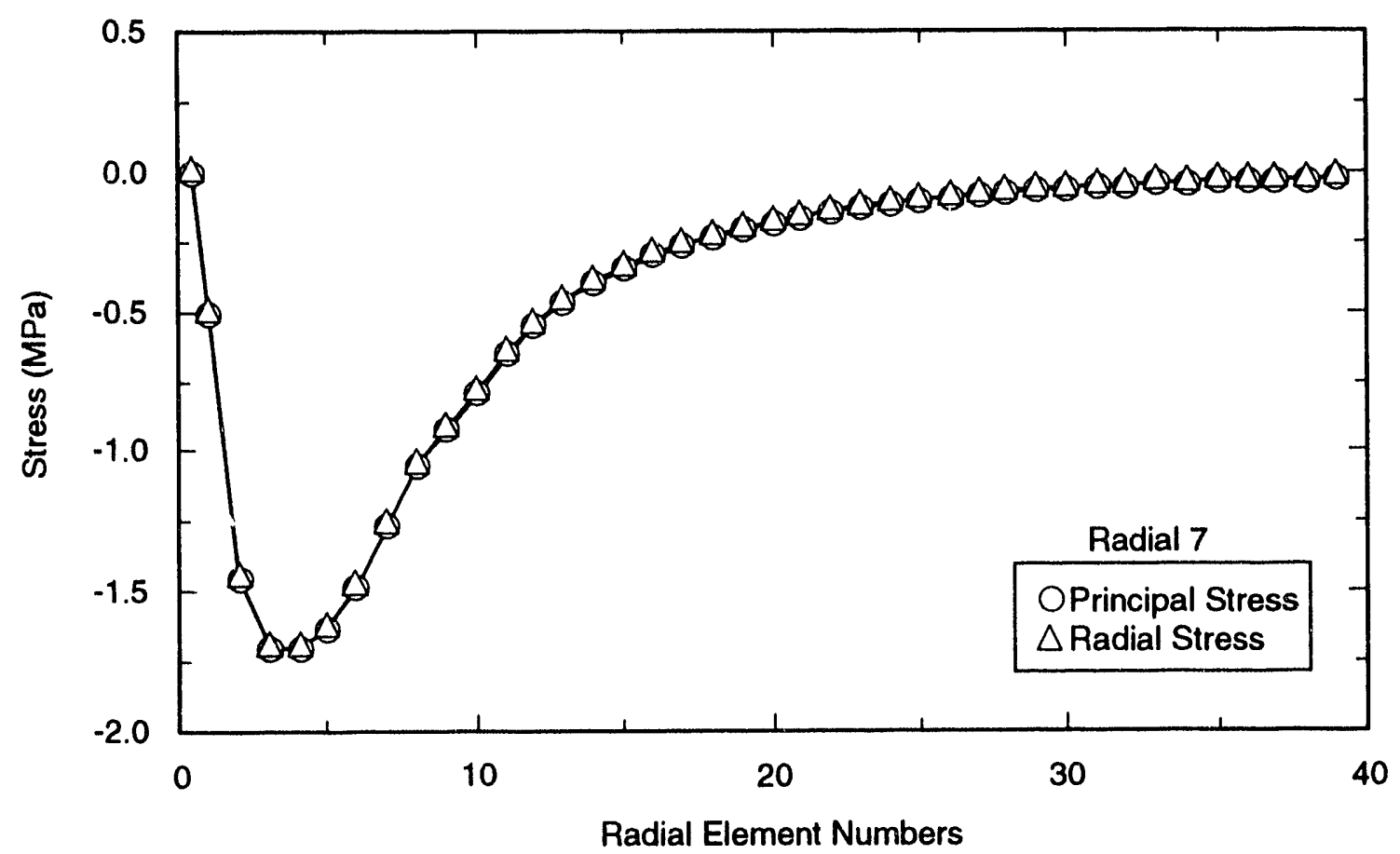

TRI-6342-1863-0

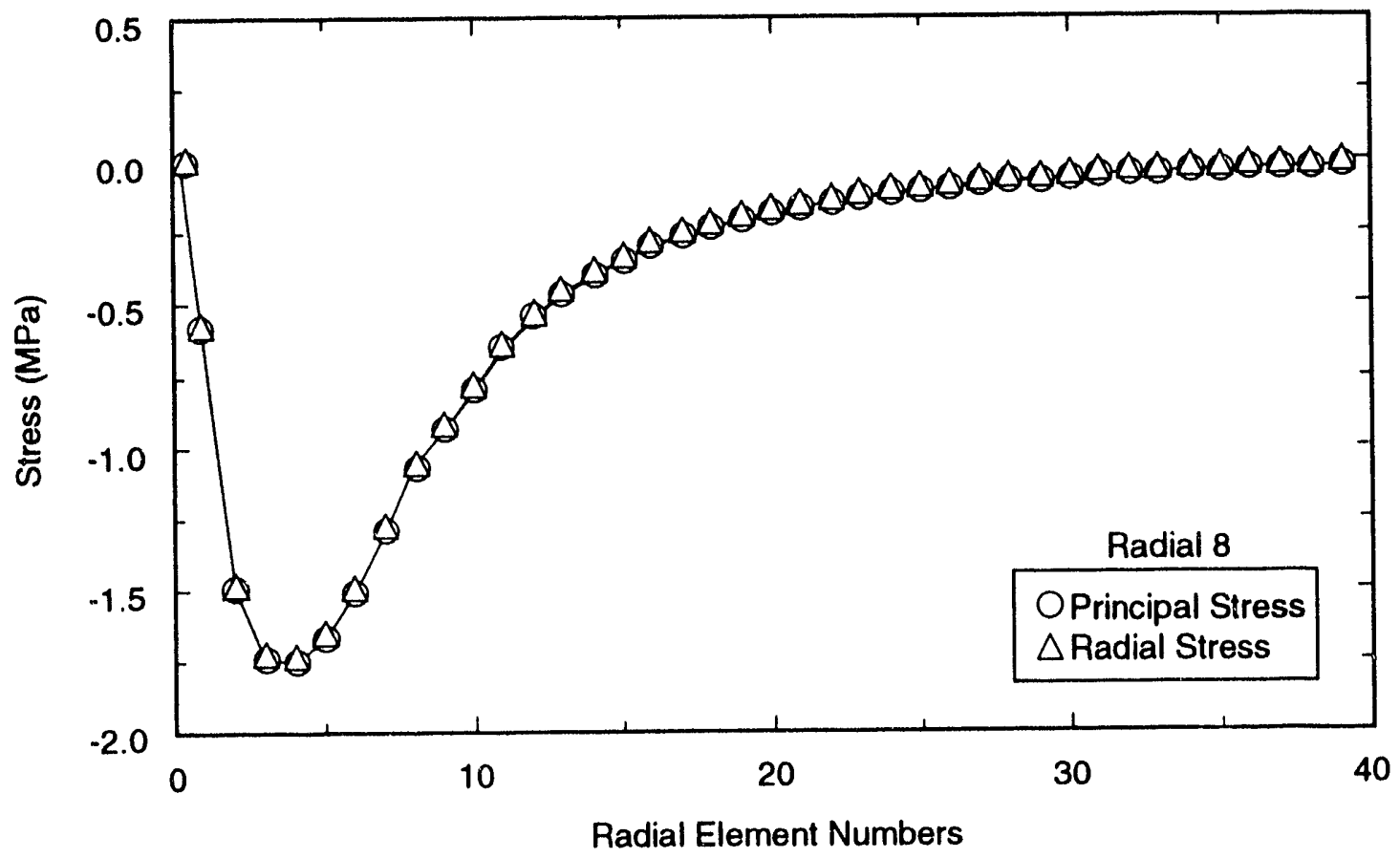

TPI.6342-1862-0

Figure 3-13d. Radial effective stress and principal effective stress for element radials at 6 seconds (continued). 


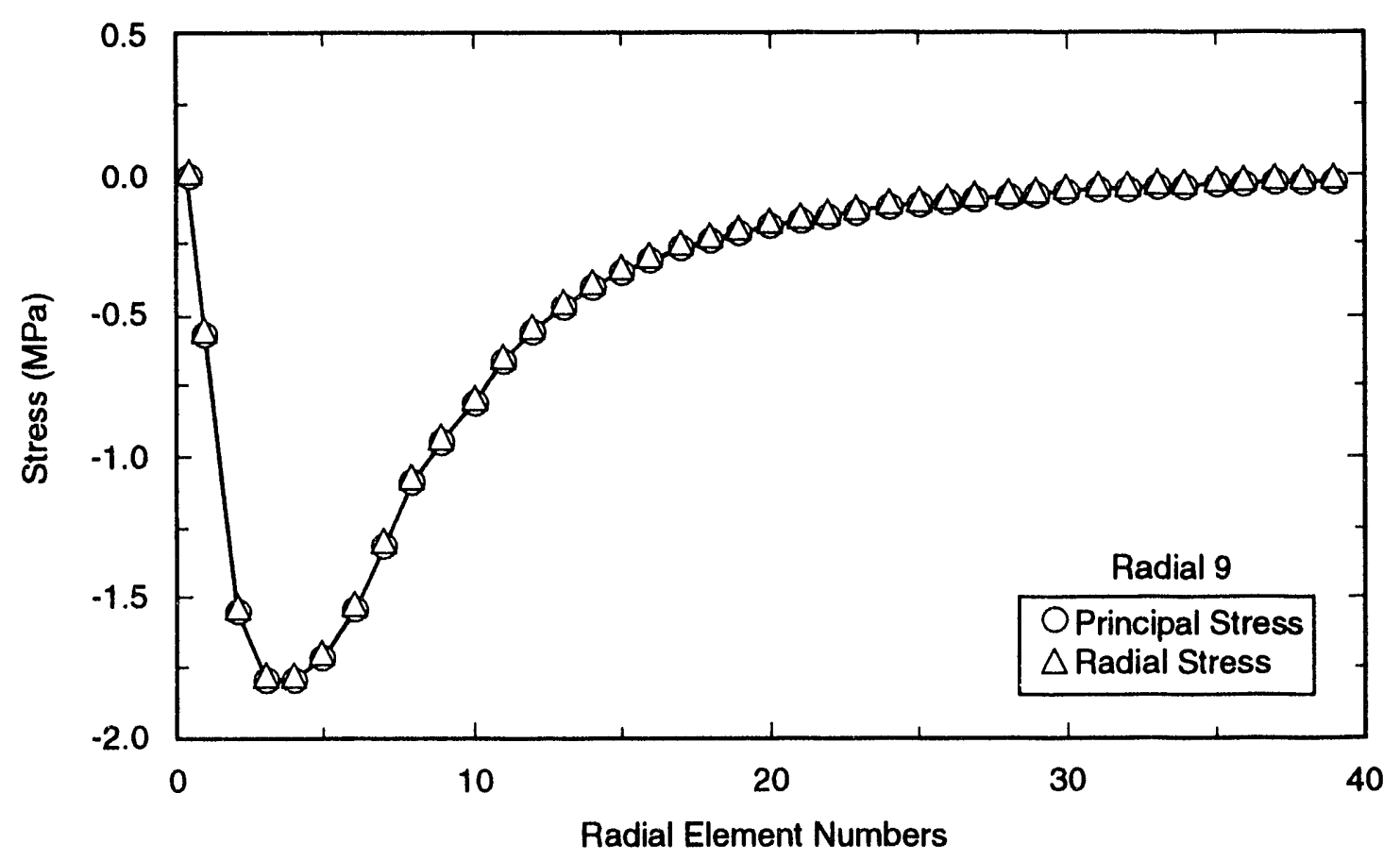

TRI-6342-1861-0

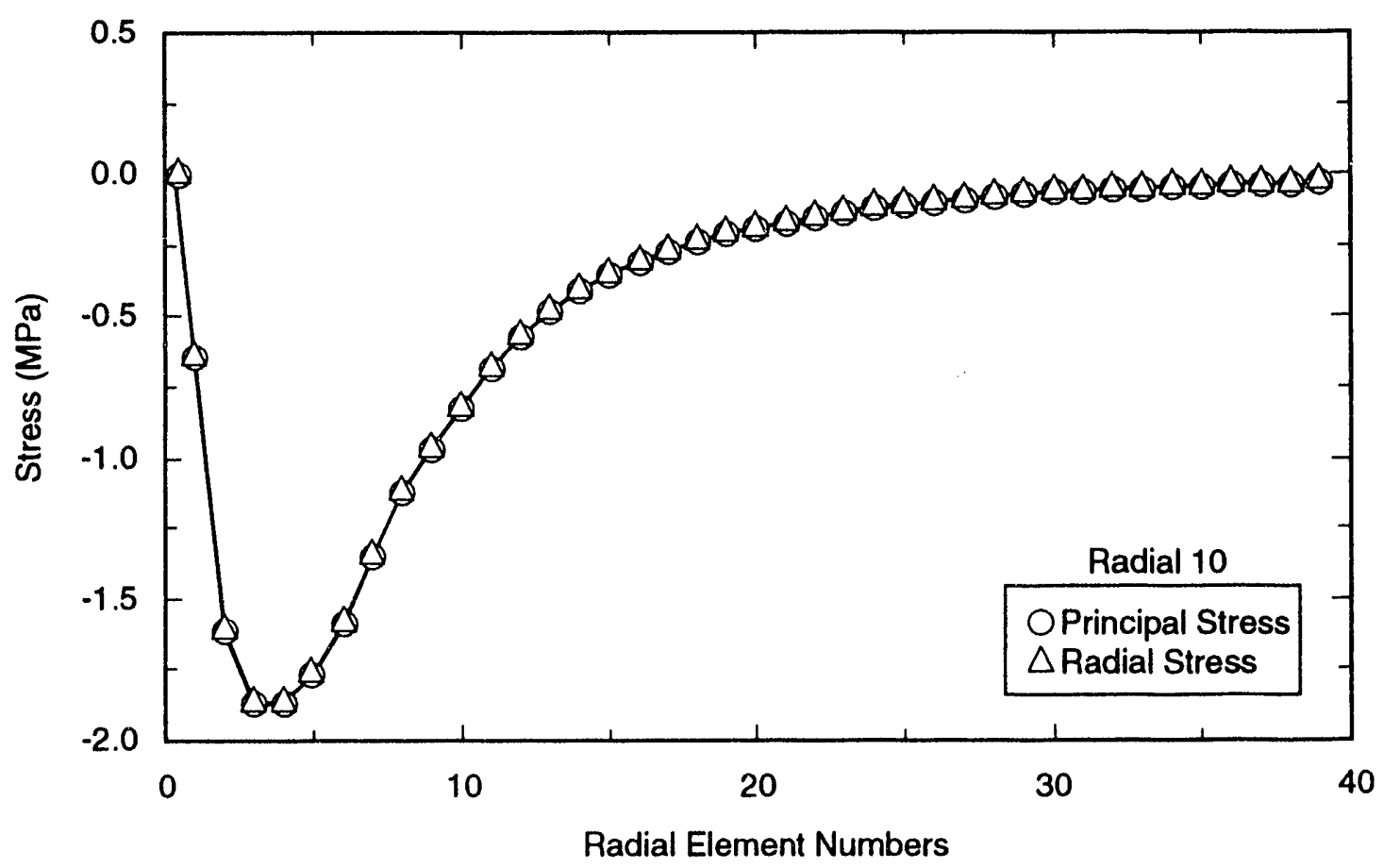

TA1-6342-1864-0

Figure 3-13e. Radial effective stress and principal effective stress for element radials at 6 seconds (continued). 
The radial effective stress field distribution shown in Figure 3-13 is very similar to that calculated using the cylindrical approximation (Figure 3-5), where the calculated effective stress remains tensile near the borehole. The maximum radial effective stress among the element radials (Figure 3-13) varies between -1.6 and -2.0 MPa and the waveforms are very similar. This suggests that an almost point symmetric response is centered at the borehole and that two-dimensional effects on elastic stresses at this time are minimal. A magnified plot of the static displacement vector field for half the grid shown in Figure 3-14 clearly indicates that nodal displacements are loward the drill bit.

\section{Borehole Pressure Decay Model}

The analysis of the transient stress state adjacent to a borehole in the one-dimensional cylindrical case reported above assumes that the pressurized repository was instantaneously exposed to the hydrostatic pressure of the drilling fluid. This assumption generates an upper bound for the calculated stresses and maximizes the elastic radial tensile stress field adjacent to the borehole. The actual pressure drop that occurs depends upon the Salado (halite) properties above the waste repository and the penetration rate of the drill bit.

To assess the probable pressure decay times that might be encountered in the penetration of the compacted waste, a one-dimensional model of drill-bit motion through the Salado is presented and solved in closed form. This steady-state model describes the flow of waste-generated gas through a porous medium with a moving boundary and provides an estimate of the pressure decay time at the waste boundary as a function of drill penetration rate and Salado properties.

The permeability of the Salado formation above the waste depends upon whether it is considicied disturbed, or disturbed and healed. For our purposes, it will be assumed that the Salado permeability ranges from $1 \times 10^{-18} \mathrm{~m}^{2}$ to $1 \times 10^{-20} \mathrm{~m}^{2}$ and that the healed porosity is 0.06 (WIPP PA Division, 1991b). The compacted waste permeability will vary between $1 \times 10^{-13} \mathrm{~m}^{2} 102.4 \times 10^{-17} \mathrm{~m}^{2}$, depending on waste form.

The low permeability of the Salado compared to the compacted wastes (for most of the permeability range) suggests that the Salado below the moving drill bit and above the waste layer acts a seal, preventing the waste from being exposed to the drilling fluid hydrostatic pressure. The effectiveness of this "seal" can be ascertained from a one-dimensional model of the drilling process through the Salado. Consider, for example, a drill bit proceeding through a Salado layer that has been saturated with gas (from the waste) and that the far-field pore pressure exceeds the hydrostatic drilling fluid pressure. As the drill proceeds, the pore pressure within the Salado will be affected by the presence of the moving drillhole boundary as gas thows to the lower-pressure borehole. At the borchole, the pore pressure in the Salado will be equal to the borehole pressure. The pore pressure distribution (p) below the drill bil can be determined from the equation

$$
\frac{k}{2 \mu} \nabla^{2} p^{2}=\varphi_{0} \frac{\partial p}{\partial t},
$$

where $k$ is permeability, $\mu$ is gas viscosity, $\varphi_{0}$ is porosity, and $t$ is time. 


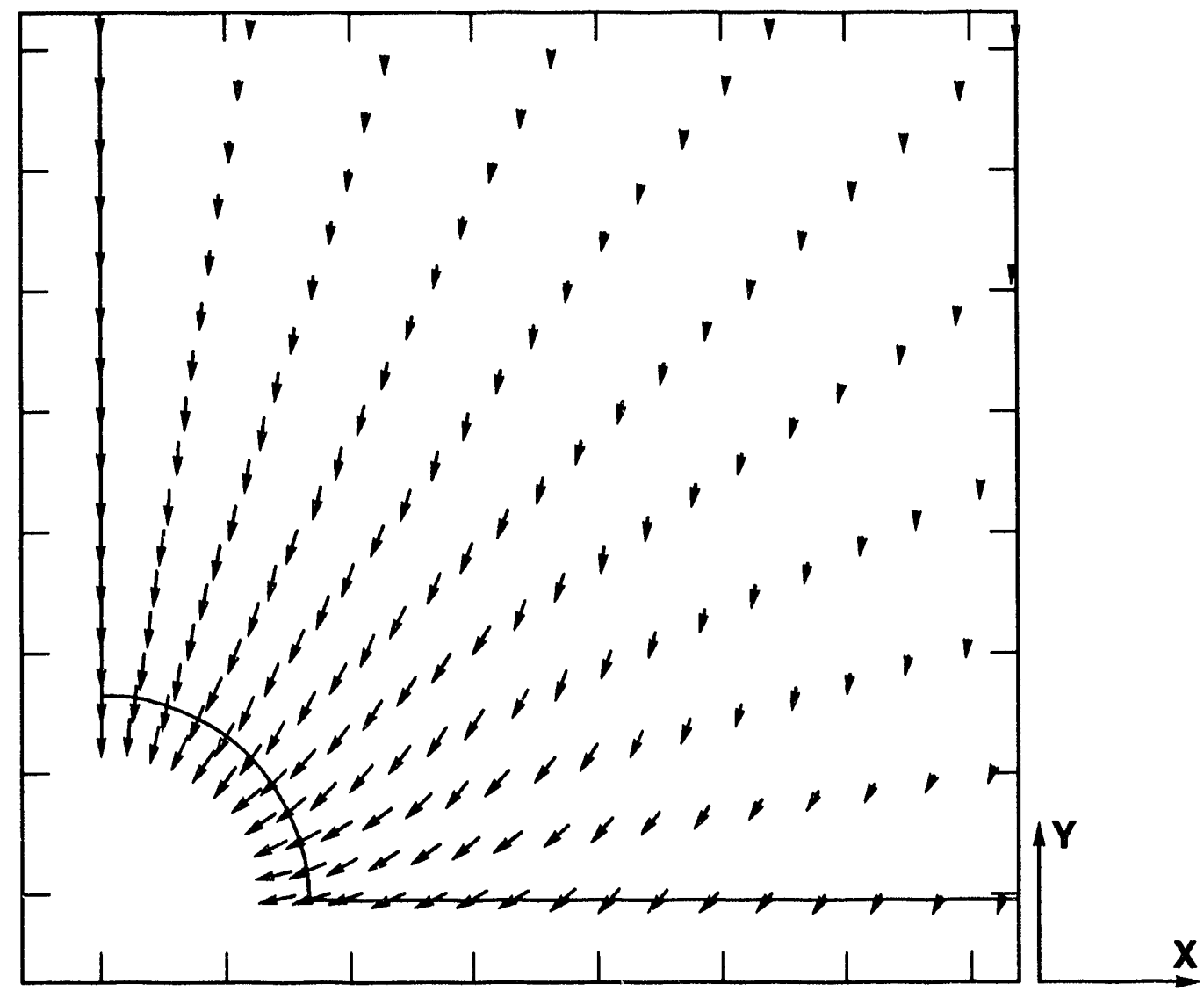

TRI-6342-3430-0

Figure 3-14. Magnified nodal displacements elastic material model. 
Assuming that the process can be adequately represented in one dimension, then in one-dimensional Cartesian coordinates, Equation (3-6) reduces to what is shown in Figure 3-15:

$$
\frac{k}{2 \mu} \frac{\partial^{2} p^{2}}{\partial x^{2}}=\varphi_{0} \frac{\partial p}{\partial t}
$$

Following the analysis of Paterson (1986) and using the transformation $\xi=x-v t$ (where $v$ is the velocity of the boundary caused by drilling), Equation (3-7) becomes

$$
\frac{k}{2 \mu} \frac{\partial^{2} p^{2}}{\partial \xi^{2}}=-v \varphi_{0} \frac{\partial p}{\partial \xi}
$$

Using the boundary conditions

$$
\begin{aligned}
& \text { at } \quad \xi=0 \quad p=p_{0} \\
& \xi \rightarrow \infty \quad p=p_{i} \quad \text { and } \quad \partial p / \partial \xi=0 \text {, }
\end{aligned}
$$

Equation (3-8) can be solved in closed form by integration, yielding

$$
\frac{\xi \varphi_{0} \mu \nu}{k p_{i}}=\left[\frac{p_{0}}{p_{i}}-\frac{p}{p_{i}}+\ln \left(\frac{1-\frac{p_{0}}{n_{i}}}{1-\frac{p}{p_{i}}}\right)\right]
$$

which can then be plotted as shown in Figure 3-16.

Figure 3-16 depicts the change in pore pressure from the moving drill bit boundary to the interior of the Salado for two different pressure ratios. Clearly, $98 \%$ of the pressure change occurs for values of $\xi_{\varphi_{0}} \mu v / k p_{i}$ less than 3.5; thus, this nondimensional quantity can be considered the thickness of a nondimensional boundary layer influenced by the Salado and gas properties as well as the drilling speed $v$. What this means in dimensional terms is illustrated in Table 3-3.

The thickness of the boundary layer $\xi$ in meters is tabulated in Table 3-3 for different values of Salado permeability and drill velocity. The porosity is fixed at 0.06 , the far-field pore pressure is fixed at $14.8 \mathrm{MPa}$, and the gas viscosity is fixed at $9.32 \times 10^{-6} \mathrm{~Pa}$ - (Pascal seconds). The time $t_{d}$ to drill through the boundary layer at a drill velocity of $v$ is also tabulated. The time parameter $t_{d}$ can also be considered a measure of the borehole pressure decay time at the waste-Salado interface. The decay time is observed to vary from as much as $517 \mathrm{~s}$ at the greatest Salado permeability and slowest drill speed, to $0.0032 \mathrm{~s}$ at the least permeability and greatest drill speed. The three ranges of drilling speeds in oil drilling units are 5, 50, and $200 \mathrm{f} / \mathrm{hr}$ (Short, 1982). 


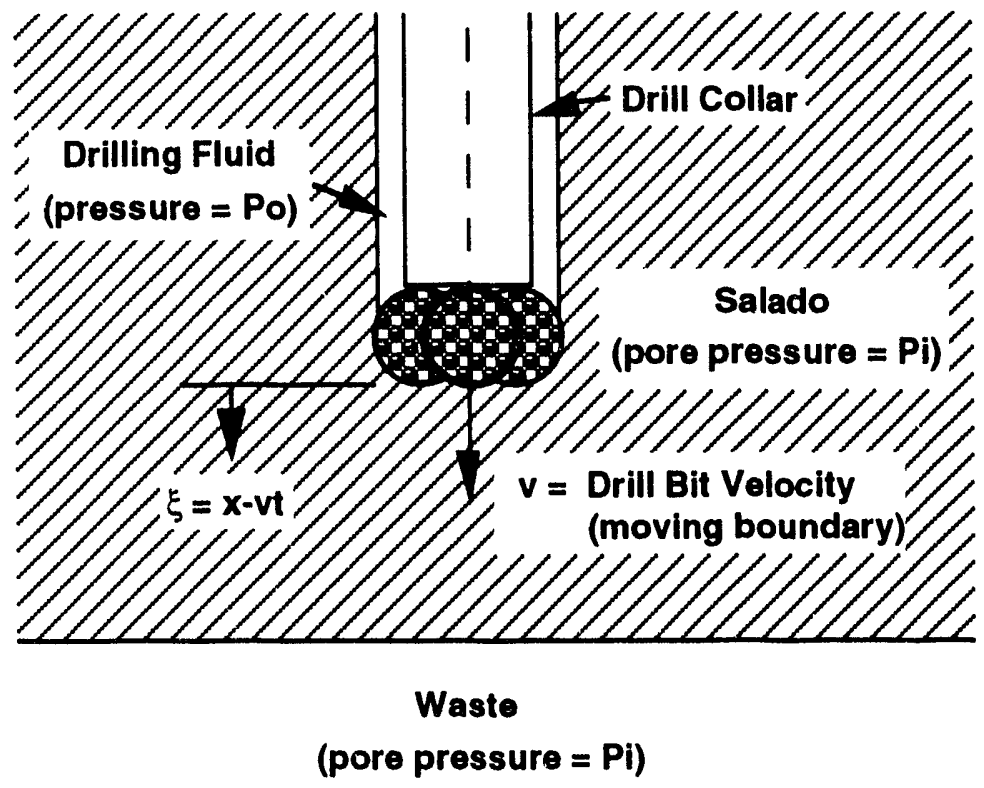

TRI-6342-1190-2

Figure 3-15. Moving Salado boundary. 
3. Mechanism II: Waste-Gas-Induced Borehole Spall

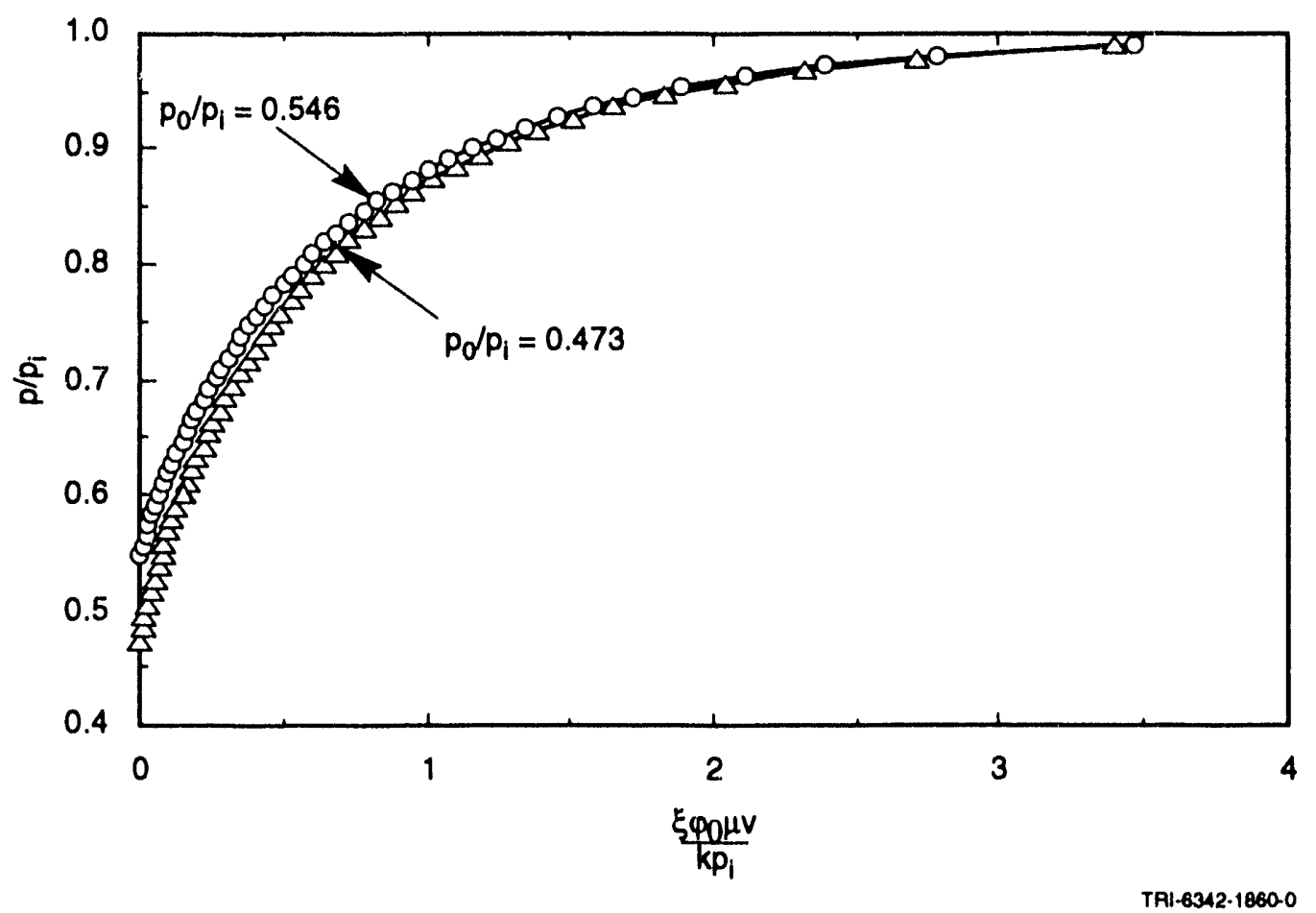

Figure 3-16. Nondimensional plot of Equation (3-9). 
Table 3-3. Thickness of Boundary Layer and Drilling Times for Different Permeabilities and Drill Velocities

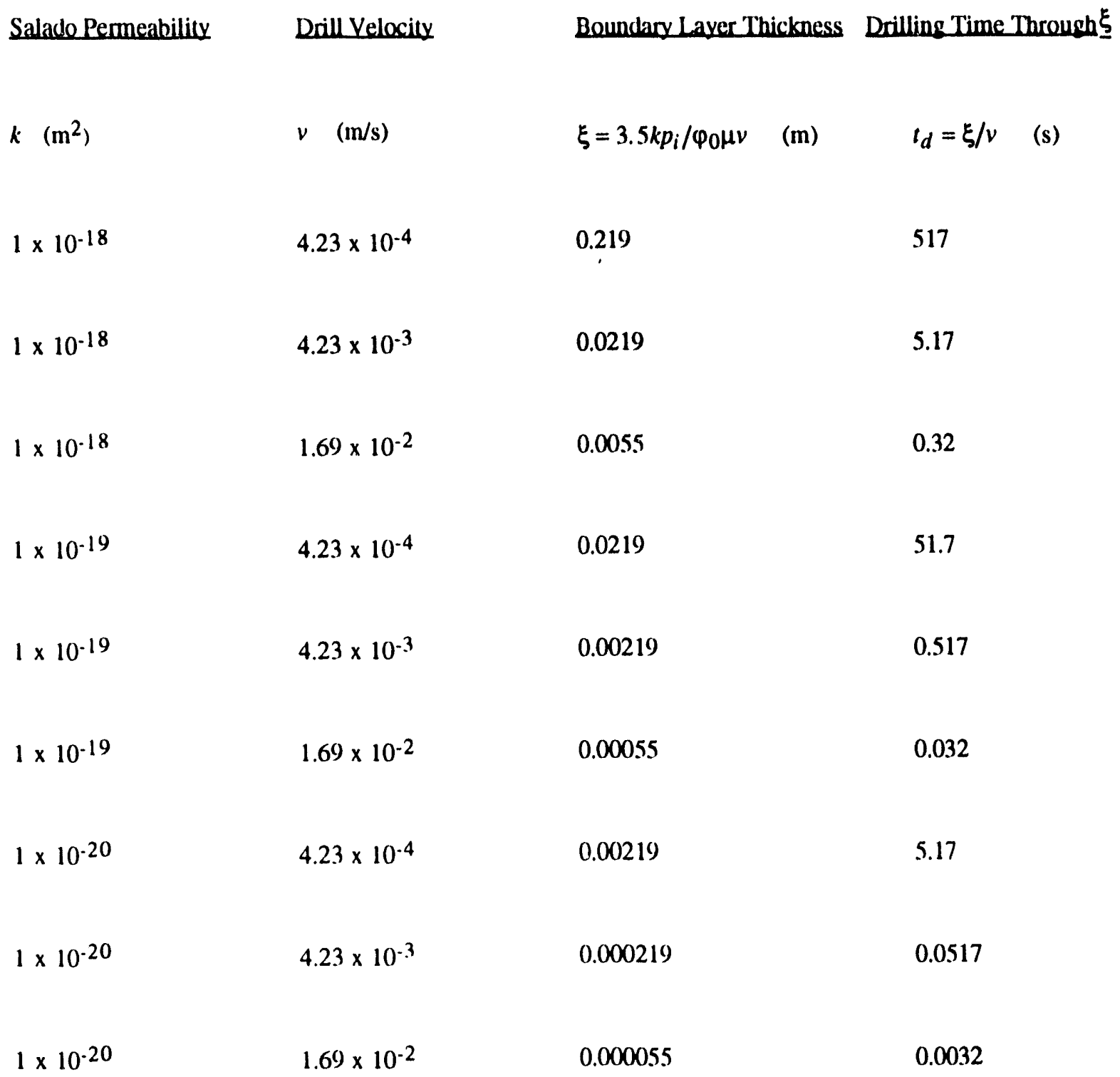




\section{Elastic Stress State Adjacent to Borehole as a Function of Pressure Decay Time}

The previous section showed that the pressure drop that occurs in the borehole when the repository is first penetrated is not instantaneous. This finite decay time must be accounted for to gain a inore accurate picture of the stress environment in the compacted waste. In the following, a linear time decay is used to represent the pressure drop that occurs at the horehole boundary in the cylindrical one-dimensional case. At time $=0$, the borehole pressure is the same as the repository pressure $p_{p}$ (Figure 3-1), but decays linearly with time to the hydrostatic pressure of the drilling fluid $p_{h}$ and then remains constant. Plots of peak tensile effective stress as a function of radius are plotted in Figures 3-17 through 3-19 for different values of decay times, waste permeabilities, and pore pressures. The paraneters used in the calculations are given in Table 3-4.

For a far-field pore pressure (initial pore pressure) equal to the lithostatic stress (Figure 3-17), the radial stress field remains tensile for all values of permeabilitics and decay rates. As might be expected, highpermeability wastes are much more sensitive to long decay times than are low-permeability wastes. A "long" decay time for the high-penneability case $\left(k=1 \times 10^{-13} \mathrm{~m}^{2}\right)$ is a fraction of a second, while for a low-permeability waste $\left(k=1 \times 10^{-17} \mathrm{~m}^{2}\right)$, the decay time is several minutes. For far-field pore pressures lower than the lithostatic stress (Figures 3-18 and 3-19), the extent of the radial tensile field is diminished, as are the decay times necessary to completely eliminate any radial tensile response. Although the coordinate geometries are not strictly compatible, it is instructive 10 compare the range of decay times (drilling time through $\xi$ ) tabulated in Table 3-3 to the tensile stresses and decay times in Figures 3-17 through 3-19. Over the ranges of variables chosen, it is apparent that the decay times, as calculated using the steady-state model (Table 3-3), are brief enough to generate borehole elastic tensile stresses with magnitudes great enough to influence borehole spall.

Table 3-4. Properties for Coupled Calculations with Varying Borehole Pressure

\begin{tabular}{|c|c|}
\hline Properiy & Values \\
\hline Repository Permeahility & $k=1 \times 10^{-17} \mathrm{~m}^{2-1} 1 \times 10^{-13} \mathrm{~m}^{2}$ \\
\hline Initial Porosity & $\varphi_{0}=0.19$ \\
\hline Hydrogen Viscosity & $\mu=9.32 \times 10^{-6} \mathrm{~Pa} \cdot \mathrm{s}$ \\
\hline Elastic Moxdulus & $\mathrm{E}=1.8 \times 10^{9} \mathrm{~Pa}$ \\
\hline Poisson's Ratio & $v=0.2$ \\
\hline Borehole Pressure & $p_{h}=7.7 \mathrm{MPa}$ \\
\hline Lithostatic Stress & $\sigma_{z z}=14.8 \mathrm{MPa}$ \\
\hline
\end{tabular}




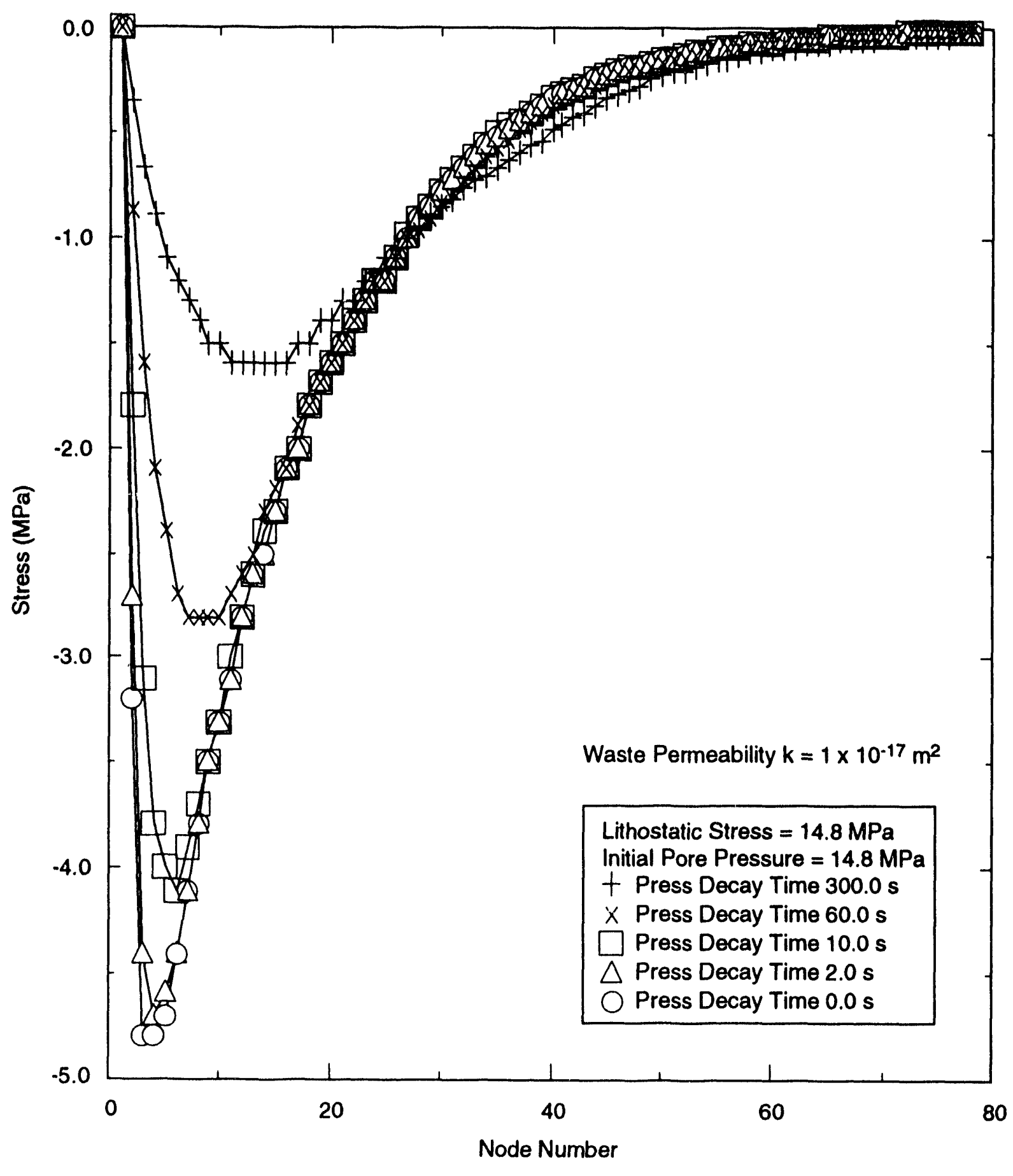

TA1.6342-1859-0

Figure 3-17a. Peak radial tensile envelopes for different decay times. Lithostatic Stress $=$ Pore Gas Pressure $=$ 14.8 MPa. Waste Permeability $k=1 \times 10^{-17} \mathrm{~m}^{2}$. 


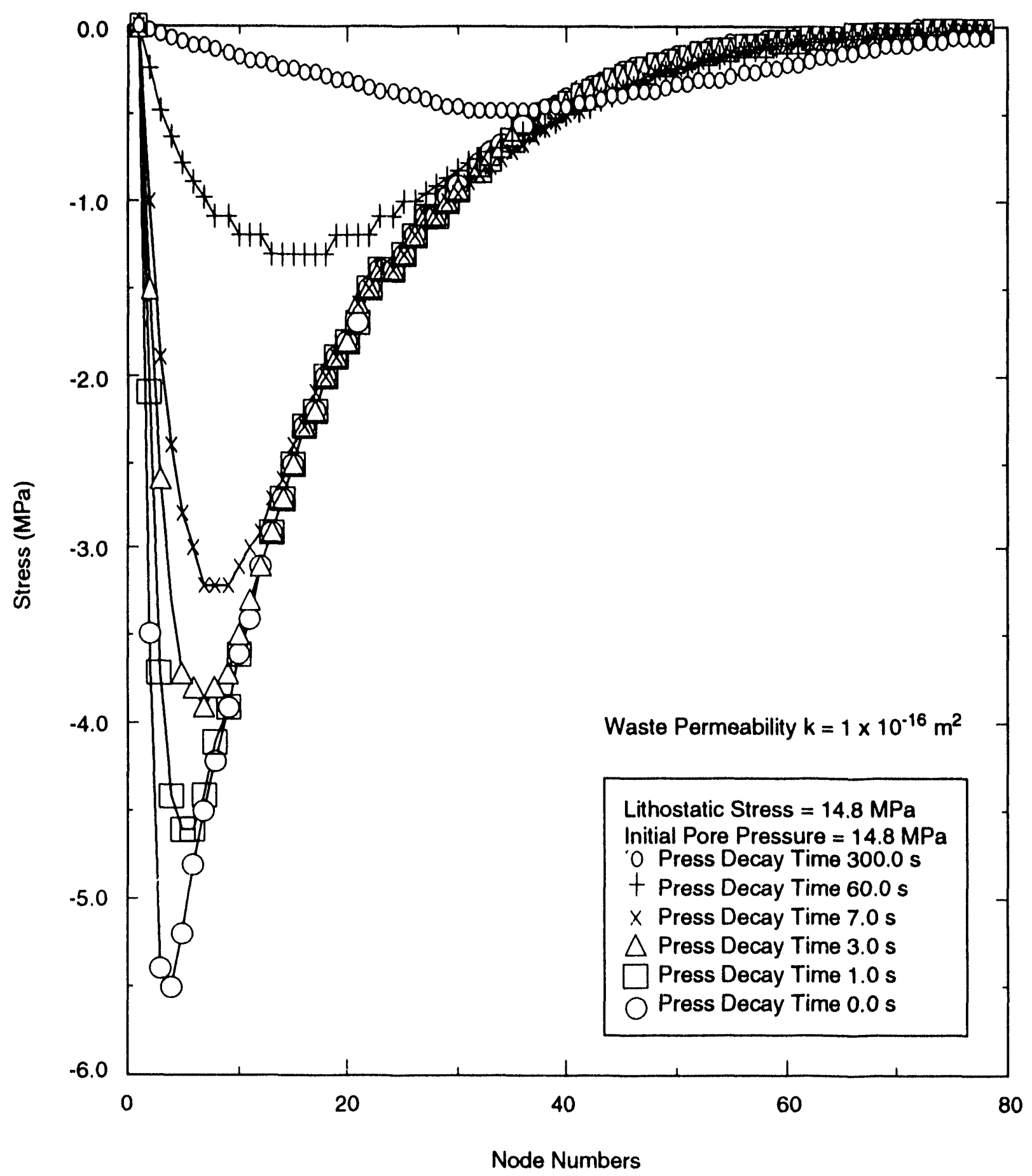

TRI.6342.1850.0

Figure 3-17b. Peak radial tensile envelopes for different decay times. Lithoslatic Stress $=$ Pore (ias Pressure $=$ 14.8 MPa. Waste Permeability $k=1 \times 10^{-16} \mathrm{~m}^{2}$. (continued) 


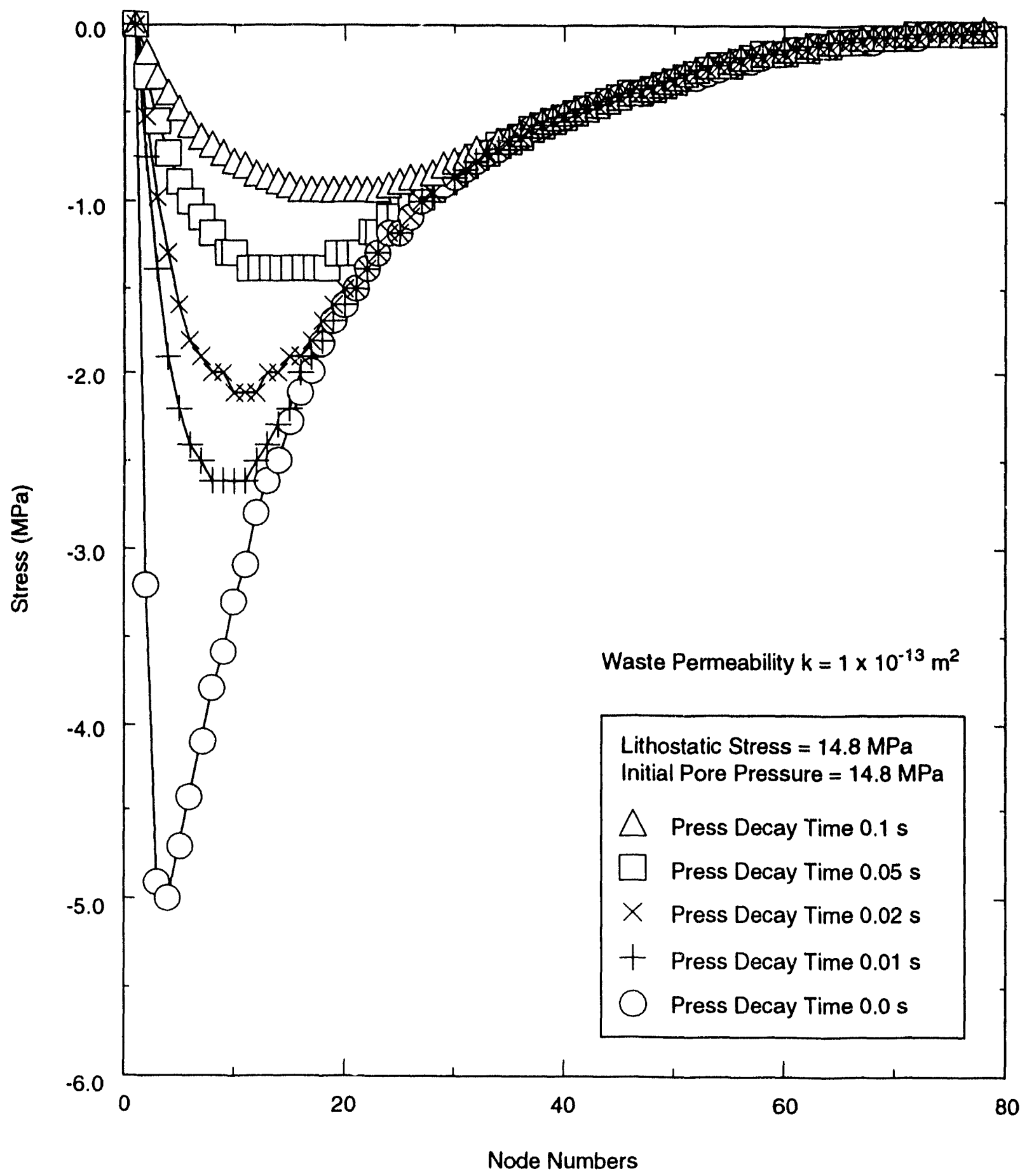

TRI.6342.1857.0

Figure 3-17c. Peak radiad Iensile envelopes for different decay times. Lithostatic Stress $=$ Pore Gas Pressure $=$ 14.8 MPa. Waste Permeability $k=1 \times 10^{-13} \mathrm{~m}^{2}$. (continued) 


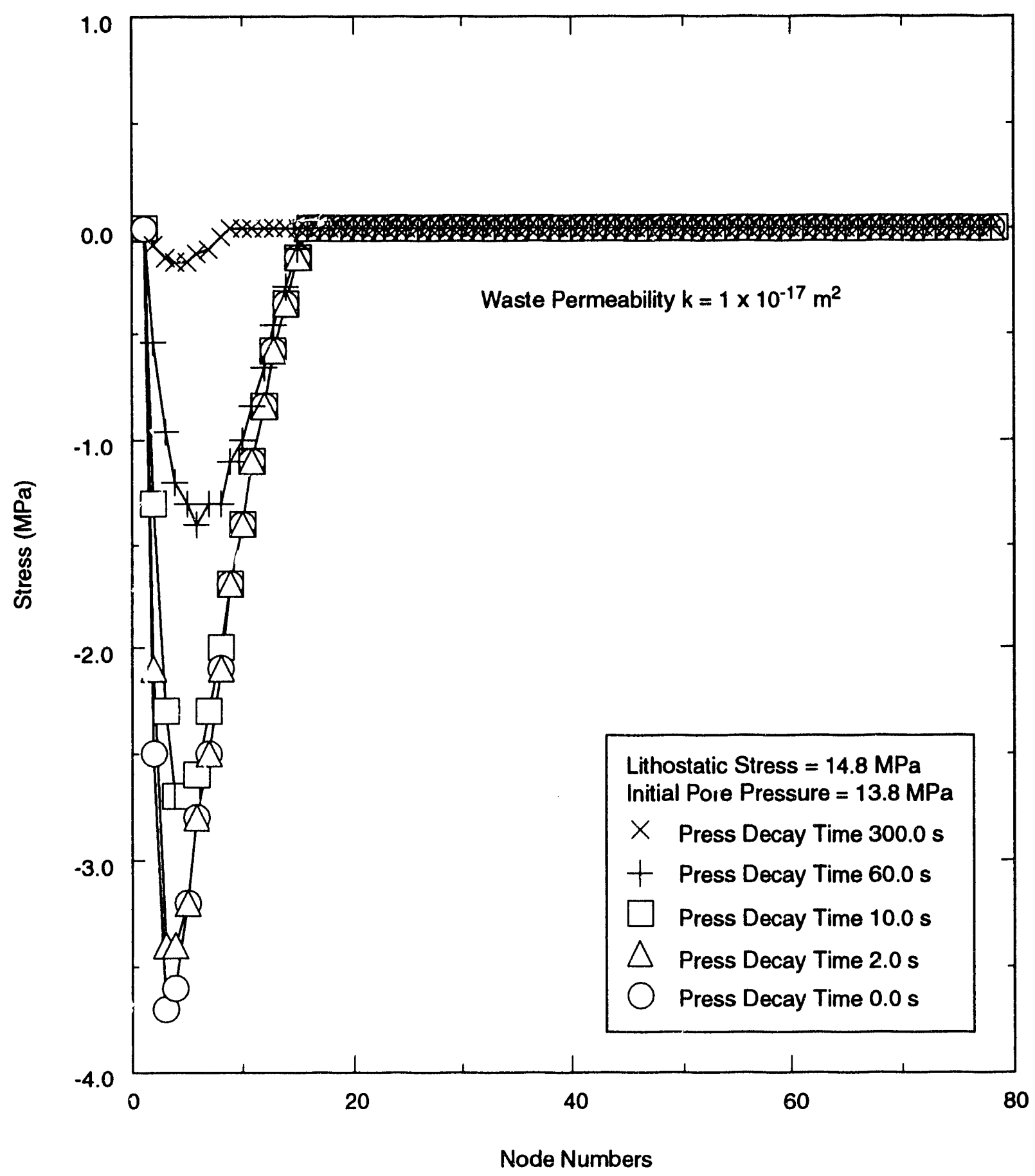

TRI-6342-1856-0

Figure 3-18a. Peak radial tensile en relopes for different decay times. Lithostatic stress $=14.8 \mathrm{MPa}$, pore gas pressure $=13.8 \mathrm{MPa}$. Waste Permeability $k=1 \times 10^{-17} \mathrm{~m}^{2}$. 


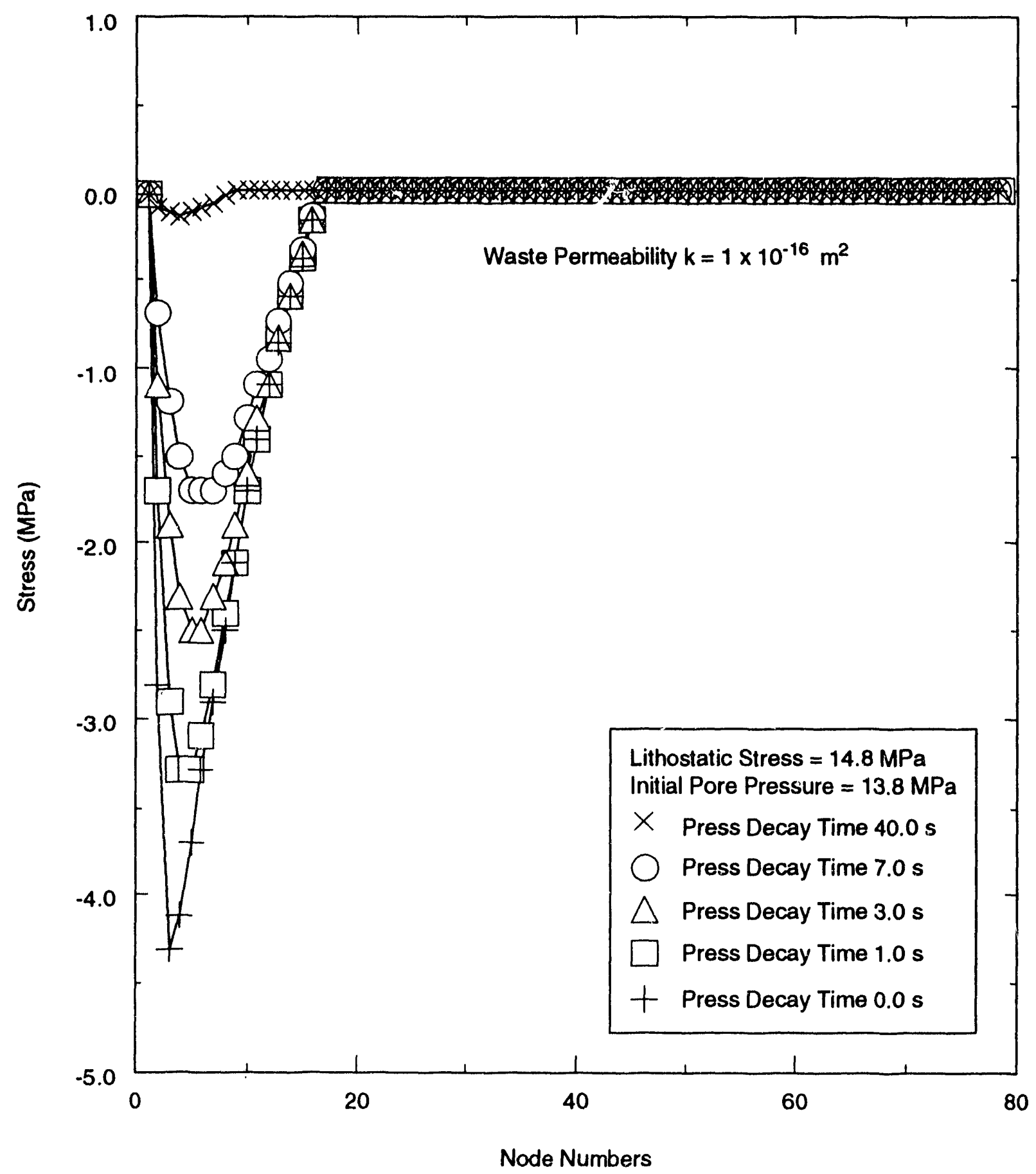

TRI-6342-1855-0

Figure 3-18b. Peak radial tensile envelopes for different decay times. Lithostatic stress $=14.8 \mathrm{MPa}$, pore gas pressure $=13.8 \mathrm{MPa}$. Waste Permeability $k=1 \times 10^{-16} \mathrm{~m}^{2}$. (continued) 


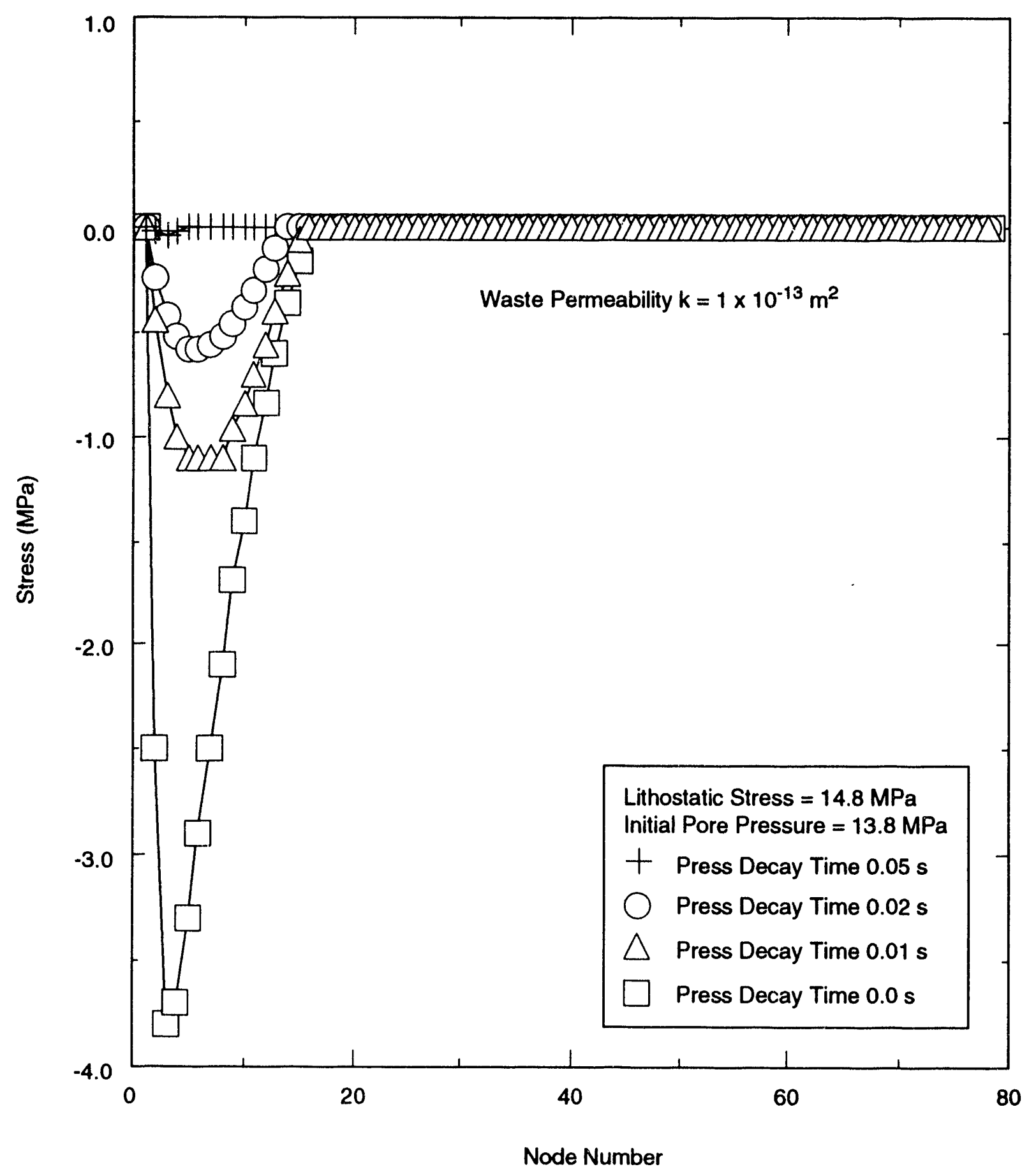

TRI-6342-1854-0

Figure 3-18c. Peak radial tensile envelopes for different decay times. Lithostatic stress $=14.8 \mathrm{MPa}$, pore gas pressure $=13.8 \mathrm{MPa}$. Waste Permeability $k=1 \times 10^{-13} \mathrm{~m}^{2}$. (continued) 


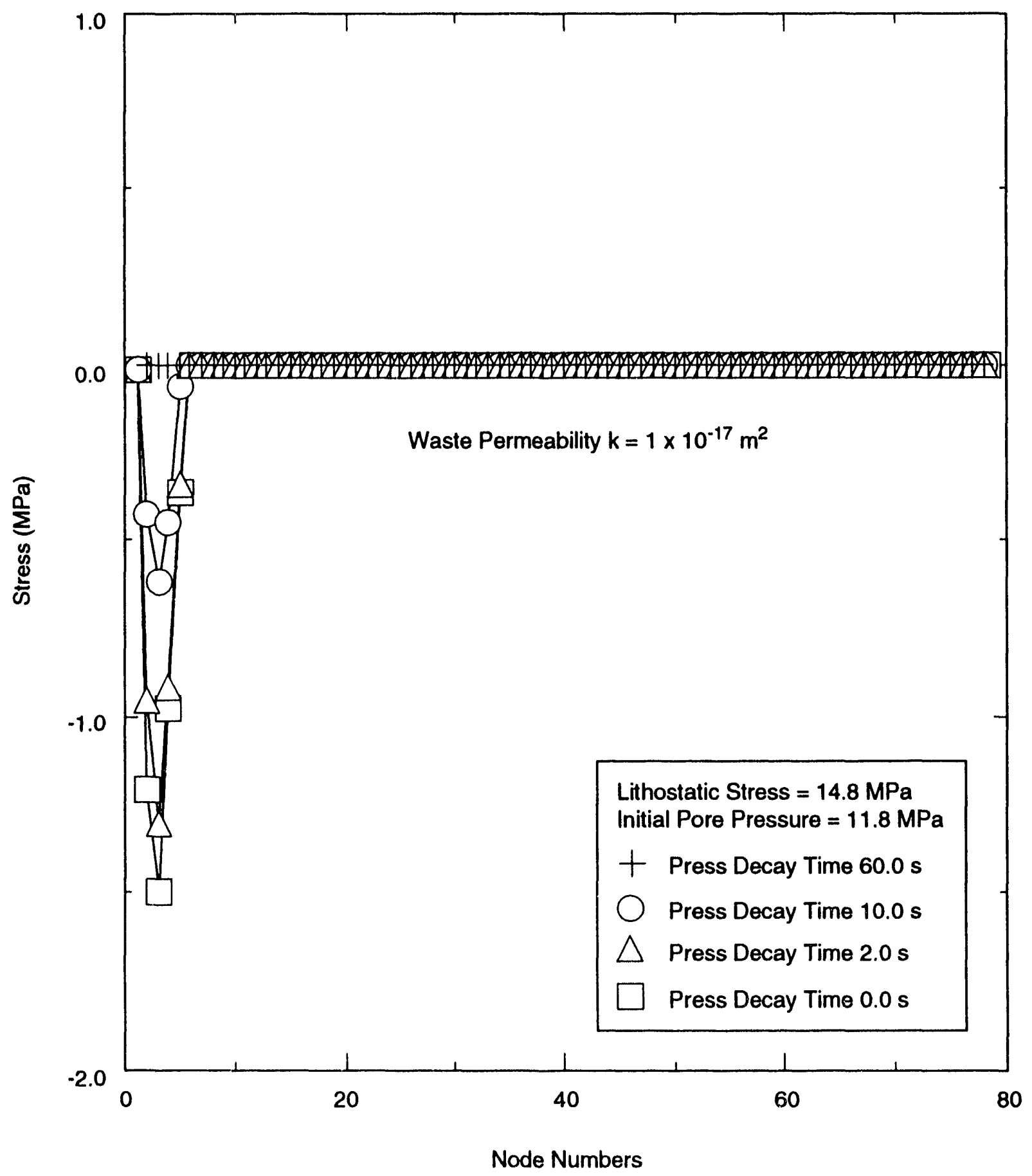

TAI-6342-1853

Figure 3-19a. Peak radial tensile envelopes for different decay times. Lithostatic stress $=14.8 \mathrm{MPa}$, pore gas pressure $=11.8 \mathrm{MPa}$. Waste Permcability $k=1 \times 10^{-17} \mathrm{~m}^{2}$. 


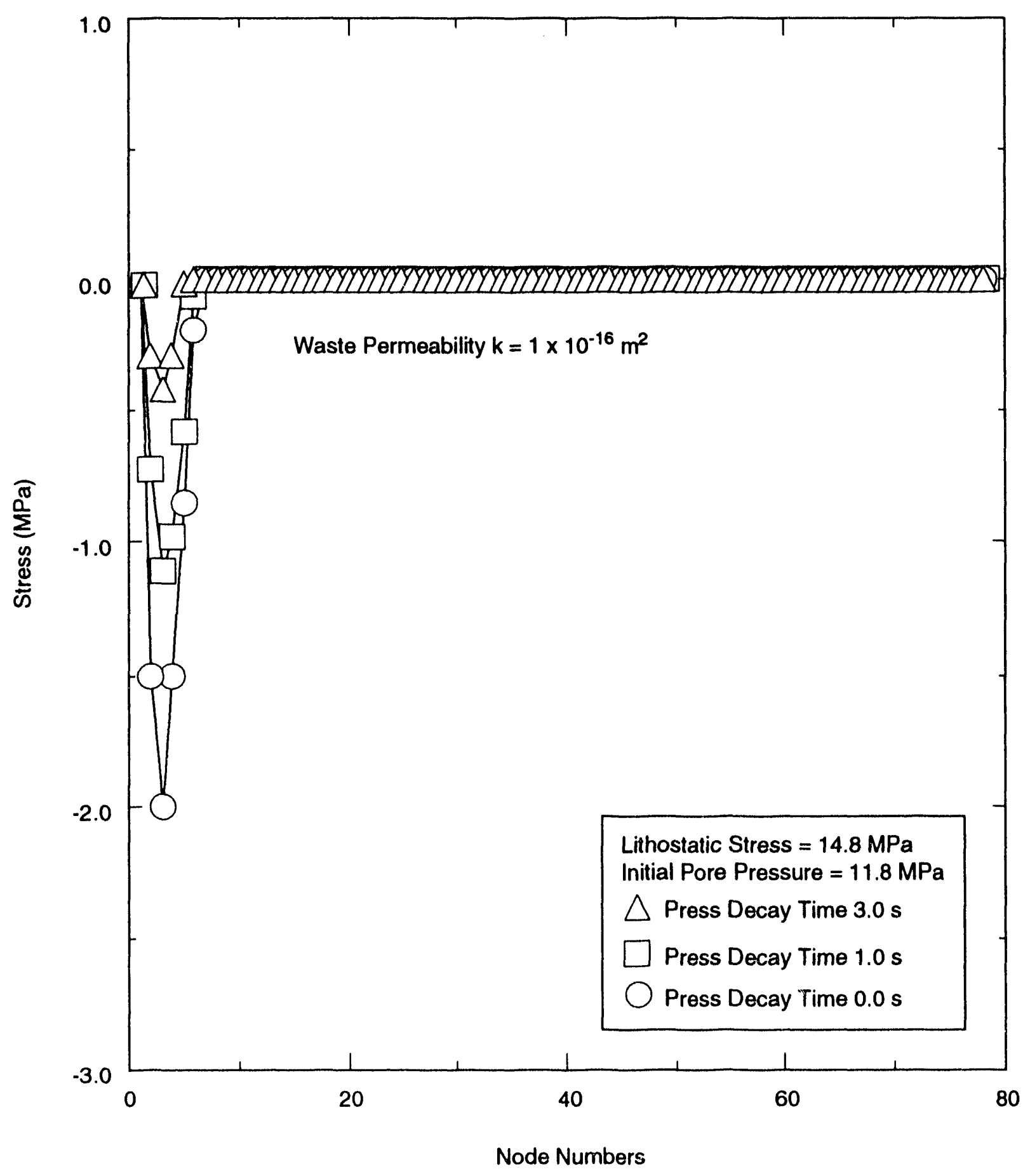

TRI.6342-1838.0

Figure 3-19b. Peak radial tensile envelopes for different decay times. Lithostatic stress $=14.8 \mathrm{MPa}$, pore gas pressure $=11.8 \mathrm{MPa}$. Waste Permeability $k=1 \times 10^{-16} \mathrm{~m}^{2}$. (continued) 


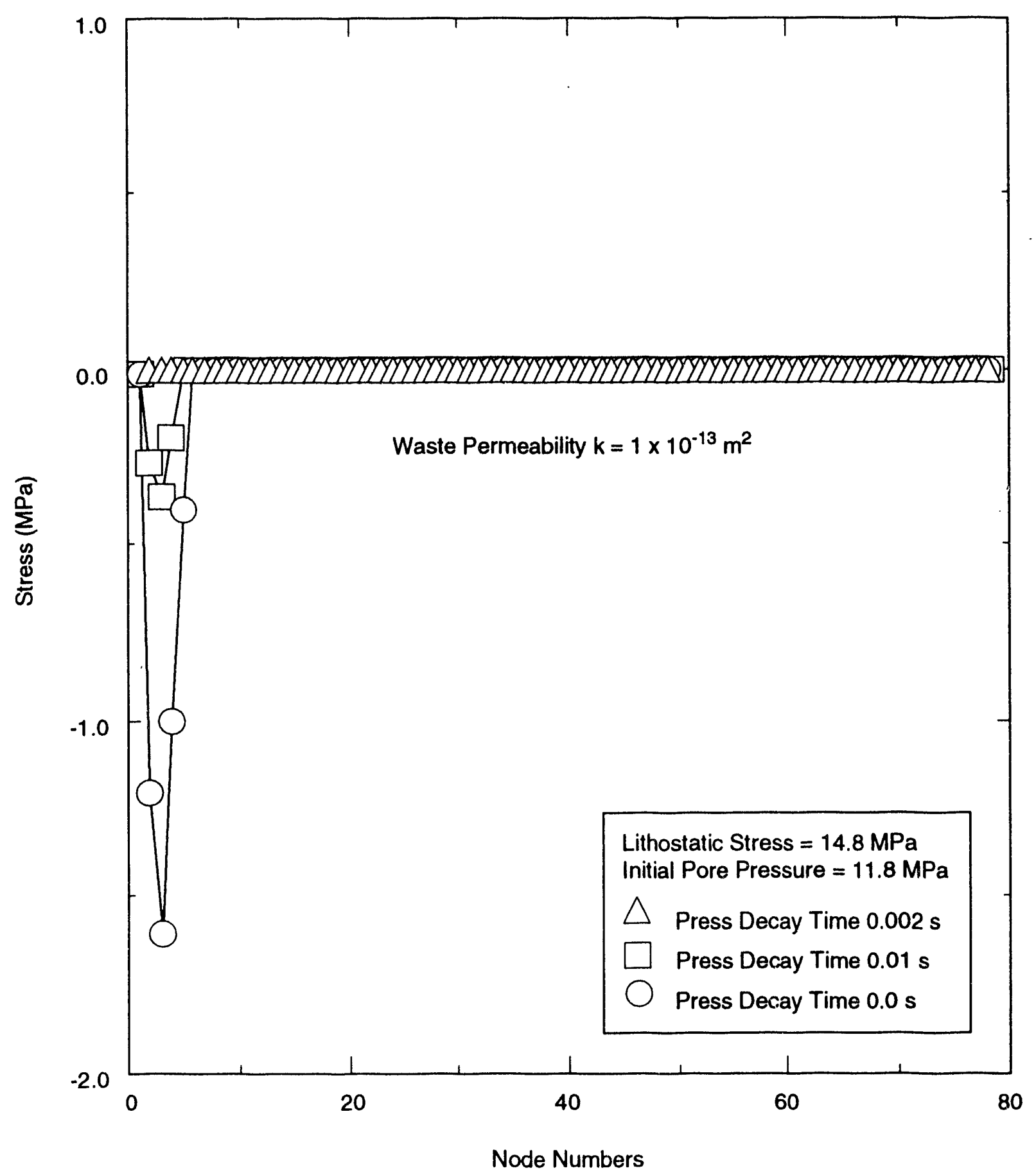

TRI-6342-1852-0

Figure 3-19c. Peak radial tensile envelopes for different decay times. Lithostatic stress $=14.8 \mathrm{MPa}$, pore gas pressure $=11.8 \mathrm{MPa}$.Waste Permeability $k=1 \times 10^{-13} \mathrm{~m}^{2}$. (continued) 
It must be noted that the analyses of the stress state near the borehole performed so far are based on linear elastic theory, and that any inelastic phenomenology is ignored. For granular materials, the region near the borehole is likely to yield plastically (Risnes et al., 1982); for materials with little or no cohesive strength, it may fail (spall) and be passed into borehole drilling fluid. The elastic analysis is not intended to replace the complete inelastic dynamic process that is likely to occur during failure. It does, however, tend to suggest conditions that are conducive to such a failure.

\section{Inelastic Dynamic Response of the Waste}

A more "realistic" representation of the decomposed, compacted waste should consider its probable granular nature and nonlinear constitutive, and perhaps soil-like, character. For this analysis, the nonlinear, dynamic solidmechanics code SAMSON2 (Rudeen and Rath, 1986) was used to calculate the one-dimensional radial dynamic response of the waste near a borehole. The governing equations for the waste motions (SAMSON2) and the gas flow equation were solved simultaneously with the pore pressure field, providing body forces for the SAMSON2 calculation. The gas flow is governed by the equation

$$
\tilde{\nabla} \bullet\left(p \phi \bar{v}_{s}\right)+\frac{1}{2 \mu} \bar{\nabla} \cdot\left(k \bar{\nabla} p^{2}\right)=\frac{\partial(p \phi)}{\partial t},
$$

where $\mu$ is gas viscosity, $k=k_{0}\left(\varphi / \varphi_{0}\right)^{3}\left[\left(1-\varphi_{0}\right)^{2} /(1-\varphi)^{2}\right]$ is permeability, $\phi_{0}$ is initial porosity, $k_{0}$ is initial permeability, $\varphi=\varphi_{0}+\varepsilon_{v o l}$ is porosity, $\varepsilon_{v o l}=\partial u / \partial r+u / r$ is volumetric strain, $\mathrm{u}$ is radial displacement, $\tilde{\nabla}$ is the divergence operator, and $\tilde{v}_{s}$ is waste velocity.

This equation is a more general form of Equation (3-3) and accounts for changes in waste porosity, permeability, and the matrix (waste) velocity. The permeability is a function of the local porosity and is based on the Kozeny-C: rmen equation (Bear, 1972). Darcy's law is assumed to be valid with respect to a coordinate system attached to tho moving waste.

The constitutive nature of the compacted, decomposed waste materials is presently not, and perhaps never will, be known with great confidence. It will, however, undoubtedly be quite different from the elastic, isotropic material assumed in the earlier analysis. A not unreasonable assumption would be that the compacted wastes behave as a soil material with little cohesive strength. Choosing a soil-constitutive model with a hydrostat, a yield surface, and a small hydrostatic tensile strength (Figure 3-20), the coupled motion of the waste and flow of the waste gas can be calculated.

"In the material model illustrated in Figure 3-20, the hydrostatic pressure is also known as the mean normal stress, which in terms of the three principal stresses is $1 / 3\left(\sigma_{1}+\sigma_{2}+\sigma_{3}\right)$. The segment bulk moduli are denoted by $K_{i, \ldots . i=1,2,3}$ and the unloading modulus is $K_{u}$. The failure or yield surface is governed by the second invariant of the stress deviation or in terms of principal stresses:

$$
J_{2}=\frac{1}{6}\left[\left(\sigma_{1}-\sigma_{2}\right)^{2}+\left(\sigma_{2}-\sigma_{3}\right)^{2}+\left(\sigma_{3}-\sigma_{1}\right)^{2}\right] .
$$


The soil model is a modified elasto-plastic model that employs a nonassociative flow rule and permits strain softening. The failure surface is isotropic with a circular cross-section in the deviatoric plane and consists of a pressure-dependent region call the Drucker-Prager failure surface and a pressure-independent region termed the von Mises failure surface (Appendix A). The model has been used extensively to calculate the dynamic response of soils.

No refined material model currently exists for decomposed compacted wastes. The particular soil model shown in Figure 3-20 and chosen to represent the waste was developed from soil data measured for near-surface soil located at McCormick ranch located south of Kirtland Air Force Base in New Mexico. This model was selected because of its ready availability to the author and, considering the lack of constitutive data for the compacted decomposed waste, is one of many other models that could have been chosen.

The finite difference grid for the gas-flow equation and the finite element mesh for SAMSON2 were defined by a borehole radius of $r_{h}=0.2 \mathrm{~m}$, an initial radial zone size of $0.01 \mathrm{~m}$, a growth factor of 1.04 , and a total of 78 nodes. This grid selection places the largest value of $\mathrm{r}$ at $5.07 \mathrm{~m}$ and is identical to the grids used in the previous elastic calculations. A single row of 77 rectangular elements consisting of 156 nodes was assumed in SAMSON2, and only radial motions were admissible. The stress state, pore pressure, and nodal motions adjacent to the borehole were calculated using the additional fixed-input variables shown in Table 3-5.

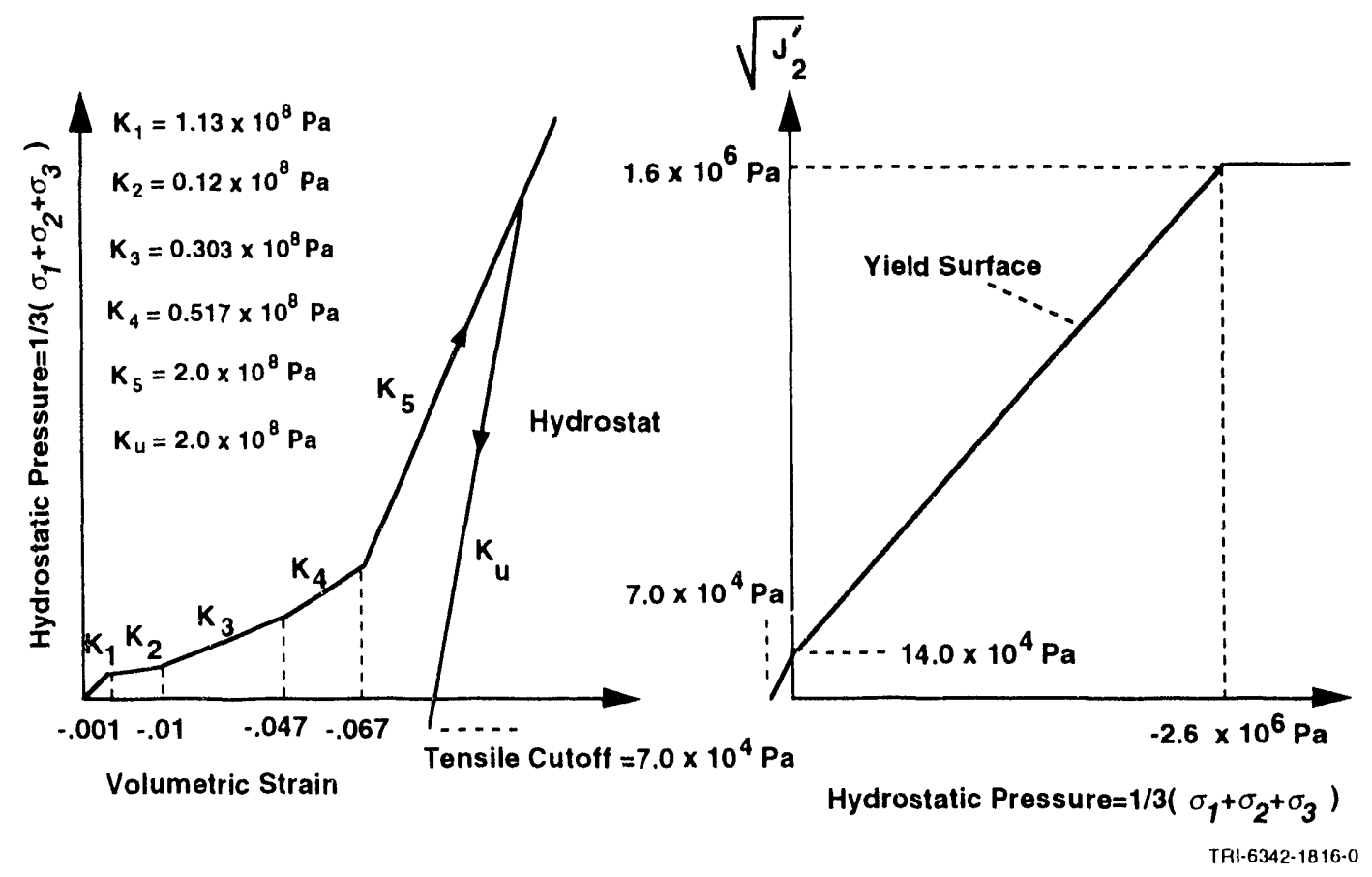

Figure 3-20. Constitutive model chosen for repository wastes. 
Table 3-5. Properties Used for Coupled Flow and Inelastic SAMSON2 Calculations

Property
Initial Compacted Repository Permeability
Initial Compacted Repository Porosity
Hydrogen Viscosity
Borehole Pressure
Initial Repository Pore Pressure
Compacted Waste Density

$$
\begin{aligned}
k_{0}= & 1 \times 10^{-13} \mathrm{~m}^{2} \text { Value } \\
\varphi_{0}= & 0.19 \\
\mu= & 9.32 \times 10^{-6} \mathrm{~Pa} \cdot \mathrm{s} \\
p_{h}= & 7.7 \mathrm{MPa} \text { (instantaneous pressure drop) } \\
p_{p}= & 14.8 \mathrm{MPa} \\
& 1400 \mathrm{~kg} / \mathrm{m}^{3}
\end{aligned}
$$

Plots of unrestricted radial displacement, pore pressure, volumetric strain, and permeability at $1.92 \times 10^{-4} \mathrm{~s}$ after the sudden initiation of gas flow are plotted in Figure 3-21. The inward motion of the waste is driven by the gaspressure gradient, which exceeds the tensile strength of the waste and which initially is greatest at the borehole boundary. This inward radial motion increases the volumetric strain (in this case, positive is tensile) and the permeability of the waste near the borehole. The process is rapid (milliseconds) and, if left unrestricted, would continue until the borehole was completely filled with waste.

Unrestricted radial motion of the waste is unrealistic because there is likely to be a drill string in the hole that will block the radially-inward motion of the waste. To study the behavior of the waste after its inward motion is prevented, the above calculations were continued but modified so that only 1 inch $(0.0254 \mathrm{~m})$ of inward radial motion of the borehole boundary was permitted. Plots of radial displacement, pore pressure, volumetric strain, and permeability at $0.032 \mathrm{~s}$ after the initiation of gas flow are shown in Figure 3-22. This time is sufficiently long after the borehole wall is stopped at 1 inch $(0.0254 \mathrm{~m})$ for the principal transients to die out near the borehole. As the waste presses against the drill string, the volumetric strains become compressive and the waste permeability decreases for the first several elements. For the chosen waste constitutive model, the permeability decreases by two orders of magnitude near the borehole wall. The negative volumetric strain reflects a compressive state of stress near the borehole. These compressive radial stresses are plotted in Figure 3-23. The compressive stress field is the result of the pressure gradient close to the borehole and the motion restraint; it follows that as the pore pressure decay extends farther into the waste, the compressive stress field does so as well.

These results suggest that the waste would continue to be impressed against the drill string until sufficient gas had leaked from the penetrated room to lower the pressure gradients below a threshold governed by the cohesive strength of the waste. The flow of gas from the room to the borehole is slowed by the decreased permeability of the waste near the borehole boundary. As the compressive stress field advances into the waste, the local permeability will also decrease, further slowing the gas outflow process.

These results are based upon a rather arbitrary constitutive model and the response for compacted waste will undoubtedly be different. One possible difference between the above response and that for compacted wastes will likely be the decrease in permeability due to compressive stresses. One of the principal constituents of the waste will be crushed halite. The permeability of the waste/halite mixture prior to intrusion is the result of compressive creep consolidation of the halite component of the waste during an extended period. Thus, after tensile or shear failure due to an intrusion, a sudden and significant decrease in permeability of the damaged waste when it is placed into a compressive state of stress is unlikely. 


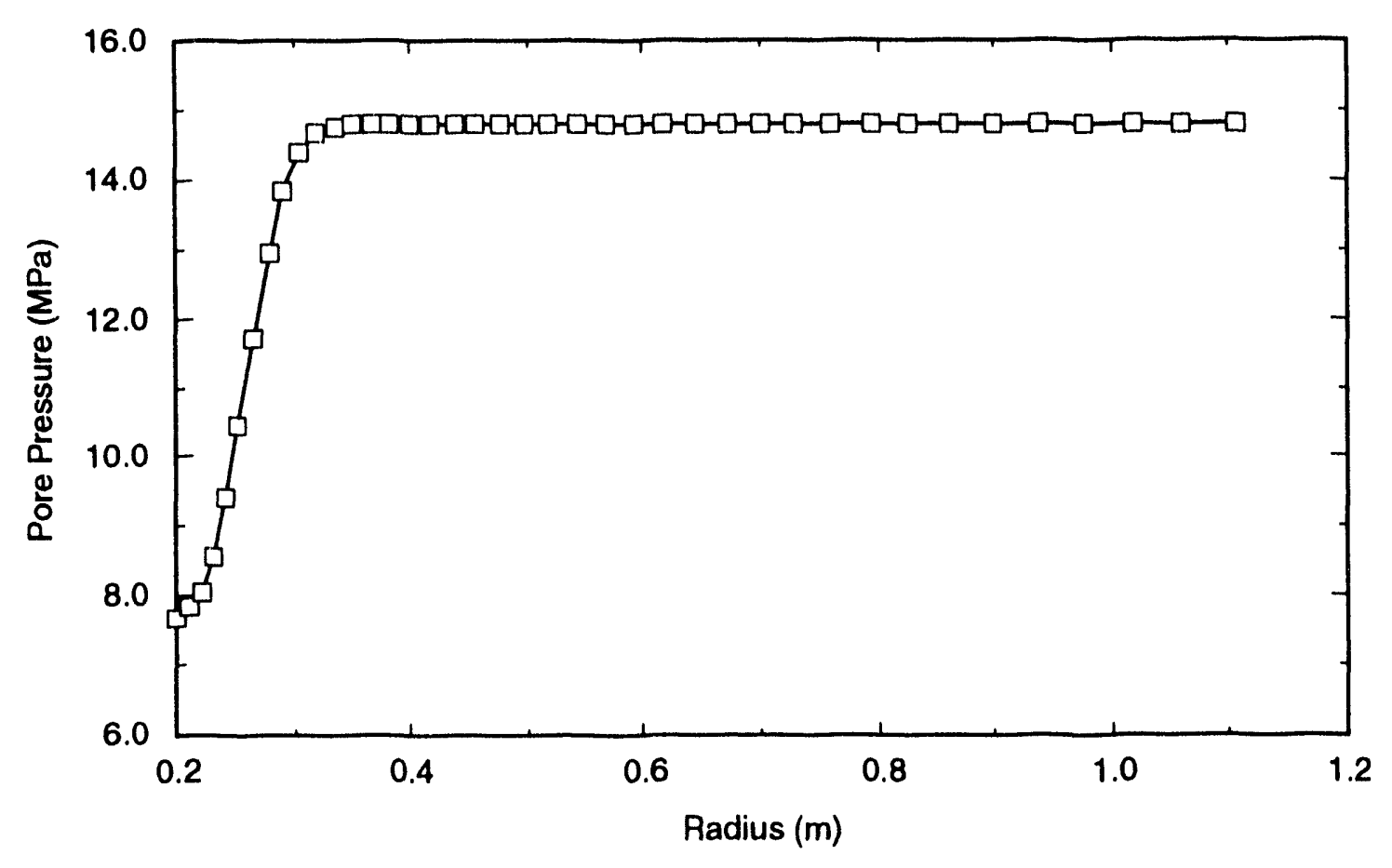

TRI.6342.1850-0

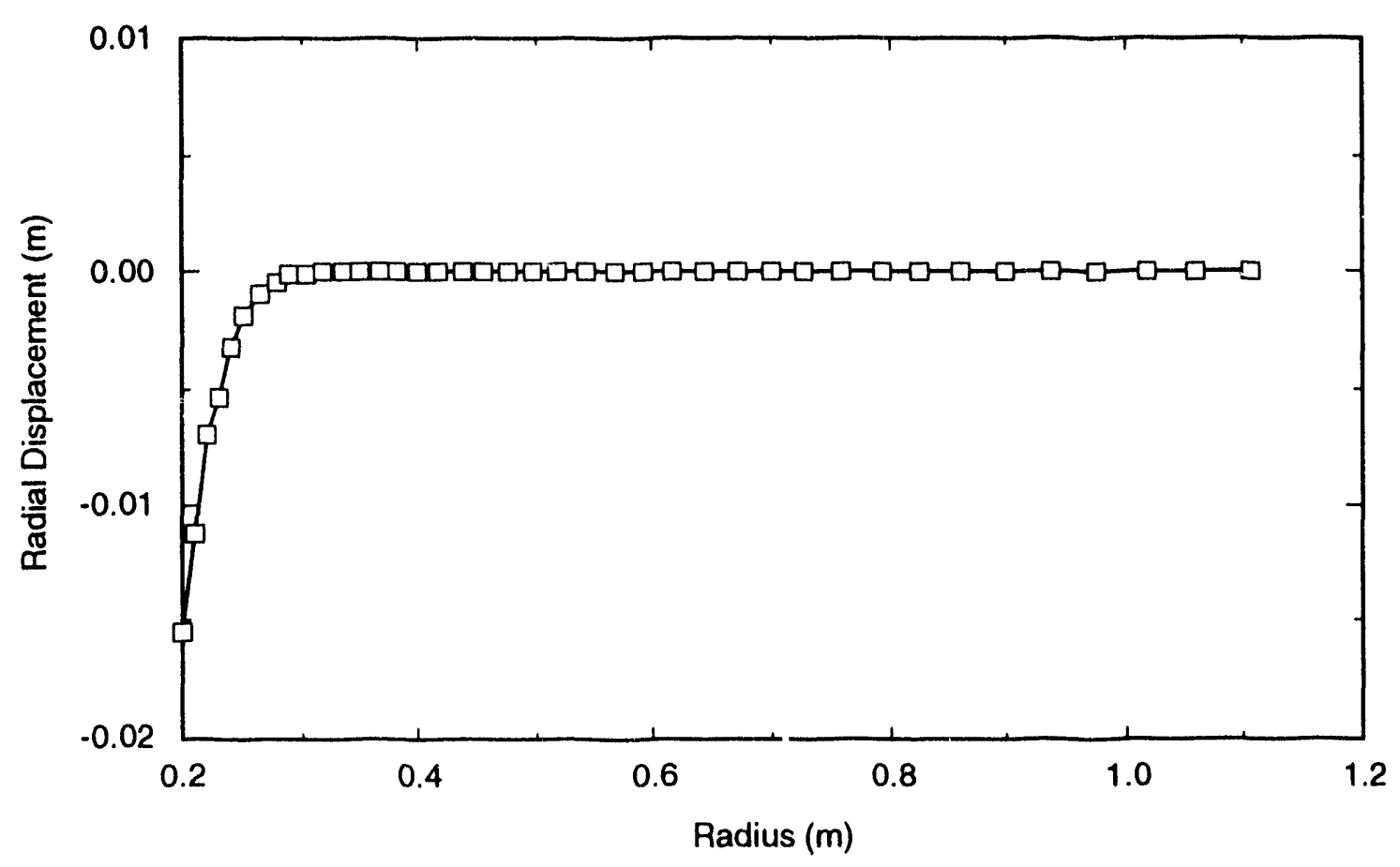

TRI.6342-1848.0

Figure 3-21a. Unrestricted waste response at $0.0001925 \mathrm{~s}$. 


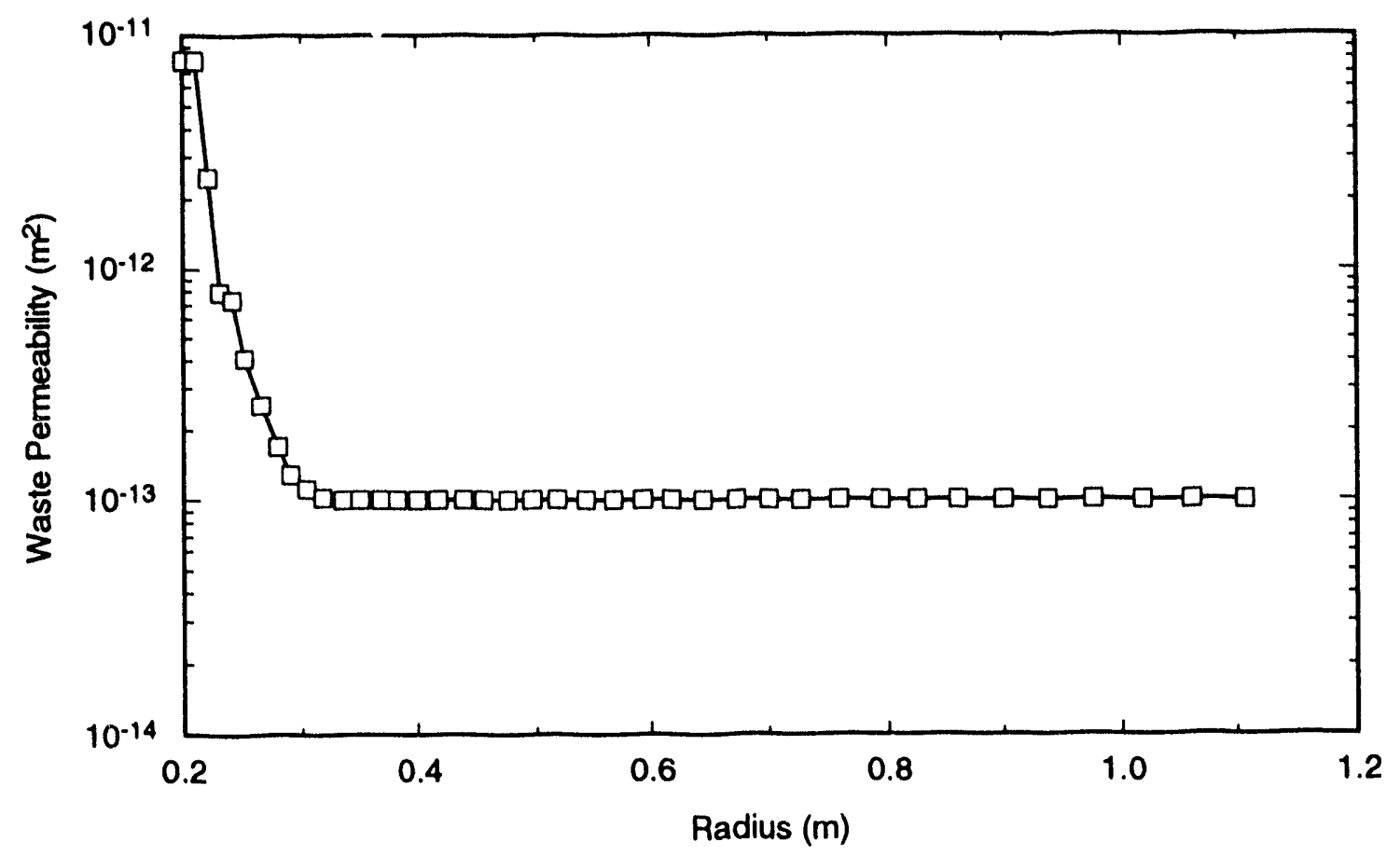

TPI-6342-1848-0

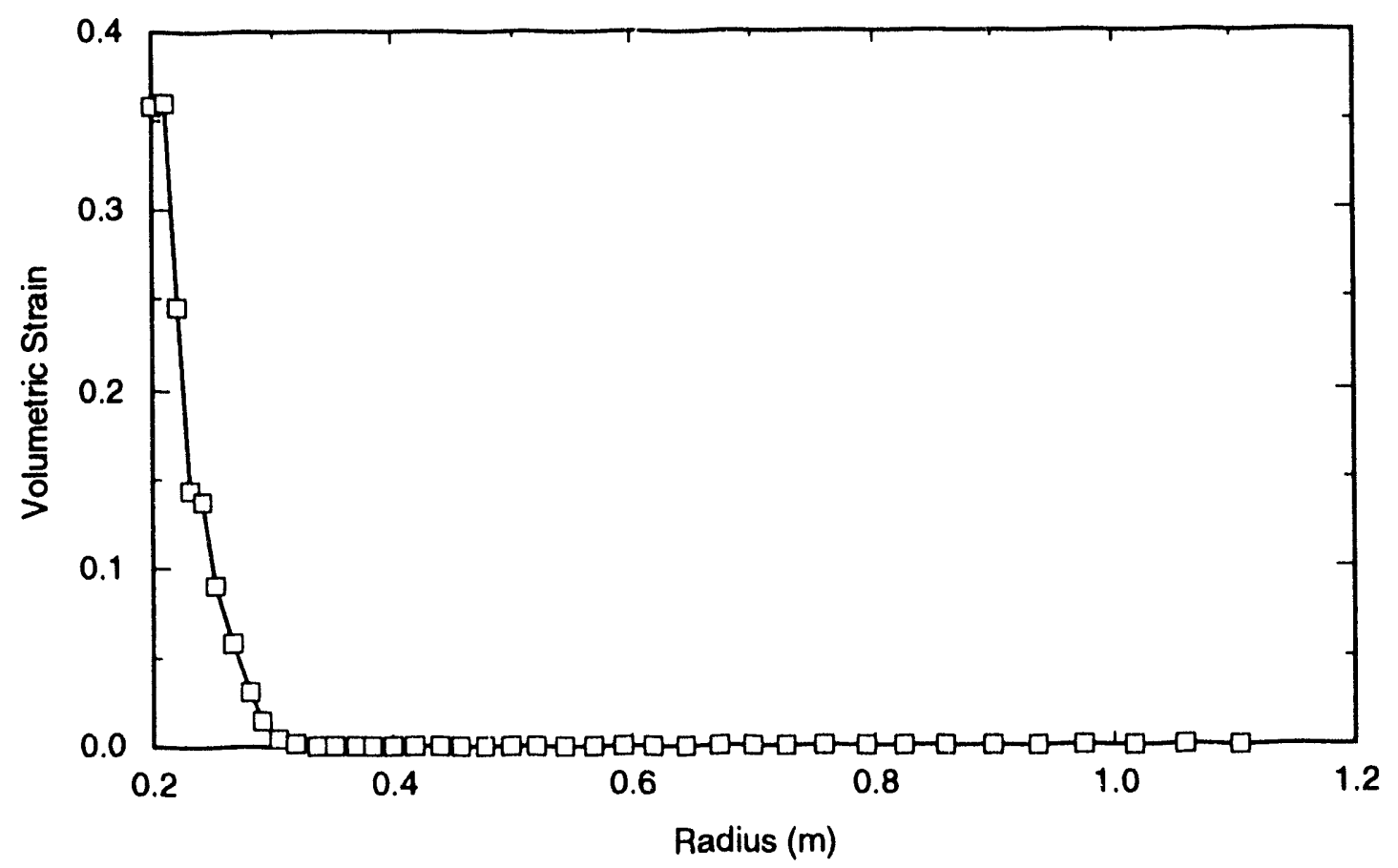

TRI-6342.1847.0

Figure 3-21b. Unrestricted waste response at $0.0001925 \mathrm{~s}$ (continued). 


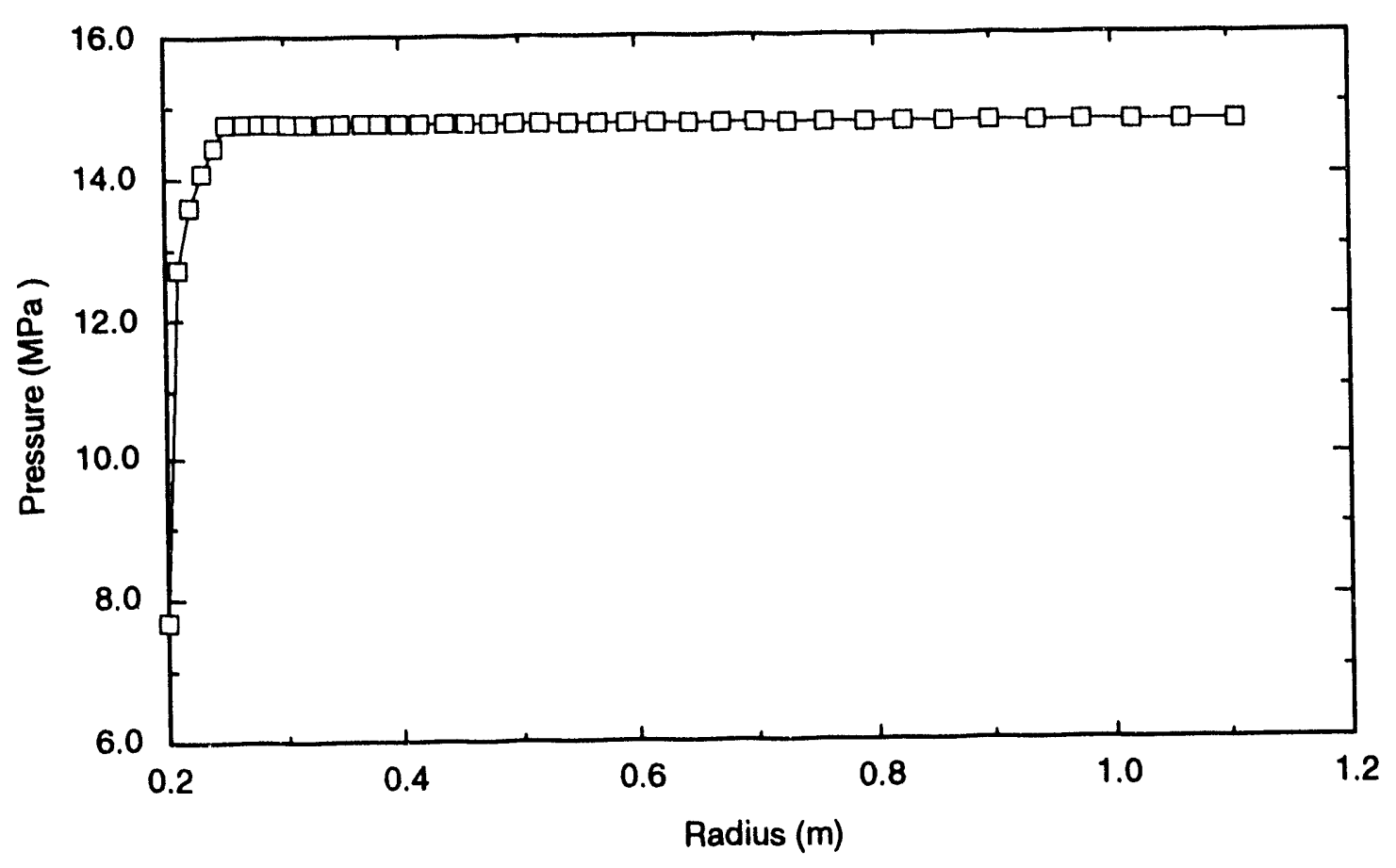

TRI-6342-1846-0

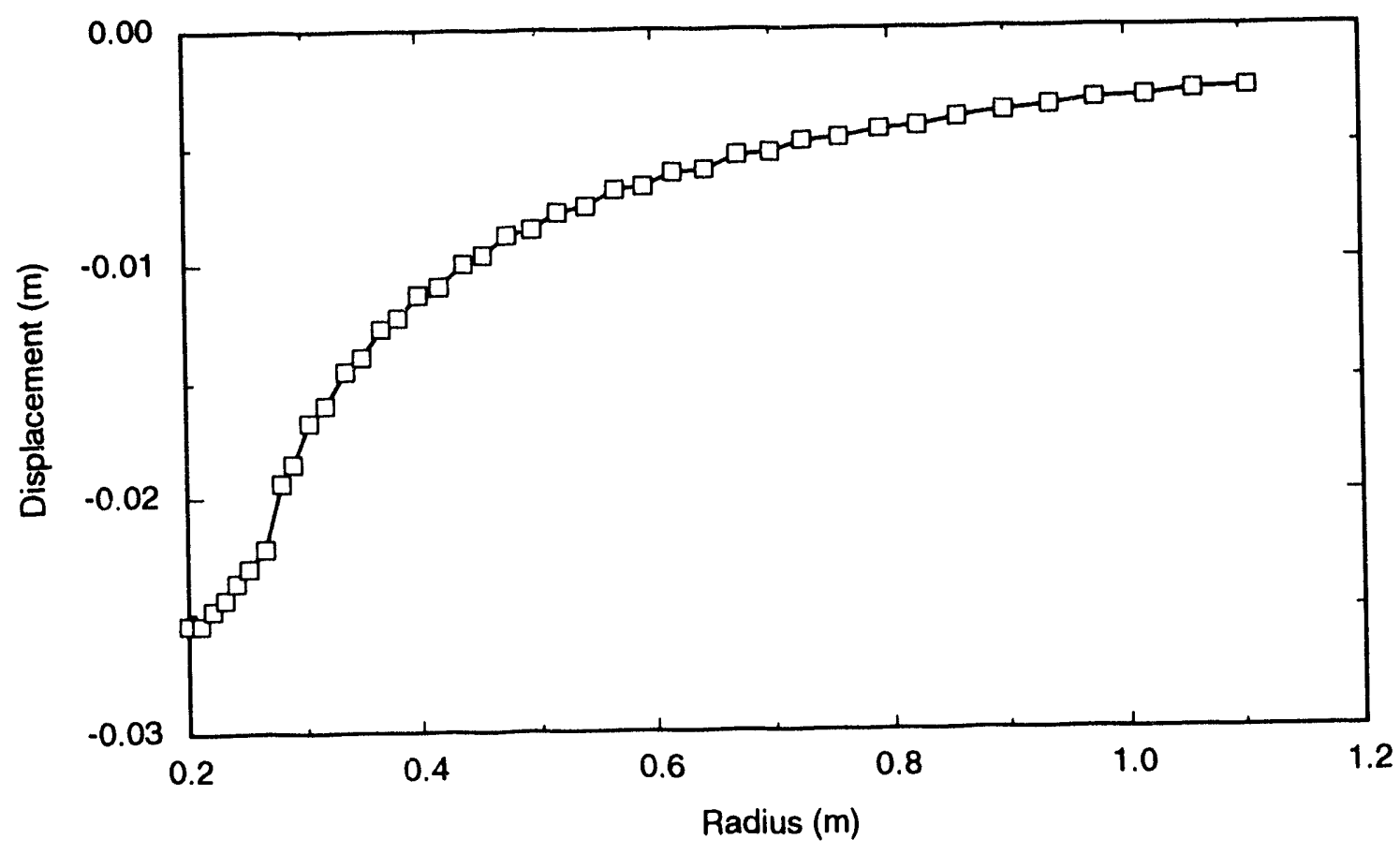

Figure 3-22a. Waste response at $0.0325 \mathrm{~s}$ (radial displacement of horehole wall limited to $0.0254 \mathrm{~m}$ ). 
3. Mechanism II: Waste-Gas-Induced Borehole Spall
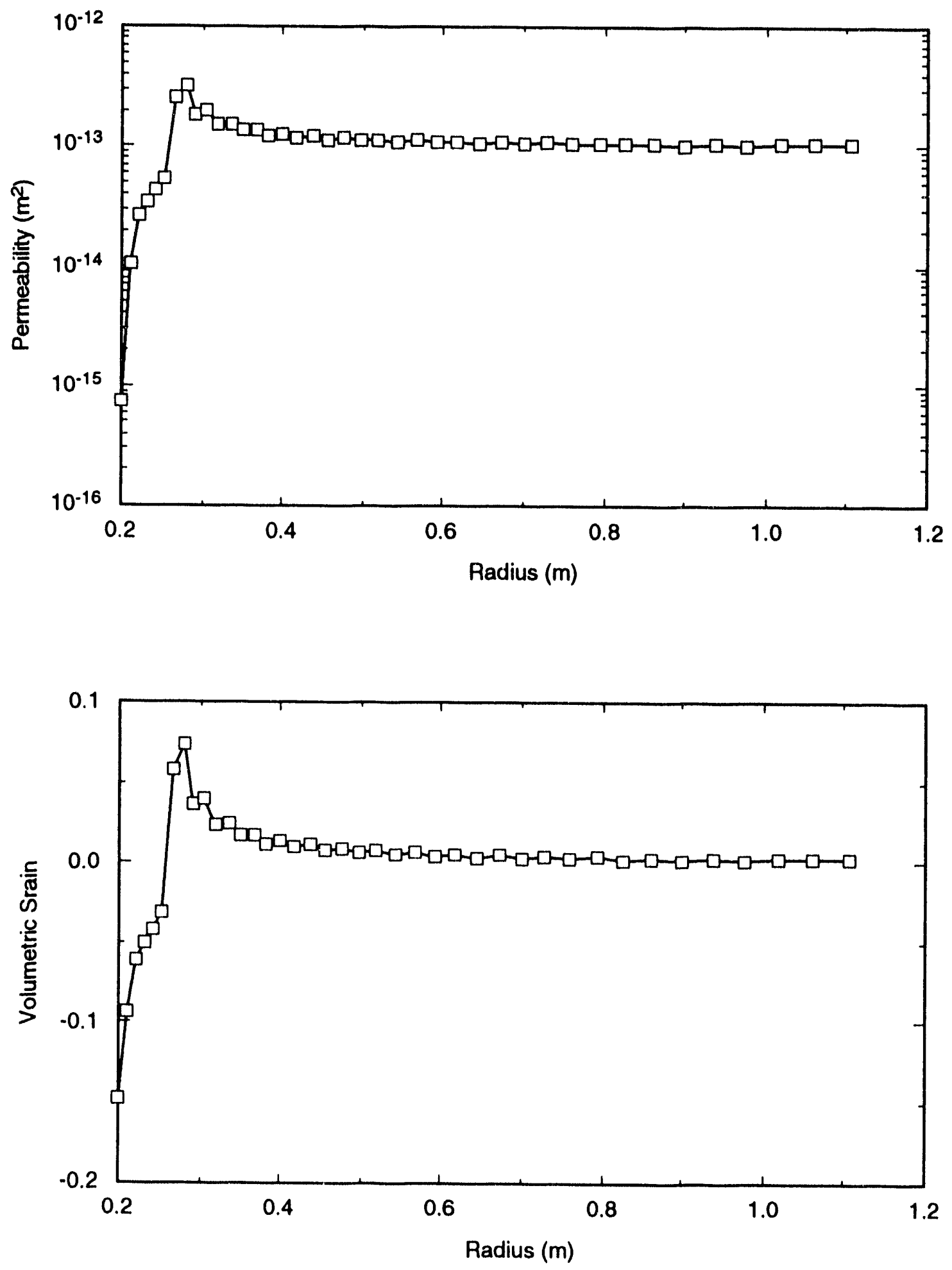

TRI.6342-1843.0

Figure 3-22b. Waste response at $0.0325 \mathrm{~s}$ (radial displacement of borchole wall limited to $0.0254 \mathrm{~m}$ ) (continued). 


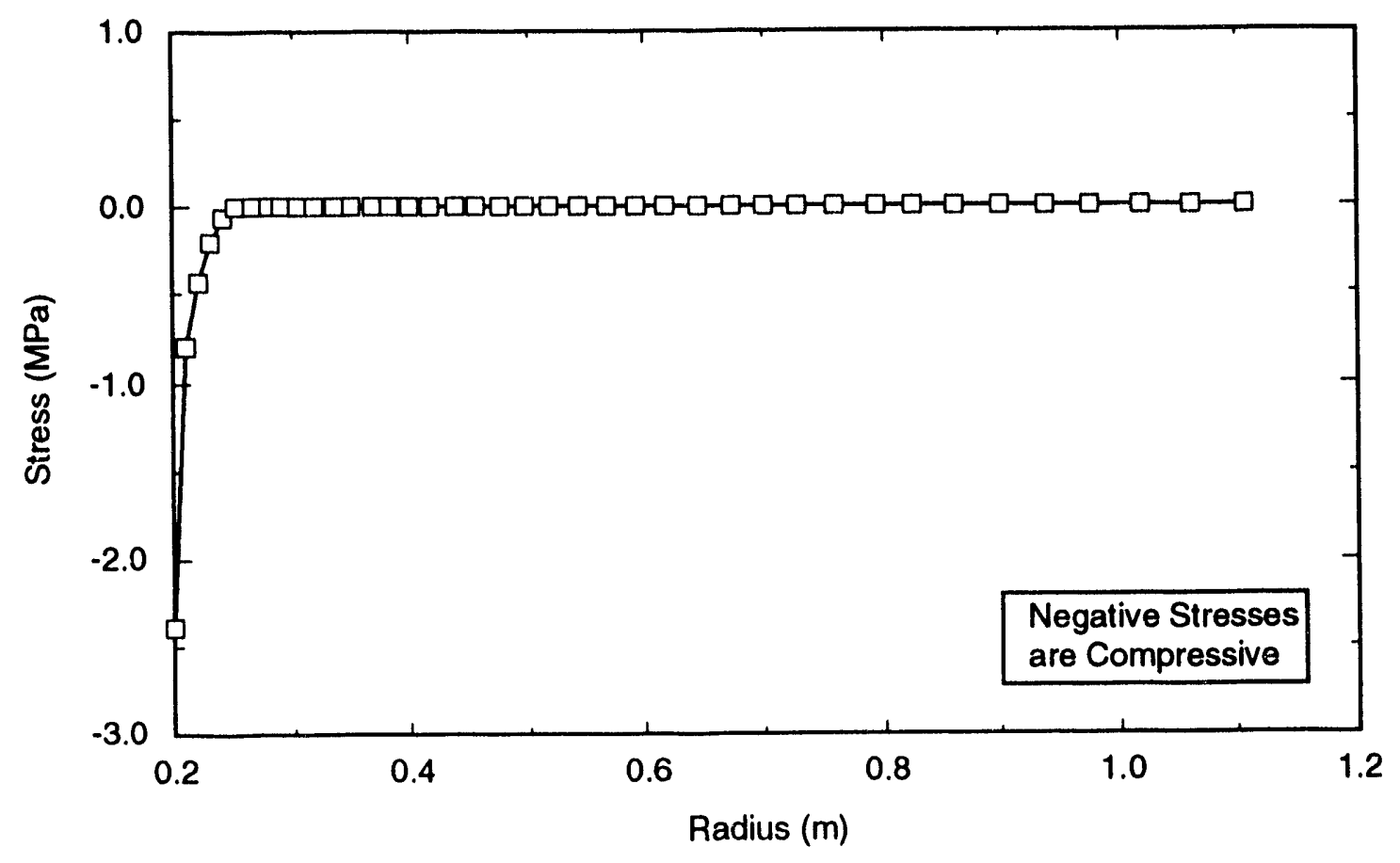

TR1-6342-1842-0

Figure 3-23. Radial effective stress distribution at $0.032 \mathrm{~s}$. 
As with the one-dimensional cylindrical case, the two-dimensional model formulated earlier can be run dynamically with an inelastic material model. Using the material model shown in Figure 3-20 and applying the same spherical pore pressure distribution (at 6 seconds) as for the static case (Figure 3-8), the dynamic material response near the borehole shown in Figure 3-24 can be of sained. Kore the coupling between gas flow and material response is neglected and the time-varying nature of the poric pressure is ignored. The borehole is observed to contract in a manner fully consistent with the stress field calculated for the elastic, two-dimensional, static case. The contraction is also consistent with the one-dimensional, inelastic cylindrical dynamic response.

\subsection{Discussion}

The literature confirms that problems of spall, sloughing, or caving of a borehole wall often c icur when an exploratory drill bit encounters a geopressurized formation. In addition, a similar phenomenon known as outbursting has been observed in the mining or drilling of coal.

The gases generated in a waste repository as the result of brine- and bacterial-induced degradation of the waste can create conditions in the repository similar to those that occur naturally, which cause problems during hydrocarbon drilling operat $n s$. The direct removal of waste is an important component in determining the overall compliance of waste epositories such as WIPP to regu'atory guidelines. To assess compliance, it is necessary to quantify the anount of waste that may reach the surface as the result of drilling. Although the available literature does discuss spall as it relates to hydrocarbon exploration, procedures that can be used to quantify this phenomenon were not uncovered.

In an effort to gain additional un' erstanding of gas-induced spall as it relates to a repository such as WIPP, a number of calculations were undertaken; the results of these calculations are reported in this document. One of the principal difficulties in these calculati, ns was the characterization of the decomposed, compacted waste. Currently, the constitutive nature of the waste is largely unknown and, to facilitate the analysis, both an elastic and an eia tic-plastic model were chosen.

The calculation and waste stress response assuming elastic behavior suggests conditions conducive to borehole failure or sloughing adjacent to the borehole when gas-pressurized waste is suddenly encountered. If the borehole pressure is allowed to decrease gradually rather that instantaneously, the tensile effective stress levels are diminished, suggesting a lessening of the tendency to spall. However, the range of possible pressure decay rates that are likely to be encountered will not eliminate the tendency for gas-flow-induced spall near the borehole.

If the waste is assumed to behave as a granular, soil-like material with a non-linear constitutive character and a small cohesive strength, again the behavior of the waste subject to gas flow indicates a movement toward the borehole. In hoth the one- and two-dimensional computational models, where an instantaneous borehole pressure drop is assumed, the inward motion of the waste-borehole boundary would quickly (in milliseconds) be blocked by the presence of the drillstring and would remain impressed against the drillstring while a sufficient pore pressure gradient is maintained. 

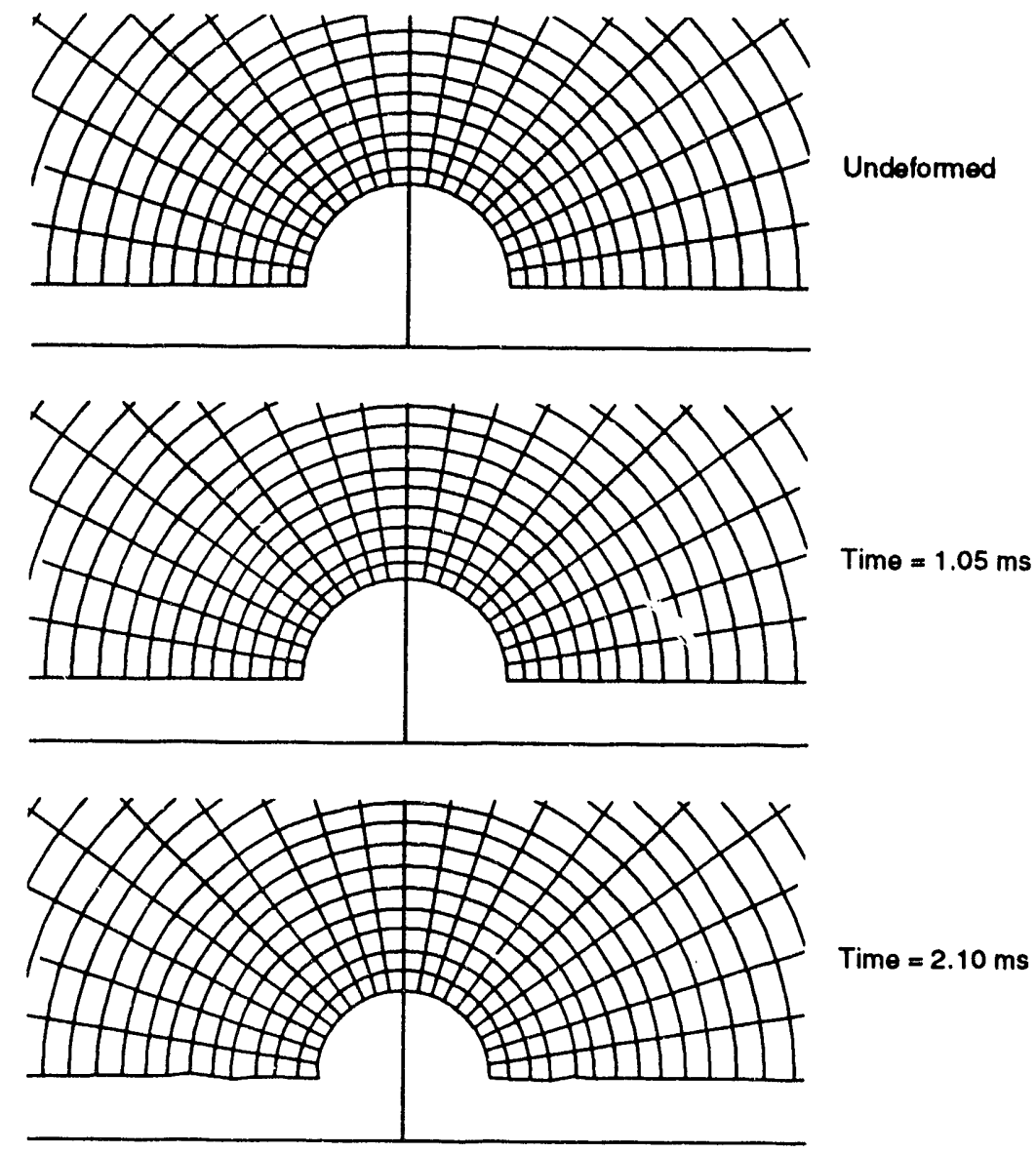

$\operatorname{Time}=2.10 \mathrm{~ms}$

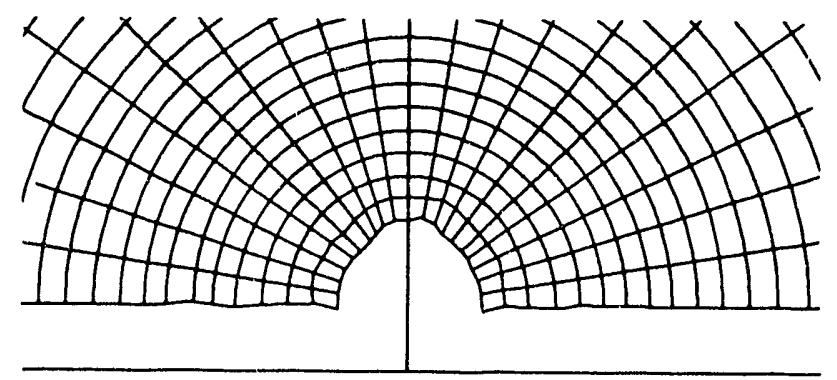

$\operatorname{Time}=3.15 \mathrm{~ms}$

TRI-6342-1822-0

Figure 3-24. Unmagnified deformed mesh using soil material model. 
What happens to the waste as it is impressed against the drillstring is not known because the interface between the waste and drilstem is very difficult to characterize without experimental verification. One possibility is the compressed waste will completely block the flow of drilling mud. Whether the drilling operation can proceed in such circumstances is unknown. Certainly the flow of gas out of the waste will be further restricted, if not completely blocked. Such a restriction would prolong the compressive stresses acting between the drillstring and the waste. Another possibility is that some drilling fluid may be able to channel its way through the wastedrillstem boundary, thus carrying eroded waste up into the upper borehole.

The driller may be able to detect the resistance afforded by the waste pressing against the drillstem by the increase in torque, circulation pressure, and by a drop in mud flowrate (Austin, 1983). Under such conditions the driller may raise the cutting bit and allow the "spall" to continue naturally, eventually proceeding after the process diminishes (Short, 1982). Often under these conditions, a repetitive process is undertaken of cleaning out, drilling ahead a few feet of new hole, picking up the drill bit to check for fill, then cleaning out again. This is repeated until spalling slows. The cleanout procedure can be used for 12 to 24 hours, or longer if it shows sign of becoming effective (Short, 1982).

If drilling can proceed with the waste impressed against the drilling equipment, erosion will probably occur at the interface and could continue until a significant portion of the gas is removed from the penetrated room or the target drill depth is reached. Based on leakage rates from the waste with uniform permeabilities, significant volumes of gas will he removed from the room, after only several hours for the greatest waste permeability and after hundreds of days for the least permeability. Moreover, any decrease in waste permeability caused by the compressive stress field at the drillstring-waste interface is likely to decrease the gas leakage rates.

It is also important to understand the actions that a driller may take after detecting gas flow from a penetrated, gas-pressurized formation. When fornation gas flow into a borehole is detected at the surface, such as by an increase in return mud volume, the driller usually will "close in" the well by engaging blowout preventers (BOPs) to prevent serious injury to personnel and damage to equipment. This action is usually taken within a minute or two after the "kick" is first observed; the effect is that the gas flow from the formation to the borehole is effectively curtailed (Mills, 1984). The well is then "killed" by increasing the mud density in the borehole so that the formation (waste) pore pressure is in balance with the mud pressure. The drilling can then safely continue. With the pressure gradient in the borehole wall thus reduced to zero, spallation will cease and waste will be brought to the surface by erosion only. BOPs are engaged only if a blowout condition is detected. For high-permeability wastes $\left(k=1 \times 10^{-13} \mathrm{~m}^{2}\right)$ the flow rate of gas to the borehole will increase the mud volume in the annulus significantly; it is likely that the well will be "killed." However for lower permeabilities, the gas flow rate is much reduced; the driller may not engage BOPs, but continue drilling, thus allowing spall into the thorehole to occur.

Estimating the aunount of material that may eventually be passed into the borehole as the result of gas generation in the repository is difficult and speculative. However, based upon the amount of analysis performed and the literature examined to date, it does not appear to be unreasonable that volumes of waste several times greater than the lower-bound volume (bit area $x$ waste depth) could eventually reach the ground surface. To quantify the volume of waste directly removed from a penetrated repository requires a much better understanding of the constitutive nature of the compacted decomposed wastes. Data to develop such a constitutive model will 
have to be generated. In addition, experimental data are required to supplement analytic results concerning the mechanisms for borehole spall and to reveal other phenomena that may not have, as yet, been uncovered. Finally, it is necessary to investigate further the actions and procedures undertaken when a driller presently encounters a pressurized or spalling zone. These actions may limit the volume of waste that could reach the surface or provide an upper bound to the volume removed. 


\section{REFERENCES}

Austin, E.H. 1983. Drilling Engineering Handbook. Boston, MA: International Human Resources Development Corporation.

Bear, J. 1972. Dynamics of Fluids in Porous Media. New York, NY: American Elsevier Publishing Company. 197-205.

Berglund, J.W. 1990. Appendix A, "Letter 1a: Bar Graphs Representing Range of Values for Drilling Operations Near WIPP Site," Data Used in Preliminary Performance Assessment of the Waste Isolation Pilot Plant (1990). SAND89-2408. R.P. Rechard, H.J. Iuzzolino, and J. Sandha. Albuquerque, NM: Sandia National Laboratories. A-157 through A-164.

Bodziony, J., A. Nelicki, and J. Topolnicki. 1989. "Results of Laboratory Investigations of Gas and Coal Outbursts," Archiwum Gornictwa. Vol. 34, no. 3, 581-591.

Bratli, R. K., and R. Risnes. 1981. "Stability and Failure of Sand Arches," SPEJ, Society of Petroleum Engineers Journal. Vol. 21, no. 2, 236-248.

Broc, R., ed. 1982. Drilling Mud and Cement Slurry Rheology Manual. Houston, TX: Gulf Publishing Company.

Cheatham, J. B., Jr. 1984. “Wellbore Stability,” JPT, Journal of Petroleum Technology. Vol. 36, no. 7, 889896.

Coleman, B.D., and W. Noll. 1959. "Helicai Flow of General Fluids," Journal of Applied Physics. Vol. 30, no. $10,1508-1515$.

Darley, H.C.H. 1969. "A Laboratory Investigation of Borehole Stability," JPT, Journal of Petroleum Technology. Vol. 21, no. 7, 883-892.

Darley, H.C.H., and G.R. Gray. 1988. Composition and Properties of Drilling and Completion Fluids. Houston, TX: Gulf Publishing Company. 243.

Detournay, E., and A. H-D. Cheng. 1988. "Poroelastic Response of a Borehole in a Non-hydrostatic Stress Field," International Journal of Rock Mechanics and Mining Sciences and Geomechanics Abstracts. Vol. 25, no. 3, 171-182.

Fanchi, J.R., J.E. Kennedy, and D.L. Dauben. 1987. BOAST II: A Three-Dimensional, Three-Phase Black Oil Applied Simulation Tool. DOE/BC-88/2/SP. Tulsa, OK: K and A Technology.

Fredrickson, A.G. 1960. "Helical Flow of an Annular Mass of Visco-Elastic Fluid," Chemical Engineering Science. Vol. 11, no. 3, 252-259. 
Hall, C. D., Jr., and W.H. Harrisberger. 1970. "Stability of Sand Arches: A Key to Sand Control," JPT, Journal of Petroleum Technology. Vol. 22, July 1970, 821-829.

Mills, P.G. 1984. Blowout Prevention Theory and Applications. Boston, MA: International Human Resources Development Corporation. 27-28.

Nakken, S. J., T.L. Christensen, R. Marsden, and R.M. Holt. 1989. "Mechanical Behaviour of Clays at High Stress Levels for Wellbore Stability Applications," Proceedings, Rock at Great Depth, International Symposium of Rock Mechanics, Pau, France, August 28-31, 1989. Eds. V. Maury and D. Fourmaintraux. Boston, MA: A. A. Balkema. Vol. 1, 141-148.

Oldroyd, J.G. 1958. "Non-Newtonian Effects in Steady Motion of Some Idealized Elastico-Viscous Liquids," Proceedings of the Royal Society of London. Series A, Vol. 245, no. 1241, 278-297.

Pace, B.O. 1990. Appendix A, "Letter 1b: Changes to Bar Graphs," Data Used in Preliminary Performance Assessment of the Waste Isolation Pilot Plant (1990). SAND89-2408. R.P. Rechard, H.J. Iuzzolino, and J. Sandha. Albuquerque, NM: Sandia National Laboratories. A-165 through A-170.

Partheniades, E., and R.E. Paaswell. 1970. "Erodibility of Channels with Cohesive Boundary," Journal of the Hydraulics Division, Proceedings of the American Society of Civil Engineers. Vol. 96, no. HY3, 755771.

Paterson, L. 1986. "Technical Note: A Model for Outbursts in Coal," International Journal of Rock Mechanics and Mining Sciences and Geomechanics Abstracts. Vol. 23, no. 4, 327-332.

Risnes, R., R.K. Bratli, and P. Horsrud. 1982. "Sand Stresses Around a Wellbore," SPEJ, Society of Petroleum Engineers Journal. Vol. 22, no. 6, 883-898.

Roegiers, J. C. 1989. "Stability and Failure of Circular Openings," Proceedings, Rock at Great Depth, International Symposium of Rock Mechanics, Pau, France, August 28-31, 1989. Eds. V. Maury and D. Fourmaintraux. Boston, MA: A.A. Balkema. Vol. 3, 1115-1122.

Rudeen, D.K., and J.S. Rath. 1986. SAMSON2, A Nonlinear Two-Dimensional Structure-Media Interaction Computer Code: User's Manual (Revised).* WA11-4. Albuquerque, NM: New Mexico Engineering Research Institute.

Sargunam, A., P. Riley, K. Arulanandan, and R.B. Krone. 1973. "Physico-Chemical Factors in Erosion of Cohesive Soils," Journal of the Hydraulics Division, Proceedings of the American Society of Civil Engineers. Vol. 99, no. HY3, 555-558.

\footnotetext{
* Copy on file in the Waste Management and Transportation Library, Sandia National Laboratories, Albuquerque, NM.
} 
Sato, K., and K. Itakura. 1989. "The Occurrence and Mechanism of Outbursts in Sandstone," Proceedings, Rock at Great Depth, International Symposium of Rock Mechanics, Pau, France, August 28-31, 1989. Eds. V. Maury and D. Fourmaintraux. Boston, MA: A.A. Balkema. Vol. 2, 635-641.

Savins, J.G., and G.C. Wallick. 1966. "Viscosity Profiles, Discharge Rates, Pressures, and Torques for a Rheologically Complex Fluid in a Helical Flow," A.I.Ch.E. Journal. Vol. 12, no. 2, 357-363.

Shepherd, J., L.K. Rixon, and L. Griffiths. 1981. "Rock Mechanics Review - Outbursts and Geological Structures in Coal Mines: A Review," International Journal of Rock Mechanics and Mining Sciences and Geomechanics Abstracts. Vol. 18, no. 4, 267-283.

Short, J.A. 1982. Drilling and Casing Operations. Tulsa, OK: PennWell Books. 183-184.

Stein, N., and D.W. Hilchie. 1972. "Estimating the Maximum Production Rate Possible from Friable Sandstones Without Using Sand Control," Journal of Petroleum Technology. Vol. 24, no. 9, 1157-1160.

Streeter, V.L. 1958. Fluid Mechanics. 2nd ed. New York, NY: McGraw-Hill.

Ujihira, M., K. Higuchi, and H. Nabeya. 1985. "Scale Model Studies and Theoretical Considerations on the Mechanism of Coal and Gas Outbursts," 21st International Conference of Safety in Mines, Sydney, Australia, October 21, 1985. Boston, MA: A.A. Balkema. 121-128.

Vardoulakis, I., J. Sulem, and A. Guenot. 1988. "Borehole Instabilities as Bifurcation Phenomena," International Journal of Rock Mechanics and Mining Sciences and Geomechanics Abstracts. Vol. 25, no. 3, 159-170.

Vaziri, H.H. 1989. “A Procedure for Analysing Seepage-Induced Collapse of Weakly-Cemented Formations," Proceedings, Rock at Great Depth, International Symposium of Rock Mechanics, Pau, France, August 28-31, 1989. Eds. V. Maury and D. Fourmaintraux. Boston, MA: A. A. Balkema. Vol. 2, 799-807.

Walker, R.E. 1976. "Hydraulic Limits are Set by Flow Restrictions," The Oil and Gas Journal. Vol. 74, no. $40,86-90$.

Walker, R.E., and W.E. Holman. 1971. "Computer Program Predicting Drilling-Fluid Perfornance," The Oil and Gas Journal. Vol. 69, no. 13, 80-90.

Whittaker, A., ed. 1985. Theory and Application of Drilling Fluid Hydraulics. Boston, MA: International Human Resources Development Corporation.

Willis, C. 1978. "Rocky Mountain Coal Seams Call for Special Drilling Techniques," The Oil and Gas Journal. Vol. 76, no. 28, 143-152. 
WIPP Performance Assessment Division (WIPP PA Division). 1991a. Preliminary Comparison with 40 CFR Part 191, Subpart B for the Waste Isolation Pilot Plant, December 1991, Volume 1: Methodology and Results. SAND91-0893/1. Albuquerque, NM: Sandia National Laboratories.

WIPP Performance Assessment Division (WIPP PA Division). 1991b. Preliminary Comparison with 40 CFR Part 191, Subpart B for the Waste Isolation Pilot Plant, December 1991, Volume 3: Reference Data. SAND91-0893/3. Albuquerque, NM: Sandia National Laboratories. 
APPENDIX A: THE AFWL ENGINEERING MODEL AND ITS USE IN A ONEDIMENSIONAL CODE/CERF1D

THE AFWL ENGINEERING MODEL AND ITS USE IN A ONE-DIMENSIONAL CODE/CERFID

\author{
James E. Bean \\ University of New Mexico \\ Albuquerque, New Hexico 87131
}

May 1983 


\section{APPENDIX A: THE AFWL ENGINEERING MODEL AND ITS USE IN A ONE- DIMENSIONAL CODE/CERFID}

1. Introduction

This note will describe the AFWL Engineering model as it is implemented in the one-dimensional explicit finite difference code CERFID*. Of particular interest is the suggested modification of the code to allow an associated flow rule to be employed and the ramifications such modifications will have on the present framework of the model. It was initial believed that using an associated flow rule would reduce numerical problems experienced in cylindrical and spherical geometries during unloading. It will be shown that these problems are caused not by the flow rule but by allowing large changes of pressure within a time step during unloading and thus encountering the tensile cut-off.

\section{Input}

The input required for the Engineering model in CERFID consists of two parts (Figure 1). The volumetric response is described by a piecewise linear approximation to the mean normal pressure (from now on referred to as pressure) and excess compression curve (both positive in compression) commonly called the hydrostat. The deviatoric response is controlled by the specification of a failure surface.

The description of the hydrostat is made by specifying Bulk modulus for each segment and the pressure to which the segment extends. Three virgin loading slopes defined by BKL1, BKL2, BKL 3 are used up to pressures $P 1, P 2, P 3 H$ respectively. For pressures above $P 3 H$ an exponential function is used based on the value of $B K Z$ and $B K M$. If $B K Z=B K M$ the result is another linear portion.

\footnotetext{
*CERFID is a modified version of WONDY IV a SANDIA Laboratories Code. Modifications basically removed rezone and fracture options, and extra equations of state which were not frequently required.
} 
The unload/reload behavior is linear and is governed by modulus BKU. To prevent generation of energy during a cycle of loading, unloading and reloading, care must be taken so that $B K U \geq \max$ (BKI, BK2, $B K 3)$. Note that unloading from a state of pressure $>P 3 H$ follows the hydrostat provided the final pressure is also >P3H; otherwise BKU is used. The values of excess compression AM1, AM2, AM3, and AMO are computed by the code based on input. Since the Engineering model in CERFID operates with totai strains rather than strain increments the pressure in virgin loading always corresponds to the pressure defined by the hydrostat for the computed excess compression.

The failure surface is isotropic with a circular cross-section in the deviatoric plane. In the $\gamma J_{2}$ vs $P$ plane the surface consisis of a pressure dependent region termed the Drucker-Prager failure surface and a pressure independent portion called the von Mises fallure surface. The Drucker-Prager criterion is basically a 3-D generalization of the Mohr-ioulomb criterion (which is known to be a good criterion for soils) which has corners. The von Mises surface has been used extensively in the study of metals. The input required here is the tensile cutoff, the slope of the Drucker-Prager portions, and the von Mises limit. These are denoted in the code as PMIN, S1, S2 and YZ respectively. Note that for a material with a tensile strength (PMIN<0) it is necessary to have , $S 1 \geq S 2$ to ensure a convex failure surface. If $P M I N=0, S 1$ may be set $=0$. The parameters YO, and PYLD are computed based on input values (Figure $1 \mathrm{~b}$ ).

Other information required by the model is an initial density RHOD. reference sound speed $C \emptyset$, and a single value of Poissons ratio for loading and unloading Pols.

\section{Model Operation}

Since we are considering one-dimensional motion, there exists only one nonvanishing component of displacement. Depending on the particular geometry (rectangular, cylindrical, or spherical) one or more nonzero components of strain exist. Note that in 1-D motion shear stresses and shear strains 
are not considered; therefore the components of stress and strain are the principal components of the respective tensors.

Based on new coordinate positions for each node a new density is computed called RN. Excess compression is defined as

$$
A M=\frac{R N-R H O Q}{R H O Q}
$$

where RHOD is the initial density prior to external loading. In the case of rectangular geometry this corresponds to

$$
A M=\frac{\ell 0-\ell}{\ell}
$$

where $\ell_{0}=$ initial height of specimen

$\ell=$ current height of specimen

which is the change in length with respect to the current length and differs from the conventional engineering strain definition.

Once the new density and the excess compression have been computed, the next step is to determine the pressure. This requires a check to see if the material is in virgin loading or in a unload/reload state. This is done by keeping track of the maximum excess compression previously experienced $(A M X)$. Thus if $A M>A M X$ the material is in virgin loading. If $A M<A M X$ it may be unloading or reloading. With this information the new pressure (PN) can be computed.

The next step is to compute the individual stress components. This is done by computing the stress deviators while assuming the total strain rate increment is elastic, i.e.

$$
s_{i}^{t}{ }^{n+1}=s_{i}^{n}+2 G \overbrace{\dot{\mathrm{e}}}^{\text {assumed elastic }} \Delta t \quad i=s, 2,3
$$


where

$$
\begin{aligned}
& S_{i}^{t}{ }^{n+1}=\text { trial deviatoric stress } \\
& S_{i}^{n}=\text { deviatoric stress at previous step } \\
& G=\text { shear modulus - computed based on appropriate BKL/or } \\
& \text { BKU and Poissons ratio } \\
& \Delta t=\text { time step } \\
& d \dot{e}_{i}=\text { deviatoric strain rate increment }
\end{aligned}
$$

The trial stress deviators can be used to complete the second invariant of the deviatoric stress tensor $j_{2}^{\prime}$

$$
J_{2}^{\prime}=\frac{1}{2}\left(s_{1}^{t_{2}}+s_{2}^{t_{2}}+s_{3}^{t_{2}}\right)
$$

Comparing this value with the limit value determined from the failure surface at the computed pressure, one can adjust the deviators if the value computed based on trial state is greater than that allowed by the limit surface. This is done by employing

$$
s_{i}=r s_{i}^{t}
$$

for $i=1,2,3$ where $r$ is a constant computed to bring the state of stress back to the failure surface

Once the deviators are known the stress may be computed from

$$
\sigma_{i}=S_{i}-P N \text { for } i=1,2,3
$$

where $\sigma_{i}$, and $S_{i}$ are positive in tension.

The scheme used to correct back to the failure surface is shown in Figure 2. This method has been called elastic prediction radial corrector 
algorithm and has been studied from a numerical error standpoint by Krieg \& Xrieg for the von Mises failure surface (Ref. 1).

Had the material unloaded to a state whereby the tensile limit was exceeded (PN<PMIN) then the deviatoric stresses are set to zero and each compunent of stress is set to the tensile limit.

\section{Theoretical Consideration}

The use of a pressure-volume relationship which yields permanent defornation on unloading implies that there exists a yield surface that expands outward as the pressure increases. Thi's concept of a "cap" yield surface has been in use for many years and was introduced by Drucker, Gibson and Henkel in 1957 (Ref. 2). The actual shape of the cap has often been the point in question. Spherical shapes and ellipses have been used. The cap in the Engineering model is a plane normal to the pressure axis. This implies that the pressure volume response for the material is identical for a variety of stress paths involving monotonically increasing pressure (Figure 3 ). This is known not to be valid for frictional materials such as soil, concrete and rock. For example, experimental results from isotropic compression tests and uniaxial strain tests where the lateral stresses are measured typically show shear enhanced compaction (Figure 4). The flow rule used for the deviatoric response is known as the Prandtl-Reuss rule and implies that the plastic strain increment vector is normal to a surface which is a cylinder with axis coinciding with the p-axis. This implies no volumetric contribution from the portion of the total plastic strain increment associated with the failure surface. Therefore materials which show volume increase during shear may not be accurately represented by the model. This may not be too bad since the pressures usually considered are high enough such that the soil may not dilate during shear, i.e., even dense sands may compact during shear if the confining stresses are large enough.

Since the deviatoric response and the volumetric response are treated separately in the Engineering model, rules for loading at the intersection of the cap and the failure surface are required. Koiter ( $\operatorname{Re}^{-} 3$ ) 
The AFWL Engineering Model and Its Use in a One-Dimensional Code/CERF1D

has shown for yield surfaces which act independently that the total plastic strain increment may be written as a sum of contributions from the laws associated with the different surfaces.

\section{Consider the following cases:}

For states of stress below the failure surface only volumetric inelastic response is computed. The concept of associated flow rule (normality) to the plane cap are satisfied here since the normal to the cap has only a component in the p-direction. Thus an associated flow rule is used for volumetric response (Figure 5).

For the cases shown in Figure 6 where the intersection of the failure surface and the cap form a corner the total plastic strain increment would lie somewhere in the quadrant defined by the respective deviatoric and volumetric plastic strain increment vectors. The exact direction is determined by the relative magnitude of each component. This appears to be consistent with Koiters definitions.

Now consider the case of a material element that has been previously loaded and is now unloaded to a state of stress intersecting the DruckerPrager portion of the failure surface (Figure 7 ). Since the Engineering model treats unload-reload as elastic the cap does not collapse. (i.e. no inelastic volumetric strain occurs in unloading). The use of the Prandt1-Reuss rule here implies that an non-associated flow rule is being employed since the plastic strain increment by definition has only a deviatoric component. Here we do not have a corner and the use of an associated rule (normality) would contradict the basic assumption that unload-relocd volumetric behavior is elastic since the plastic strain-increment vector wouid necessarily have a component in the negative p-direction. (Note that unloading to a state of stress intersecting the von Mises surface produces a response consistent with an associated flow rule.)

5. Source of Difficulties in Cylindrical \& Spherical Test

Since the unload slope of the hydrostat is typically large compared to the virgin loading slopes, relatively small changes in the excess 
compression may make large jumps in the pressure. The large decreases in pressure often cause the tensile cut-off pressure to be exceeded and the correction made by the model is to set the stress deviators to zero and thus the stress components to PMIN. Thus the problems are being caused by large changes in the state of stress of an element/cell over a single time step rather than the flow rule in use. The size of the step introduces numerical errors which have teen discussed by Krieg \& Krieg. The solution would appear to be to reduce the time step, so that the material will yield smoothly. However, it would probably require some sort of subcycling through the equations of motion if large steps were occuring. This would not be a trivial task to correctly implement.

\section{Conclusion}

While the Engineering Model may not be capable of accurately predicting the response of soils for all stress paths it should be quite capable for paths close to uniaxial strain (Note that this does not include cylindrical and spherical geometries since hoop strains are present). It appears that the use of the Prandt1-Reuss rules for the failure surface is entirely consistent with the manner in which the hydrostatic response in handled, i.e., elastic unload-reload. The use of an associated rule for the occasion when the Drucker-Prager surface is encountered in unloading wou?d require a reformulation of the model in terms of the volumetric behavior. 


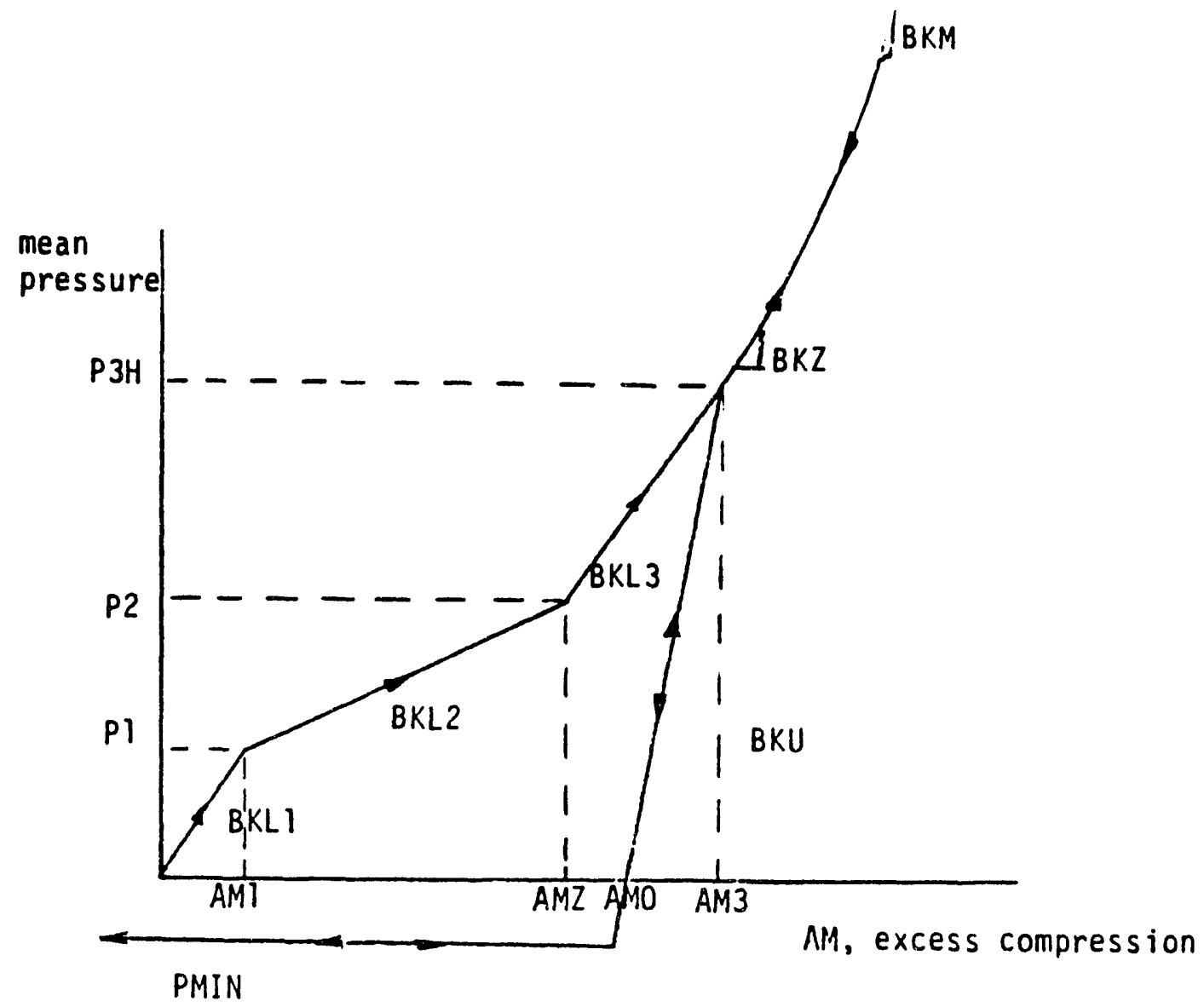

Figure la. Hydrostat

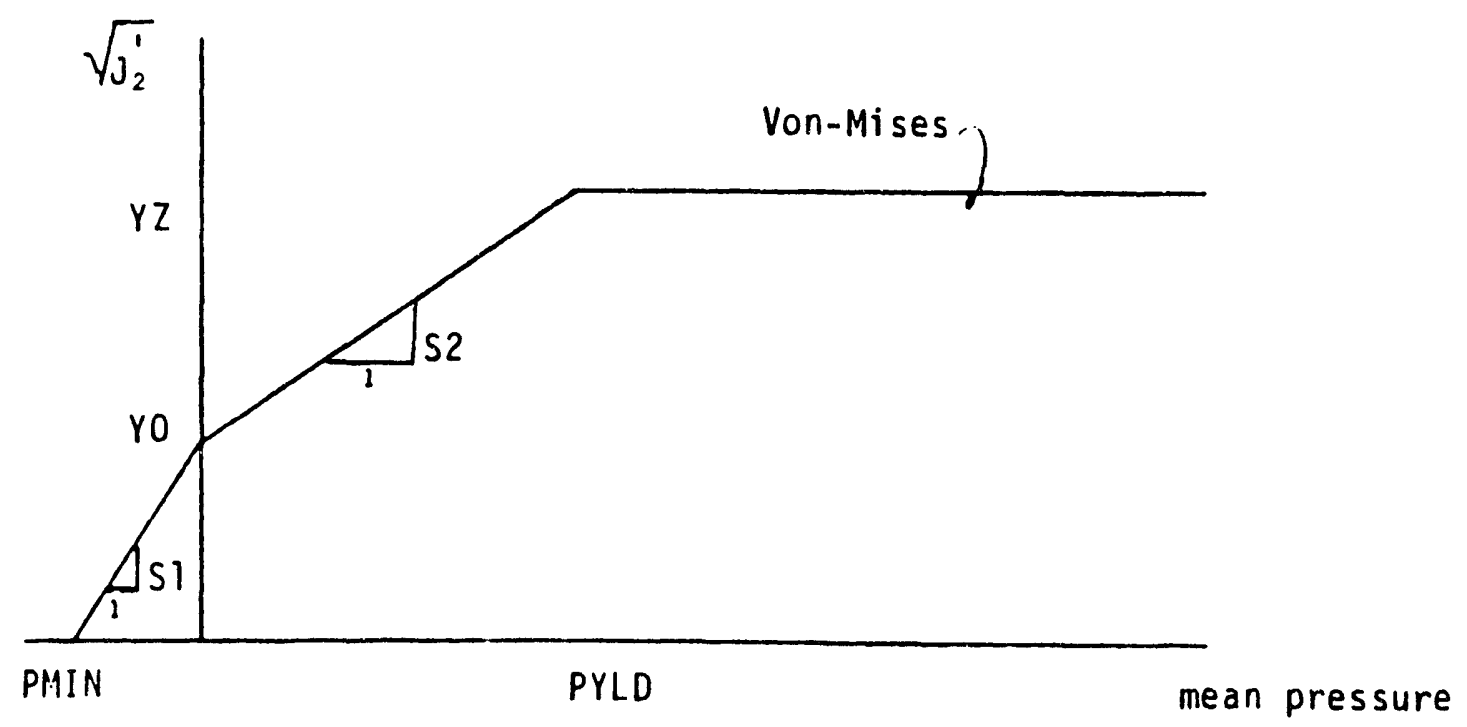

Figure lb. Failure surface 


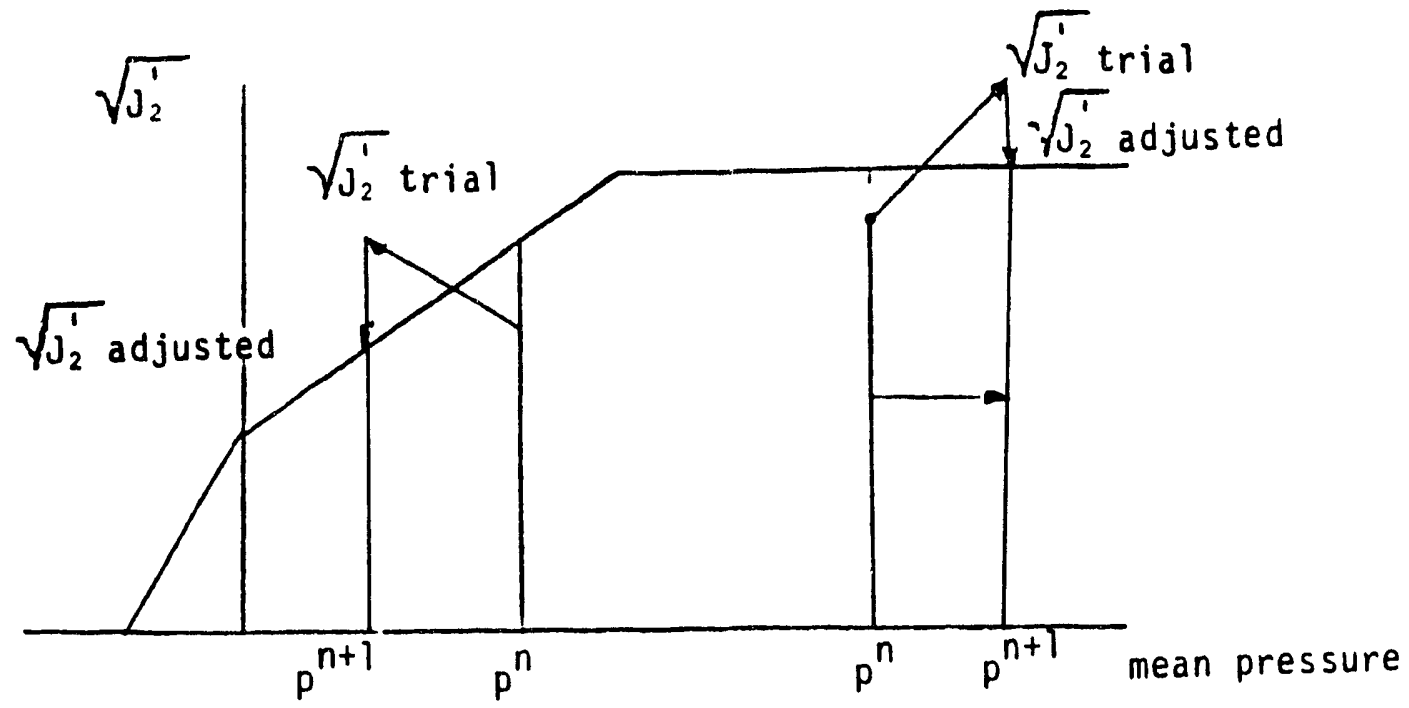

Figure 2. Correction scheme

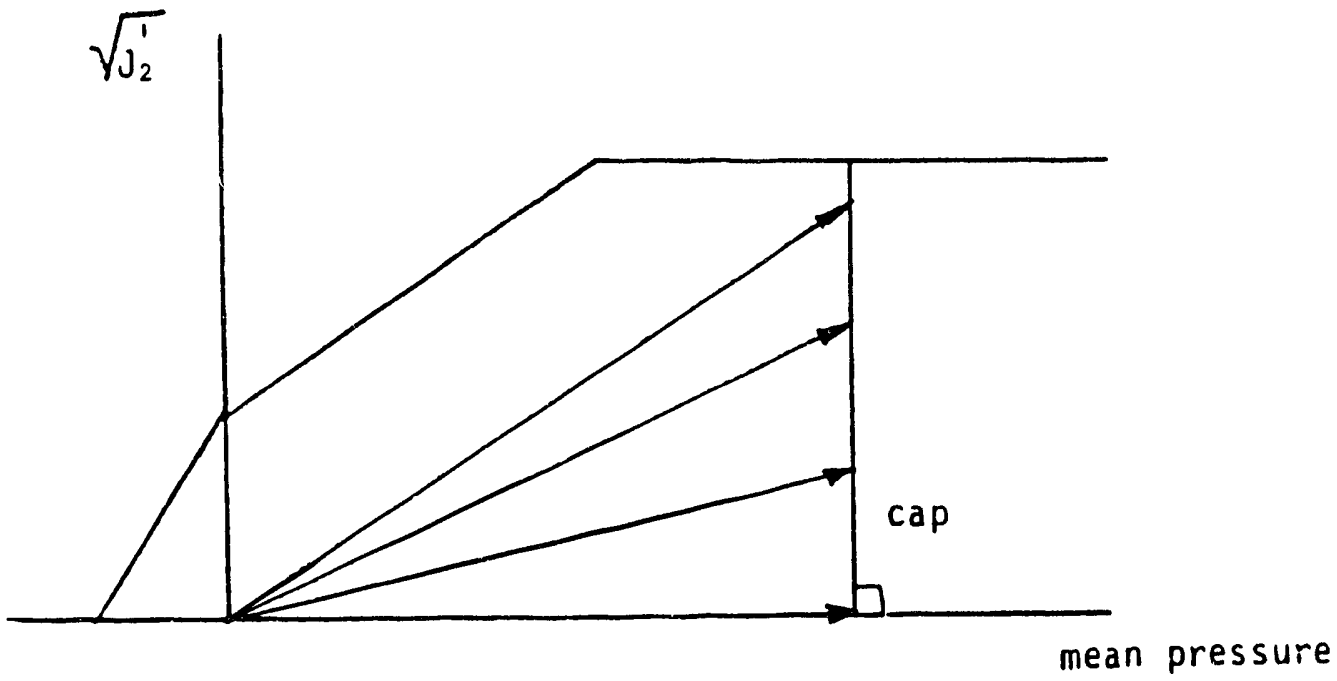

Figure 3. Different proportional loading paths which predict identical volumetric response. 


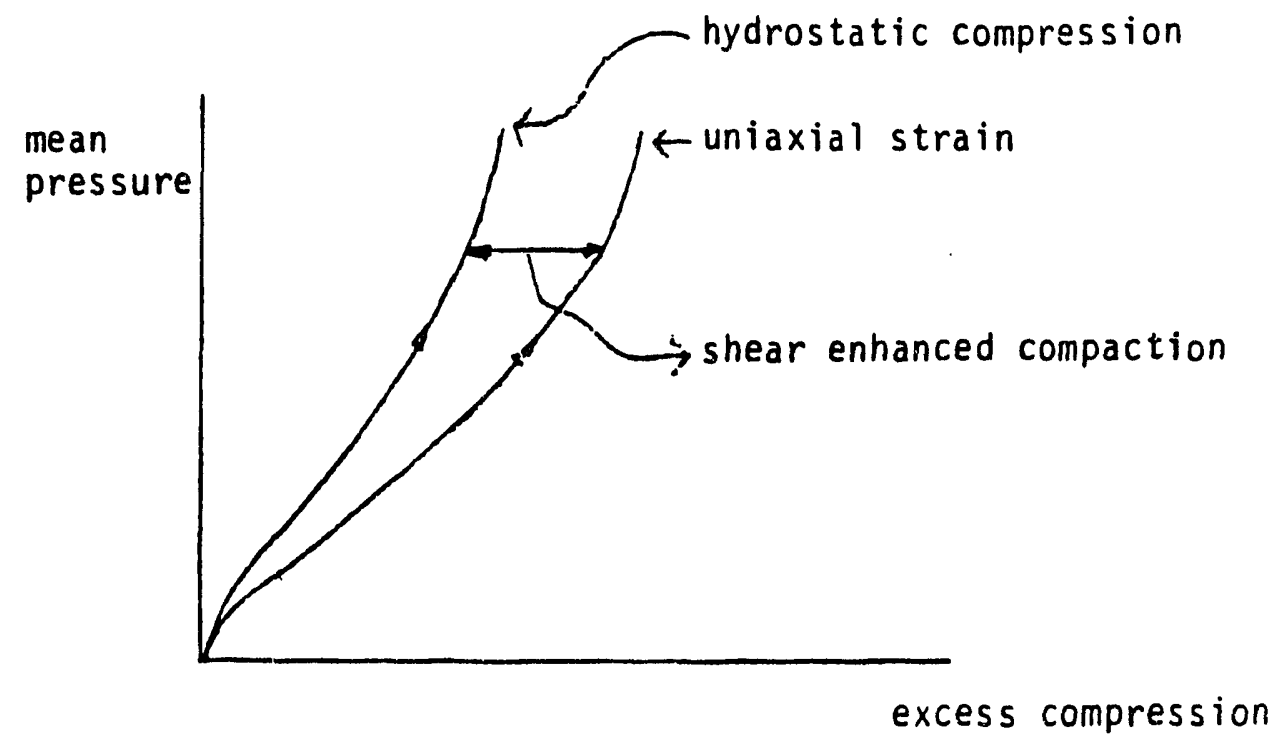

Figure 4. Comparison of typical response for frictional materials.

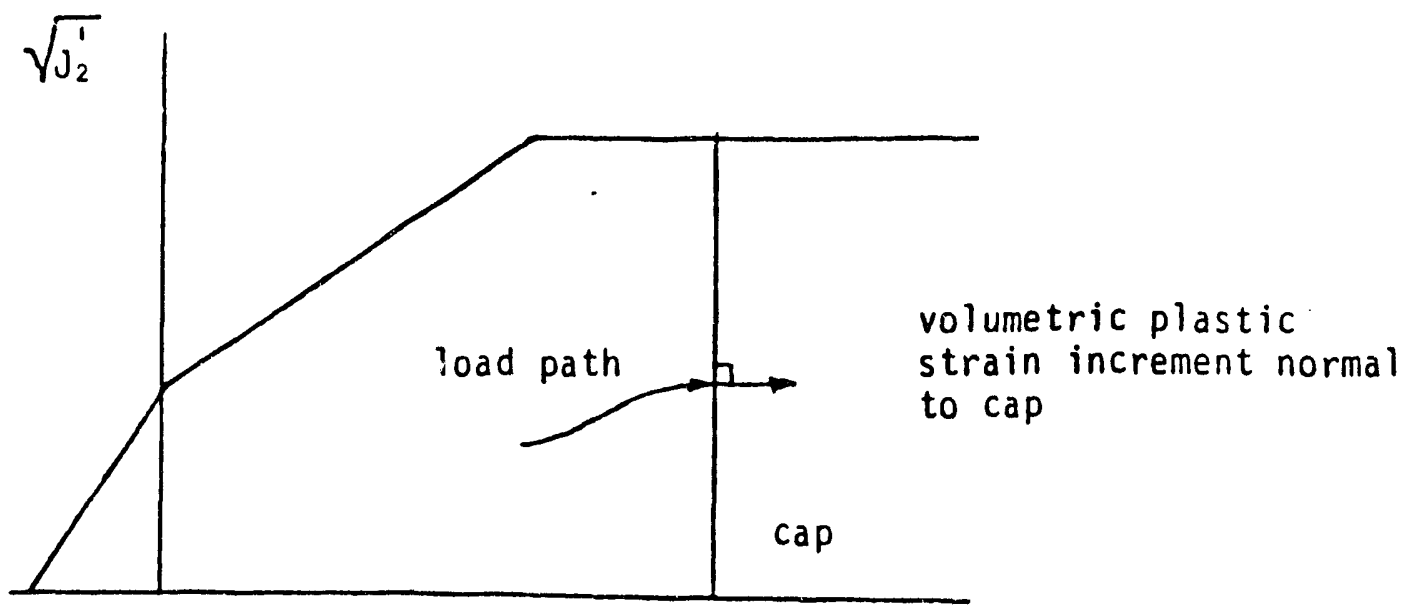

mean pressure

Figure 5. Response governed by cap. Normality satisfied. 


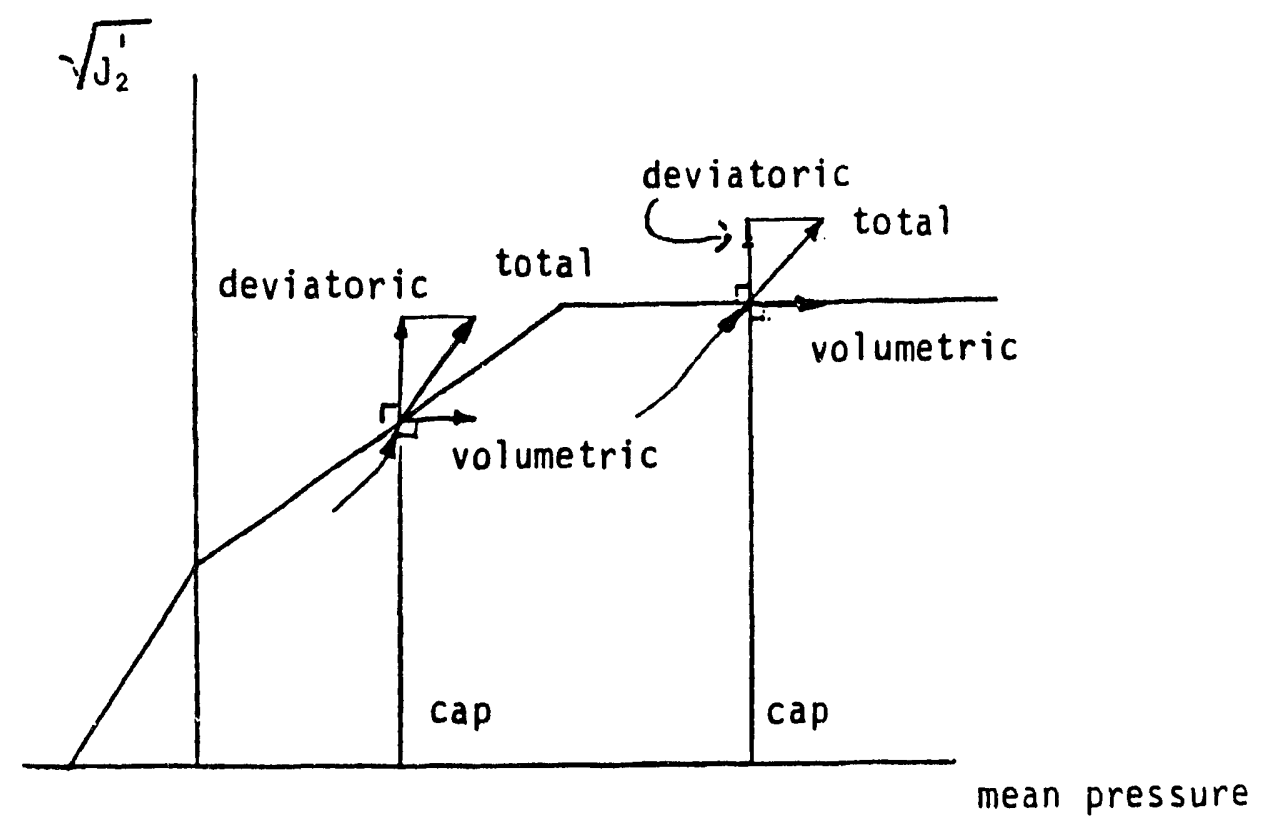

Figure 6. Loading into a corner for 2 different stress paths - definition of plastic strain increment components.

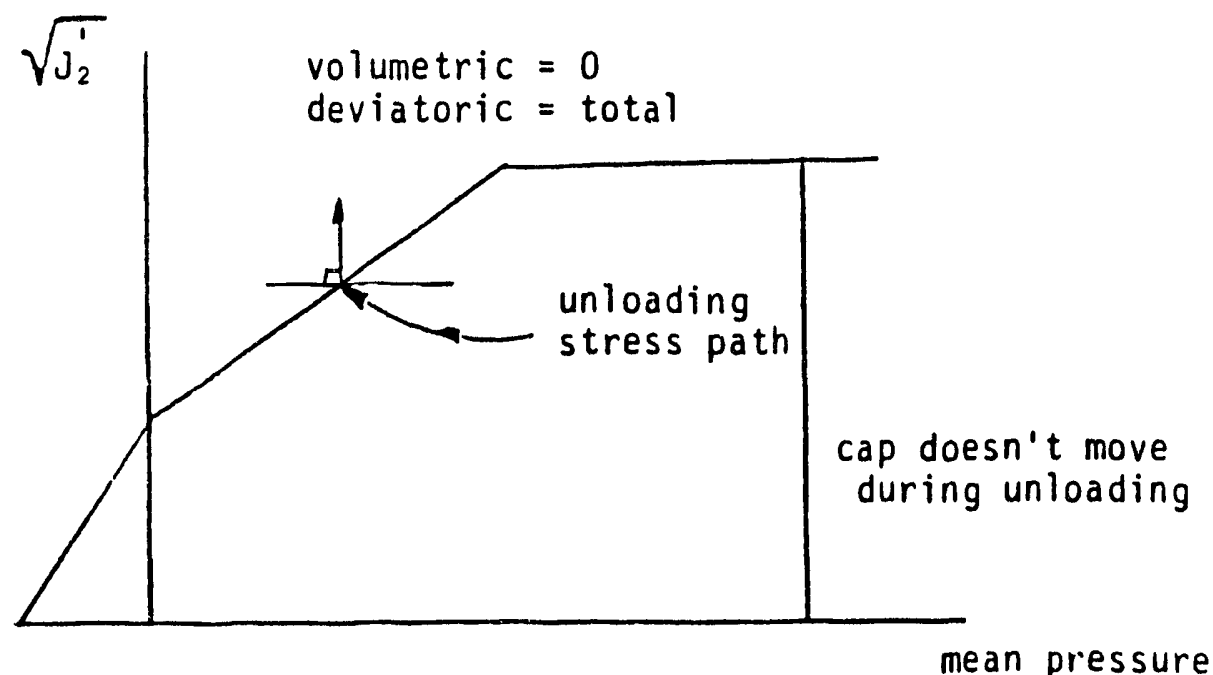

Figure 7. Definition of plastic strain increment for unloading while encountering the DruckerPrager surface. 
The AFWL Engineering Model and lts Use in a One-Dimensional Code/CERF1D

\section{REFERENCES}

1. Krieg, R. D., and Krieg, D. B., "Accuracies of Numerical Solution Methods for the Elastic-Perfectly Plastic Hodel", Journal of Pressure Vessel Technology, Vol. 99, November 1977.

2. Drucker, D. C., Gibson, R. E., and Henke1, D. J., "Soil Mlechanics and Work Hardening Theories of Plasticity". Transactions of ASCE Vol. 122, pp 338-346, 1957.

3. Koiter, W. T. , "Stress-Strain Relations, Uniqueness and Variational Theorems for Elastic-Plastic Materials with a Singular Yield Surface", Quarterly Applied Mathematics, 11, pp 350-354, 1953. 


\section{PERFORMANCE ASSESSMENT DISTRIBUTION LIST}

(Send Distribution list changes to M.M. Gruebel, Dept. 6342, Sandia

National Laboratories, PO Box 5800, Albuquerque, NM 87185-5800)

\section{Federal Agencies}

US Department of Energy (2)

office of Environmental Restoration and Waste Management

Attn: L.P. Duffy, EM-1

C. Frank, EM-50

Washington, DC 20585

US Department of Energy (3)

Office of Environmental Restoration and Waste Management

Attn: M. Frei, EM-34 (Trevion II)

Director, Waste Management Projects

Washington, DC 20585-0002

US Department of Energy

Office of Environmental Restoration and Waste Management

Attn: J. Lytle, EM-30 (Trevion II)

Washington, DC 20585-0002

US Department of Energy

Office of Environmental Restoration and Waste Management

Attn: S. Schneider, EM-342

(Trevion II)

Washington, DC 20585-0002

US Department of Energy

WIPP Task Force

Attn: G.H. Daly

S. Fucigna

B. Bower

12800 Middlebrook Rd.

Suite 400

Germantown, MD 20874

US Department of Energy (4)

Office of Environment, Safety and Health

Attn: R.P. Berube, EH-20

C. Borgstrum, EH-25

R. Pelletier, EH-231

K. Taimi, EH-232

Washington, DC 20585
US Department of Energy (5)

WIPP Project Integration office

Attn: W.J. Arthur III

R. Becker

P. Dickman

L.W. Gage

P.J. Higgins

D A. Olona

PO Box 5400

Albuquerque, NM 87115-5400

US Department of Energy (10)

WIPP Project Site Office (Carlsbad)

Attn: A. Hunt (4)

V. Daub (4)

$\mathrm{J}$. Lippis

$\mathrm{K}$. Hunter

PO Box 3090

Carlsbad, NM 88221-3090

US Department of Energy, (5)

Office of Civilian Radioactive Waste Management

Attn: Deputy Director, RW-2

Associate Director, RW-10

Office of Program

Administration and

Resources Management

Associate Director, RW-20

office of Facilities

Siting and Development

Associate Director, RW-30

Office of Systems

Integration and

Regulations

Associate Director, RW-40

Office of External

Relations and Policy

Office of Geologic Repositories

Forrestal Building

Washington, DC 20585

US Department of Energy

Attn: National Atomic Museum Library

Albuquerque Operations office

PO Box 5400

Albuquerque, NM 87185 
US Department of Energy

Research \& Waste Management Division

Attn: Director

PO Box E

Oak Ridge, TN 37831

US Department of Energy (2)

Idaho Operations office

Fuel Processing and Waste

Management Division

785 DOE Place

Idaho Falls, ID 83402

US Department of Energy

Savannah River Operations Office

Defense Waste Processing

Facility Project office

Attn: W.D. Pearson

PO Box A

Aiken, SC 29802

US Department of Energy (2)

Richland Operations office

Nuclear Fuel Cycle \& Production

Division

Attn: R.E. Gerton

$825 \mathrm{~J}$ adwin Ave.

PO Box 500

Richland, WA 99352

US Department of Energy (3)

Nevada Operations Office

Attn: J.R. Boland

D. Livingston

P.K. Fitzsimmons

2753 S. Highland Drive

Las Vegas, NV 89183-8518

US Department of Energy (2)

Technical Information Center

PO Box 62

Oak Ridge, TN 37831

US Department of Energy (2)

Chicago Operations office

Attn: J.C. Haugen

9800 South Cass Avenue

Argonne, IL 60439

US Department of Energy

Los Alamos Area Office

52835 th Street

Los Alamos, NM 87544
US Department of Energy

Rocky Flats Area Office

(3)

Attn: W.C. Rask

G. Huffman

$T$. Lukow

PO Box 928

Golden, CO 80402-0928

US Department of Energy

Dayton Area Office

Attn: R. Grandfield

PO Box 66

Miamisburg, OH 45343-0066

US Department of Energy

Attn: E. Young

Room E-178

GAO/RCED/GTN

Washington, DC 20545

US Bureau of Land Management

101 E. Mermod

Carlsbad, NM 88220

US Bureau of Land Management

New Mexico State Office

PO Box 1449

Santa Fe, NM 87507

US Environmental Protection

Agency (2)

office of Radiation Protection

Programs

ANR -460

Washington, DC 20460

US Nuclear Regulatory Commission

Division of Waste Management

Attn: H. Marson

Mail. Stop 4-H-3

Washington, DC 20555

US Nucle.rr Regulatory Commission (4)

Advisory Committee on Nuclear Waste

Attn: D. Moeller

M.J. Steindler.

P.W. Pomeroy

W.J. Hinze

7920 Norfolk Ave.

Bethesda, MD 20814 
Defense Nuclear Facilities Safety Board

Attn: D. Winters

625 Indiana Ave. NW

Suite 700

Washington, DC 20004

Nuclear Waste Technical Review Board (2)

Attn: Library

1100 Wilson Blvd., Suite 910

Arlington, VA 22209-2297

Energy and Science Division Office of Management and Budget

Attn: K. Yuracko

72517 th Street NW

Washington, DC 20503

US Geological Survey (2)

Water Resources Division

Attn: C. Peters

4501 Indian School NE

Suite 200

Albuquerque, NM 87110

\section{State Agencies}

New Mexico Bureau of Mines

and Mineral Resources

Socorro, NM 87801

New Mexico Energy, Minerals and

Natural Resources Department

Attn: Librarian

2040 South Pacheco

Santa Fe, NM 87505

New Mexico Energy, Minerals and Natural Resources Department

New Mexico Radioactive Task Force (2)

(Governor's WIPP Task Force)

Attn: A. Lockwood, Chairman

C. Wentz, Policy Analyst

2040 South Pacheco

Santa Fe, NM 87505

Bob Forrest

Mayor, City of Carlsbad

PO Box 1569

Carlsbad, NM 88221
Executive Director

Carlsbad Department of Development

Attn: C. Bernard

PO Box 1090

Carlsbad, NM 88221

New Mexico Environment Department Secretary of the Environment (3)

Attn: J. Espinosa

PO Box 968

1190 St. Francis Drive

Santa Fe, NM 87503-0968

New Mexico Environment Department

Attn: P. McCasland

WIPP Project Site Office

PO Box 3090

Car1sbad, NM 88221-3090

New Mexico State Engineer's Office Attn: M. Chudnoff

PO Box 25102

Santa Fe, NM 87504-5102

Environmental Evaluation Group (5)

Attn: R. Neill

7007 Wyoming Blvd. NE

Suite F-2

Albuquerque, NM 87109

\section{Advisory Committee on Nuclear Facility Safety}

John F. Ahearne

Executive Director, Sigma Xi

99 Alexander Drive

Research Triangle Park, NC 27709

James E. Martin

109 Observatory Road

Ann Arbor, MI 48109

\section{WIPP Panel of National Research Council's Board on Radioactive Waste Management}

Charles Fairhurst, Chairman

Department of Civil and

Mineral Engineering

University of Minnesota

500 Pillsbury Dr. SE

Minneapolis, MN 55455-0220 
John 0. Blomeke

3833 Sandy Shore Drive

Lenoir City, TN 37771-9803

John D. Bredehoeft

Western Region Hydrologist

Water Resources Division

US Geological Survey ( $M / S$ 439)

345 Middlefield Road

Menlo Park, CA 94025

Fred M. Ernsberger

1325 NW 10th Avenue

Gainsville, FL 32601

Rodney C. Ewing

Department of Geology

University of New Mexico

200 Yale NE

Albuquerque, NM 87131

B. John Garrick

PLG, Inc.

Suite 400

4590 MacArthur Blvd.

Newport Beach, CA 92660-2027

Leonard F. Konikow

US Geological Survey

431 National Center

Reston, VA 22092

Jeremiah 0'Driscoll

505 Valley Hill Drive

Atlanta, GA 30350

Christopher Whipple

Clement International Corp.

160 Spear St.

Suite 1380

San Francisco, CA 94105-1535

National Research Council (3)

Board on Radioactive

Waste Management

RM HA456

Attn: P.B. Myers (2)

G.J. Grube

2101 Constitution Ave.

Washington, DC 20418

\section{Performance Assessment Peer Review Panel}

G. Ross Heath

College of Ocean and

Fishery Sciences, HN-15

583 Henderson Hall

University of Washington

Seattle, WA 98195

Thomas H. Pigford

Department of Nuclear Engineering

4159 Etcheverry Hall

University of California

Berkeley, CA 94720

Thomas A. Cotton

JK Research Associates, Inc.

4429 Butterworth Place NW

Washington, DC 20016

Robert J . Budnitz

President, Future Resources

Associates, Inc.

2000 Center Street

Suite 418

Berkeley, CA 94704

C. John Mann

Department of Geology

245 Natural History B1dg.

1301 West Green Street

University of Illinois

Urbana, IL 61801

Frank W. Schwartz

Department of Geology and Mineralogy

The Ohio State University

Scott Hall

1090 Carmack Rd.

Columbus, $\mathrm{OH} \quad 43210$

\section{National Laboratories}

Argonne National Laboratory (2)

Attn: A. Smith

D. Tomasko

9700 South Cass

B1dg. 201

Argonne, IL 60439 
Battelle Pacific Northwest Laboratory

(3)

Attn: R.E. Westerman

S. Bates

H.C. Burkholder

Battelle Boulevard

Richland, WA 99352

Idaho National. Engineering Laboratory

(2)

Attn:

H. Loo

R. K1 inger

Mail Stop 5108

Idaho Falls, ID 83403-4000

Los Alamos National Laboratory

Attn: B. Erda1, CNC-11

PO Box 1663

Los Alamos, NM 87545

Los Alamos National Laboratory

Attn: A. Meijer

PO Box 1663, Mail Stop J514

Los Alamos, NM 87545

Los Alamos National Laboratory (3) HSE - 8

Attn: M. Enoris

L. Soholt

$\mathrm{J}$. Wenze1

PO Box 1663

Los Alamos, NM 87545

Los Alamos National Laboratory EM-7

Attn: S. Kosiewicz

PO Box 1663, Mail Stop J595

Los Alamos, NM 87545

Oak Ridge National Laboratory

Transuranic Waste Manager

Attn: D.W. Turner

PO Box 2008

Bldg. 3047

Oak Ridge, TN 37831-6060

Pacific Northwest Laboratory

Attn: B. Kennedy

PO Box 999

Richland, WA 99352
Savannah River Laboratory (3)

Attn: N. Bibler

M.J. Plodinec

G.G. Wicks

Aiken, SC 29801

Savannah River Plant (2)

Attn: R.G. Baxter B1dg. 704-S

K.W. Wierzbicki

Bldg. $703-\mathrm{H}$

Aiken, SC 29808-0001

\section{Corporations/Members of the Public}

Benchmark Environmental Corp.

Attn: C. Frederickson

4501 Indian School NE

Suite 105

Albuquerque, NM 87110

City of Albuquerque

Public Works Department

Utility Planning Division

Attn: W.K. Summers

PO Box 1293

Albuquerque, NM 87103

Deuel and Associates, Inc.

Attn: R.W. Prindle

7208 Jefferson NE

Albuquerque, NM 87109

Disposal Safety, Inc.

Attn: B. Ross

$1660 \mathrm{~L}$ Street NW

Suite 314

Washington, DC 20036

Ecodynamics (2)

Attn: P. Roache

R. Blaine

PO Box 9229

Albuquerque, NM 87119.9229

EG \& G Idaho (3)

1955 Fremont Street

Attn: C. Atwood

C. Hertzler

T.I. Clements

I Uaho Falls, ID 83415 
Geomatrix

Attn: K. Coppersmith

100 Pine street, Suite 1000

San Francisco, CA 94111

Golder Associates, Inc. (3)

Attn: M. Cunnane

R. Kossik

I. Miller

4104 148th Avenue NE

Redmond, WA 98052

INTERA, Inc.

Attn: A.M. LaVenue

1650 University B1vd. NE

Suite 300

Albuquerque, NM 87102

INTERA, Inc.

Attn: J.F. Pickens

6850 Austin Center Blvd.

Suite 300

Austin, TX 78731

INTERA, Inc.

Attn: W. Stensrud

PO Box 2123

Carlsbad, NM 88221

INTERA, Inc .

Attn: W. Nelson

101 Convention Center Drive

Suite 540

Las Vegas, NV 89109

IT Corporation (2)

Attn: R.F. Mckinney

$\mathrm{J}$. Myers

Regional office, suite 700

5301 Central Avenue NE

Albuquerque, NM 87108

John Hart and Associates, P.A.

Attn: J.S. Hart

2815 Candelaria Road NW

Albuquerque, NM 87107

John Hart and Associates, P.A.

Attn: K. Lickliter

1009 North Washington

Tacoma, WA 98406
MACTEC (2)

Attn: J.A. Thies

D.K. Duncan

8418 Zuni Road SE, Suite 200

Albuquerque, NM 87108

Newman and Holtzinger

Attn: C. Mallon

1615 L Street NW, Suite 1000

Washington, DC 20036

RE/SPEC, Inc. (2)

Attn: W. Coons

4775 Indian School NE, Suite 300

Albuquerque, NM 87110

$\mathrm{RE} / \mathrm{SPEC}$, Inc.

Attn: J.L. Ratigan

PO Box 725

Rapid City, SD 57709

Reynolds Elect/Engr. Co., Inc.

Attn: E.W. Kenda11

Building 790, Warehouse Row

PO Box 98521

Las Vegas, NV 89193-8521

Roy F. Weston, Inc.

CRWM Technical Support Team

Attn: C.J. Noronha

955 L'Enfant Plaza SW

North Building, Eighth Floor

Washington, DC 20024

Science Applications International Corporation (SAIC)

Attn: H.R. Pratt

10260 Campus Point Drive

San Diego, CA 92121

Science Applications International Corporation (2)

Attn: D.C.Royer

C.G. Pflum

101 Convention Center Dr.

Las Vegas, NV 89109

Science Applications International Corporation (2)

Attn: M. Davis

J. Tollison

2109 Air Park Road SE

Albuquerque, NM 87106 
Science Applications International Corporation (2)

Attn: J. Young

D. Lester

18706 North Creek Parkway, Suite 110

Bothe11, WA 98011

Southwest Research Institute

Center for Nuclear Waste Regulatory Analys is (2)

Attn: P.K. Nair

6220 Culebra Road

San Antonio, TX 78228-0510

Systems, Science, and Software (2)

Attn: E. Peterson

P. Lagus

Box 1620

La Jolla, CA 92038

TASC

Attn: S.G. Oston

55 Walkers Brook Drive

Reading, MA 01867

Tech Reps, Inc. (6)

Attn: J. Chapman

C. Crawford

D. Marchand

J. Stikar

P. Oliver

D. Scott

5000 Marble NE, Suite 222

Albuquerque, NM 87110

Tolan, Beeson \& Associates

Attn: T.L. Tolan

$232.0 \mathrm{~W}$. 15th Avenue

Kennewick, WA 99337

TRW Environmental Safety Systems (2)

Attn: I. Sacks, Suite 800

L. Wildman, Suite 1300

2650 Park Tower Drive

Vienna, VA 22180-7306

Westinghouse Electric Corporation (5)

Attn: Library

L. Trego

C. Cox

L. Fitch

R.F. Kehrman

PO Box 2078

Carlsbad, NM 88221
Westinghouse Hanford Company

Attn: D.E. Wood

MSIN HO- 32

PO Box 1970

Richland, WA 99352

Western Water Consultants

Attn: D. Fritz

1949 Sugarland Drive \#134

Sheridan, WY 82801-5720

Western Water Consultants

Attn: P.A. Rechard

PO Box 4128

Laramie, WY 82071

P. Drez

8816 Cherry Hills Road NE

Albuquerque, NM 87111

D.W. Powers

Star Route Box 87

Anthony, TX 79821

Shirley Thieda

PO Box 2109, RR1

Bernalillo, NM 87004

Jack Urich

c/o CARD

144 Harvard SE

Albuquerque, NM 87106

\section{Universities}

University of California

Mechanical, Aerospace, and

Nuclear Engineering Department (2)

Attn: W. Kastenberg

D. Browne

5532 Boelter Hall

Los Angeles, CA 90024

University of California

Mine Engineering Dept.

Attn: N. Cook

Rock Mechanics Engineering

Berkeley, CA 94720

University of Hawaii at Hilo

Attn: S. Hora

Business Administration

Hilo, HI 96720-4091 
University of New Mexico

Geology Department

Attn: Library

Albuquerque, NM 87131

University of New Mexico

Research Administration

Attn: H. Schreyer

102 Scholes Hall

Albuquerque, NM 87131

University of Wyoming

Department of Civil Engineering

Attn: V.R. Hasfurther

Laramie, WY 82071

University of Wyoming

Department of Geology

Attn: J.I. Drever

Laramie, WY 82071

University of Wyoming

Department of Mathematics

Attn: R.E. Ewing

Laramie, WY 82071

\section{Libraries}

Thomas Brannigan Library

Attn: D. Dresp

106 W. Hadley St.

Las Cruces, NM 88001

Hobbs Public Library

Attn: M. Lewis

509 N. Ship Street

Hobbs, NM 88248

New Mexico State Library

Attn: N. McCallan

325 Don Gaspar

Santa Fe, NM 87503

New Mexico Tech

Martin Speere Memorial Library

Campus Street

Socorro, NM 87810

New Mexico Junior College

Pannell Library

Attn: R. Hill

Lovington Highway

Hobbs, NM 88240
Carlsbad Municipal Library

WIPP Public Reading Room

Attn: L. Hubbard

$101 \mathrm{~S}$. Halagueno St.

Carlsbad, NM 88220

University of New Mexico

General Library

Government Publications Department

Albuquerque, NM 87131

\section{NEA/Performance Assessment Advisory Group (PAAG)}

P. Duerden

ANSTO

Lucas Heights Research Laboratories

Private Mail Bag No. 1

Menai, NSW 2234

AUSTRALIA

Gordon S. Linsley

Division of Nuclea: Fuel Cycle and

Waste Management

International Atomic Energy Agency

PO Box 100

A-1400 Vienna, AUSTRIA

Nicolo Cadelli

Commission of the European Communities 200, Rue de la Loi

B-1049 Brussels, BELGIUM

R. Heremans

Organisme Nationale des Déchets Radioactifs et des Matiéres Fissiles

ONDRAF

Place Madou 1, Boitec 24/25

B-1030 Brussels, BELGIUM

J. Marivoet

Centre d'Etudes de 1'Energie Nucléaire $\mathrm{CEN} / \mathrm{SCK}$

Boeretang 200

B-2400 Mol, BELGIUM

P. Conlon

Waste Management Division

Atomic Energy Control Board (AECB)

PO Box 1046

Ottawa, Canada KIP 559, CANADA 
A.G. Wikjord

Manager, Environmental and Safety Assessment Branch

Atomic Energy of Canada Limited

Whiteshell Nuclear Research Establishment.

Pinewa, Manitoba ROE 1 LO

CANADA

Jukka-Pekka Salo

Teollisuuden Voima Oy (TVO)

Fredrikinkatu 51-53 B

SF-00100 Helsinki

FINLAND

Timo Vieno

Technical Research Centre of Finland (VTT)

Nuclear Energy Laboratory

PO Box 208

SF-02151 Espoo, FINLAND

Timo Äikäs

Teollisuuden Voima Oy (TVO)

Fredrikinkatu 51-53 B

SF-00100 Helsinki, FINLAND

M. Claude Ringeard

Division de la Sécurité et de la Protection de l'Environment (DSPE)

Commissariat á l'Energie Atomique

Agence Nationale pour la Gestion des Déchets Radioactifs (ANDRA)

Route du Panorama Robert Schuman

B. P. No. 38

F-92266 Fontenay-aux-Roses Cedex

FRANCE

Gérald Ouzounian

Agence Nationale pour la Gestion des Déchets Radioactifs (ANDRA)

Route du Panorama Robert Schuman

B.P. No. 38

F-92266 Fontenay-aux-Roses Cedex

FRANCE

Claudio Pesca re

Division of Radiation Protection and Waste Management

OECD Nuclear Energy Agency

38, Boulevard Suchet

F-75016 Paris, FRANCE
M. Dominique Greneche

Commissariác á l'Energie Atomique IPSN/DAS, /SASICC/SAED

B.P. No. 6

F-92265 Fontenay-aux-Roses Cedex

FRANCE

Robert Fabriol

Bureau de Recherches Géologiques et Miniéres (BRGM)

B.P. 6009

45060 Orléans Cedex 2, FRANCE

P. Bogorinski

Gesellschaft für Reaktorsicherheit (GRS) $\mathrm{mbH}$

Schwertnergasse 1

D-5000 K.öln 1, GERMANY

R. Storck

GSF - Institut für Tieflagerung

Theodor-Heuss-Strabe 4

D-3300 Braunschweig, GERMANY

Ferrucio Gera

ISMES S.p.A

Via del Crociferi 44

I-00187 Rome, ITALY

Hiroyuki Umeki

Isolation System Research Program

Radioactive Waste Management Project

Power Reactor and Nuclear Fuel

Development Corporation (PNC)

1-9-13, Akasaka

Minato-ku

Tokyo 107, JAPAN

P. Carboneras Martinez.

ENRESA

Calle Emilio Vargas, 7

R-28043 Madrid, SPAIN

Tönis Papp

Swedish Nuclear Fuel and Waste Management Co.

Box 5864

S 10248 Stockholm, SWEDEN

Conny Hägg

Swedish Radiation Protection Institute (SSI)

Box 60204

S-104 01 Stockholm, SWEDEN 
J. Hadernann

Paul Scherrer Institute

Waste Management Programme

CH-5232 Villigen PSI, SWITZERLAND

$\mathrm{J}$. Vigfusson

USK- Swiss Niclear Safety Inspectorate

Federal office of Energy

$\mathrm{CH}-5303$ würenlingen, SWITZERLAND

D.E. Billington

Departmental Manager-Assessment Studies

Radwaste Disposal R\&D Division

AEA Decommissioning \& Radwaste

Harwell Laboratory, B60

Didcot Oxfordshire OX11 ORA

UNITED KINGDOM

P. Grimwood

Waste Management Unit

BNFL

Sellafield

Seascale, Cumbria CA20 1PG

UNITED KINGDOM

Alan J. Hooper

UK Nirex Ltd

Curie Avenue

Harwe11, Didcot

Oxfordshire, OX11 ORH

UNITED KINGDOM

Jerry M. Boak

Yucca Mountain Project Office

US Department of Energy

PO Box 98608

Las Vegas, NV 89193

Seth M. Coplan (Chairman)

US Nuclear Regulatory Comnission

Division of High-Level Waste

Management

Mail Stop 4-H-3

Washington, DC 20555

A.E. Van Luik

INTERA/M\&O

The Valley Bank Center

101 Convention Center Dr.

Las Vegas, NV 89109

\section{NEA/PSAG User's Group}

Shaheed Hossain

Division of Nuclear Fuel Cycle and Waste Management

International Atomic Energy Agency

Wagramerstrasse 5

PO Box 100

A-1400 Vienna, AUSTRIA

Alexander Nies (PSAC Chairman)

Gesellschaft für Strahlen- und

Institut für Tieflagerung

Abteilung für Endlagersicherheit

Theodor-Heuss-Strasse 4

D-3300 Braunschweig, GERMANY

Eduard Hofer

Gesellschaft für Reaktorsicherheit (GRS) MBH

Forschungsgelände

D-8046 Garching, GERMANY

Andrea Sa1te1li

Commission of the European Communities

Joint Resarch Centre of Ispra

I-21020 Ispra (Varese), ITALY

Alejandro Alonso

Cátedra de Tecnología Nuclear

E.T.S. de Ingenieros Industriales

José Gutiérrez Abascal, 2

E-28006 Madrid, SPAIN

ENRESA (2)

Attn: M. A. Cuñado

F. J. Elorza

Calle Emilio Vargas, 7

E-28043 Madrid, SPAIN

Pedro Prado

CIEMAT

Instituto de Tecnología Nuclear

Avenida Complutense, 22

E-28040 Madrid, SPAIN

Nils A. Kjellbert

Swedish Nuclear Fuel and Waste

Management Company (SKB)

Box 5864

S-102 48 Stockholm, SWEDEN 
Björn Cronhjort

Swedish National Board for Spent Nuclear Fuel (SKN)

Sehlsedtsgatan 9

S-115 28 Stockholm, SWEDEN

Richard A. Klos

Paul-Scherrer Institute (PSI)

$\mathrm{CH}-5232$ Villingen PSI

SWITZERI_AND

NAGRA (2)

Attn: C. McCombie

F. Van Dorp

Parkstrasse 23

CH-5401 Baden, SWITZERLAND

N. A. Chapman

Intera Information Technologies

Park View House, 14B Burton Street

Melton Mowbray

Leicestershire, LE13 $1 \mathrm{AE}$

UNITED KINGDOM

Daniel A. Galson

Galson Sciences Ltd.

35, Market Place

Oakham

Leicestershire LE15 6DT

UNITED KINGDOM

David P. Hodgkinson

Intera Information Technologies

Chiltern House

45 Station Road

Henley-on-Thames

Oxfordshire RG9 1AT, UNITED KINGDOM

Brian G.J. Thompson

Department of the Environment: Her

Majesty's Inspectorate of Pollution

Room A5.33, Romney House

43 Marsham Street

London SW1P 2PY, UNITED KINGDOM

Intera Information Technologies

Attn: M.J.Apted

3609 South Wadsworth Blvd.

Denver, CO 80235

US Nuclear Regulatory Commission (2)

Attn: R. Codell

N. Eisenberg

Mail Stop 4-H-3

Washington, DC 20555
Battelle Pacific Northwest

Laboratories

Attn: P.W. Eslinger

PO Box 999, MS K2-32

Richland, WA 99352

Center for Nuclear Waste Regulatory Analysis (CNWRA)

Southwest Research Institute

Attn: B. Sagar

PO Drawer 28510

6220 Culebra Road

San Antonio, TX 78284

\section{Geostatistics Expert Working Group (GXG)}

Rafael L. Bras

R.L. Bras Consulting Engineers

44 Percy Road

Lexington, MA 02173

Jesus Carrera

Universidad Politécnica de Cataluña

E.T.S.I. Caminos

Jordi, Girona 31

E-08034 Barcelona, SPAIN

Gedeon Dagan

Department of Fluid Mechanics and Heat Transfer

Tel Aviv University

PO Box 39040

Ramat Aviv, Tel Aviv 69978

ISRAEL

Ghislain de Marsily (GXG Chairman)

University Pierre et Marie Curie

Laboratorie de Geologie Applique

4, Place Jussieu - T.26 - 5e etage

75252 Paris Cedex 05

FRANCE

Alain Galli

Centre de Geostatistique

Ecole des Mines de Paris

35 Rue St. Honore

77035 Fontainebleau, FRANCE

Steve Gorelick

Department of Applied Earth Sciences

Stanford University

Stanford, CA 94305-2225 
Peter Grindrod

INTERA Information Technologies Ltd.

Chiltern House

45 Station Road

Henley-on-Thames

Oxfordshire, RG9 IAT

UNITED KINGDOM

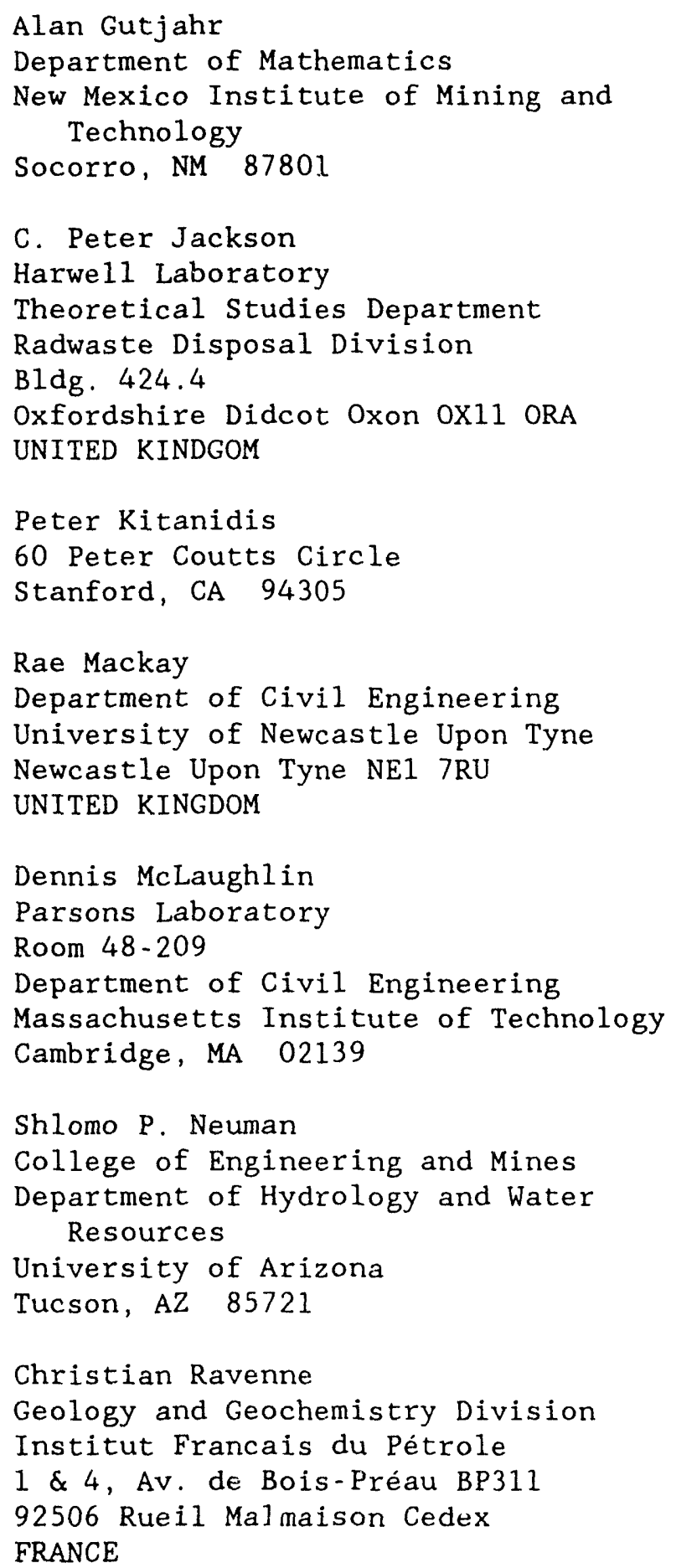

Yoram Rubin

Department of Civil Engineering University of California

Berkeley, CA 94720

\section{Foreign Addresses}

Studiecentrum Voor Kernenergie Centre D'Energie Nucleaire

Attn: A. Bonne

SCK/CEN

Boeretang 200

B-2400 Mo1, BELGIUM

Atomic Energy of Canada, Ltd. (3)

Whiteshell Research Estab.

Attn: M.E. Stevens

B.W. Goodwin

D. Wushke

Pinewa, Manitoba

ROE 1LO, CANADA

Esko Peltonen

Industrial Power Company Ltd.

TVO

Fredrikinkatu 51-53

SF-00100 Helsinki 10, FINLAND

Jean-Pierre Olivier

OECD Nuclear Energy Agency (2)

38 , Boulevard Suchet

F-75016 Paris, FRANCE

D. Alexandre, Deputy Director ANDRA

31 Rue de la Federation

75015 Paris, FRANCE

Claude Sombret

Centre D'Etudes Nucleaires

De La Vallee Rhone

CEN/VALRHO

S.D.H.A. BP 171

30205 Bagnols-Sur-Ceze, FRANCE

Bundesministerium fur Forschung und

Technologie

Postfach 200706

5300 Bonn 2, GERMANY

Bundesanstalt fur Geowissenschaften und Rohstoffe

Attn: M. Langer

Postfach 510153

3000 Hanover 51, GERMANY 
Gesellschaft fur Reaktorsicherheit (GRS) (2)

Attn: B. Baltes

W. Muller

Schwertnergasse 1

D-5000 Cologne, GERMANY

Institut fur Tieflagerung (2)

Attn: K. Kuhn

Theodor-Heuss-Strasse 4

D-3300 Braunschweig, GERMANY

Physikalisch-Technische

Bundesanstalt

Attn: P. Brenneke

Postfach 3345

D-3300 Braunschweig, GERMANY

Shingo Tashiro

Japan Atomic Energy Research Institute

Tokai-Mura, Ibaraki-Ken

319-11, JAPAN

Netherlands Energy Research

Foundation (ECN)

Attn: L.H. Vons

3 Westerduinweg

PO Box 1

1755 ZG Petten, THE NETHERLANDS

Johan Andersson

Swedish Nuclear Power Inspectorate

Statens Kärnkraftinspektion (SKI)

Box 27106

S-102 52 Stockholm, SWEDEN

Fred Karlsson

Svensk Karnbransleforsorjning

$A B$ SKB

Box 5864

S-102 48 Stockholm, SWEDEN

Nationale Genossenschaft fur die Lagerung Radioaktiver Abfalle (NAGRA) (2)

Attn: S. Vomvoris

P. Zuidema

Hardstrasse 73

$\mathrm{CH}-5430$ Wettingen, SWITZERLAND
AEA Technology

Attn: J.H. Rees

D5W/29 Culham Laboratory

Abington

Oxfordshire OX14 3DB, UNITED KINGDOM

AEA Technology

Attn: W.R. Rodwell

044/A31 Winfrith Technical Centre

Dorchester

Dorset DT2 8DH, UNITED KINGDOM

AEA Technology

Attn: J.E. Tinson

B4244 Harwel1 Laboratory

Didcot, Oxfordshire OXI1 ORA

UNITED KINGDOM

D.R. Knowles

British Nuclear Fuels, plc

Risley, Warrington

Cheshire WA3 6AS, 1002607

UNITED KINGDOM

\section{Internal}

1

20 O.E. Jones

1502 J.C. Cummings

1511 D.K. Gartling

6000 D.L. Hartley

6115 P.B. Davies

6119 E.D. Gorham

6119 Staff (14)

6121 J.R. Tillerson

6121 Staff (7)

6233 J.C. Eichelberger

6300 D.E. E11is

6302 L.E. Shephard

6303 S.Y. Pickering

6303 W.D. Weart

6305 S.A. Goldstein

6306 A.L. Stevens

6312 F.W. Bingham

6313 L.S. Costin

6331 P.A. Davis

6341 Sandia WIPP Central Files (100)

6342. D.R. Anderson

6342 J.W. Berglund (20)

6342 Staff (30) 


\begin{tabular}{ll}
6343 & S.A. Orrell, Acting \\
6343 & Staff (3) \\
6345 & R.C. Lincoln \\
6345 & Staff (9) \\
6347 & D.R. Schafer \\
6348 & J.T. Holmes \\
6351 & R.E. Thompson \\
6352 & D.P. Garber \\
6352 & S.E. Sharpton \\
6400 & N.R. Ortiz \\
6613 & R.M. Cranwel1 \\
6613 & R.L. Iman \\
6613 & C. Leigh \\
6622 & M.S.Y. Chu \\
6641 & R.E. Luna, Acting \\
7141 & Technical Library (5) \\
7151 & Technical Publications \\
$7613-2$ & Document Processing for \\
\multicolumn{2}{l}{ DOE/OSTI (10) } \\
$8523-2$ & Central Technical Files \\
9300 & J.E. Powel1 \\
9310 & J.D. Plimpton \\
9330 & J.D. Kennedy
\end{tabular}



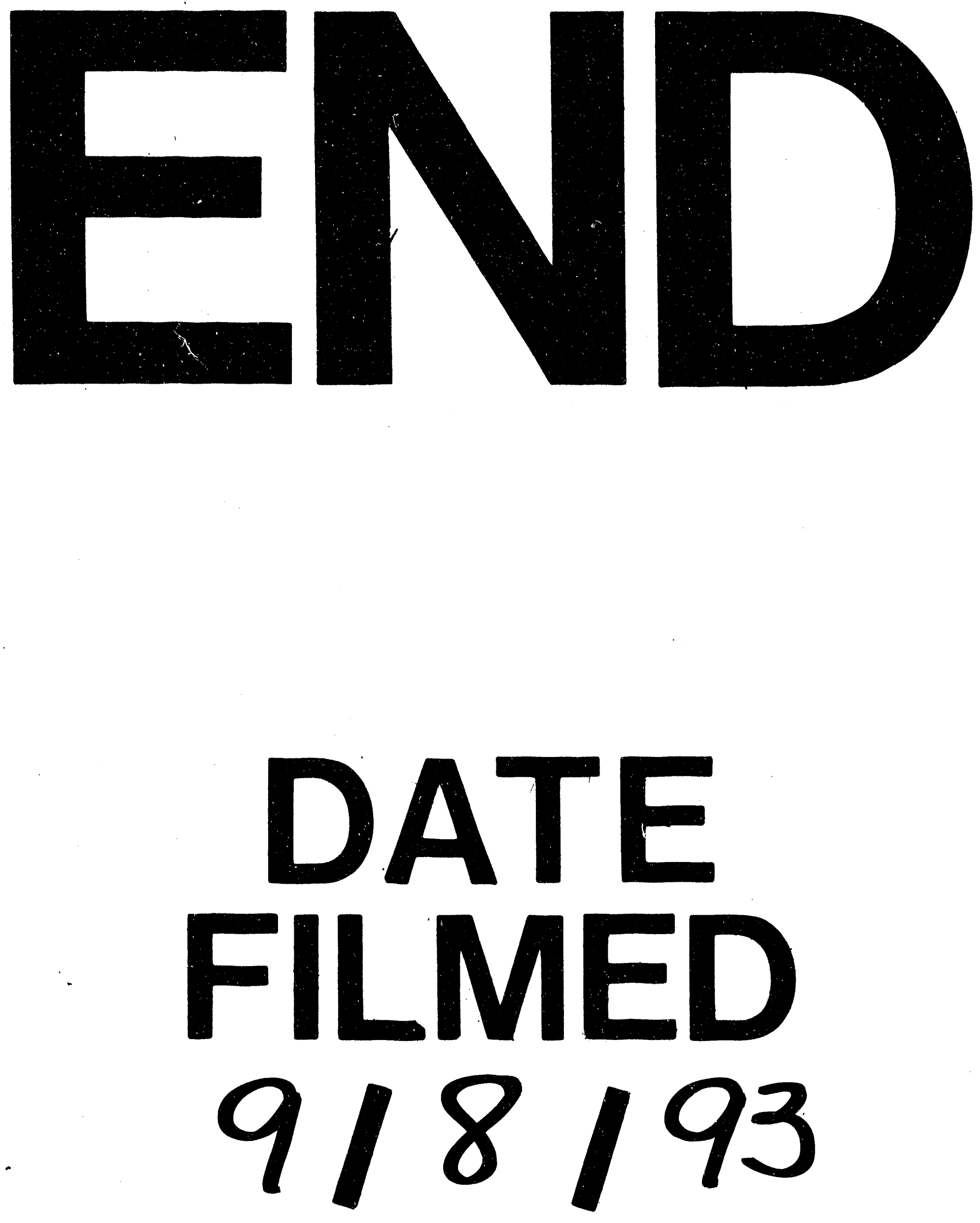
